\title{
ÍNDICE PARA A SELEÇÃO DE CULTIVARES
}

\author{
ANTONIO AUGUSTO FRANCO GARCIA \\ Engenheiro Agrônomo
}

Orientador : Prof. Dr. CLÁUDIO LOPES DE SOUZA JÚNIOR

Tese apresentada à Escola Superior de Agricultura "Luiz de Queiroz", Universidade de São Paulo, para obtenção do título de Doutor em Agronomia, Área de Concentração: Genética e Melhoramento de Plantas.

PIRACICABA

Estado de São Paulo - Brasil

Novembro - 1998 
Dados Internacionais de Catalogação na Publicação (CIP) DIVISĀO DE BIBLIOTECA E DOCUMENTAÇĀO - Campus "Luiz de Queiroz"/USP

Garcia, Antonio Augusto Franco

Índice para a seleçāo de cultivares / Antonio Augusto Franco Garcia. - - Piracicaba, 1998.

$112 \mathrm{p}$.

Tese (doutorado) - - Escola Superior de Agricultura Luiz de Queiroz, 1998.

Bibliografia.

1. Índice de seleção 2. Melhoramento genético vegetal 3. Seleção fenotípica 4. Seleção genética vegetal I. Título

$\operatorname{CDD} 575.1$ 
A minha mãe Maura, que muito trabalhou para que eu até aqui chegasse, ao meu pai Wilson (in memoriam) e aos meus irmãos Zaíra, Ana Lúcia e Alexandre,

\section{DEDICO}

A minha querida esposa

Luciana, cujo apoio, carinho, dedicação e companheirismo foram indispensáveis, 


\section{AGRADECIMENTOS}

Ao Prof. Dr. Ciáudio Lopes de Souza Jr., pela orientação, ensinamentos, estímulo, exemplo e amizade, dedicados nestes onze anos de convívio tão proveitoso, desde os tempos da Iniciação Científica. É impossível em espaço tão pequeno registrar a profunda gratidão que sinto.

Aos amigos do Programa de Melhoramento Genético da Cana-de-açúcar (PMGCA), da Universidade Federal de São Carlos (UFSCar), pelo apoio e convívio de três anos: Pesquisadores Antonio C. A. Gheller, Antonio I. Bassinello, Éder A. Giglioti, Gustavo H.R. dos Santos, Hermann P. Hoffmann, Hideto Arizono, Silvana P. Meneghin, Sizuo Matsuoka e Yodiro Masuda; Administrativos José A. Cruz, Maria A. F. Ciofi, Sonia A. Fachini; Técnicos Carlos J. Loureiro, César E. Ciola, Ciáudio J. Mendes, José Ciofi, Luiz P. Zavaglia, Lungas L. Menezes, Marilson S. Wermelinger.

Aos amigos do Departamento de Matemática e Estatística, pelo estímulo e constante incentivo: Professores Antonio F. Iemma, Carlos T. S. Dias, Ciarice G. B. Demétrio, Décio Barbin, José E. Corrente, Maria Cristina S. Nogueira, Roseli A. Leandro, Sônia M. D. S. Piedade, Silvio S. Zocchi, Gabriel A. Sarriés; Funcionários Expedita M. Azevedo, Luciane Brajão, Rosa M. Alves, Rosni O. A. Pinto, Solange A. P. Sabadin.

Ao Centro Nacional de Pesquisa de Milho e Sorgo, da EMBRAPA, através dos pesquisadores Luíz André Correa e Nádia Maciel, pela cessão dos resultados experimentais.

Ao CNPq e a CAPES, pelo auxílio financeiro.

A todos os colegas da pós-graduação, particularmente Sérgio Augusto Moraes Carbonell, Maria Cristina Falco, José Baldin Pinheiro, Francisco Pinheiro Lima Neto e Rogério Melo Costa Pinto.

À bibliotecária Silvana M. Gregório, pela revisão das normas bibliográficas.

A Cássio van den Berg, pelo auxílio na confecção do "summary".

A minha esposa Luciana Aparecida Carlini-Garcia, pela leitura dos originais e ótimas sugestões. 


\section{SUMÁRIO}

SUMARIO

Página

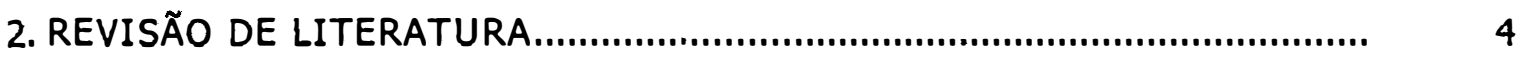

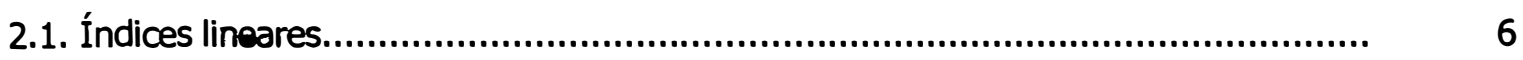

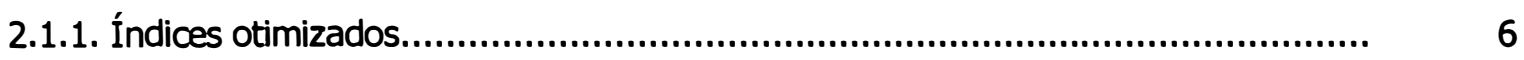

2.1.2. Índices básicos................................................................................ 14

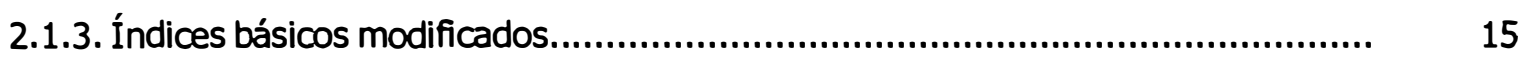

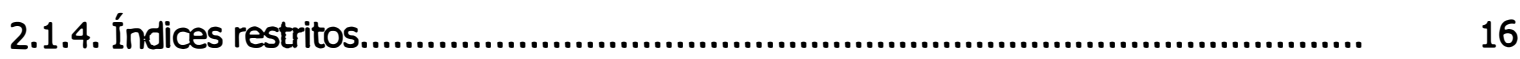

2.1.5. Índices de resposta à seleção desejada................................................... 18

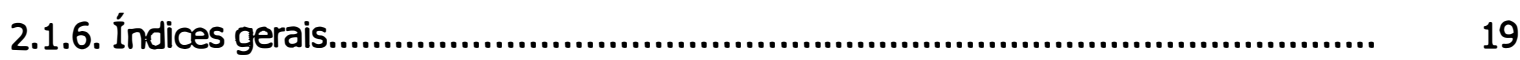

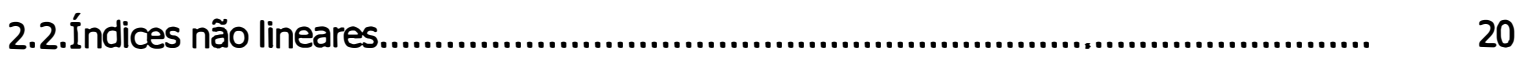

2.2.1. Índice multiplicativo.......................................................................... 20

2.2.2. Índice de soma de classificação.............................................................. 26

2.2.3. Índices baseados em medidas de distância................................................ 27

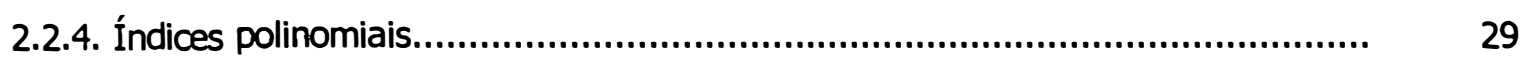

2.3. Considerações gerais sobre os índices........................................................ 29

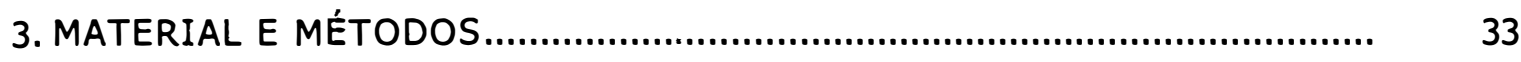

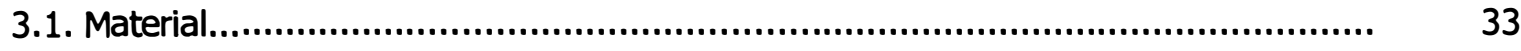

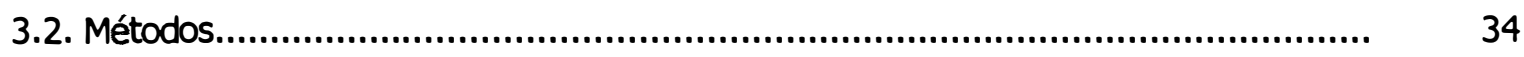

3.2.1. Análises de variância e estabilidade....................................................... 34

3.2.2. Obtenção dos índices de seleção............................................................ 37

3.2.2.1. Índice multiplicativo...................................................................... 38

3.2.2.2. Índice de soma de classificação.......................................................... 39

3.2.2.3. Índice baseado em medida de distância................................................. 40

3.2.3. Índice para a seleção de cultivares........................................................ 41

3.2.3.1. Etapas para o cálculo do índice............................................................ 41

4. RESULTADOS E DISCUSSÃO............................................................. 48

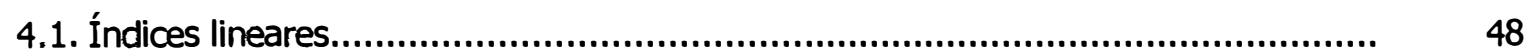




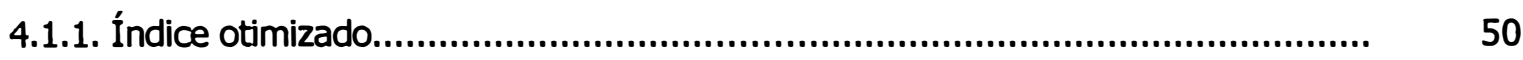

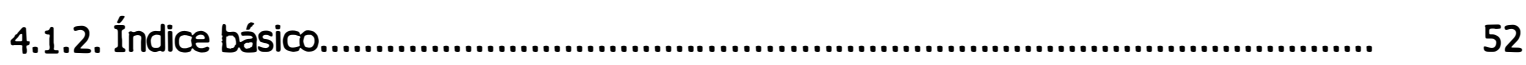

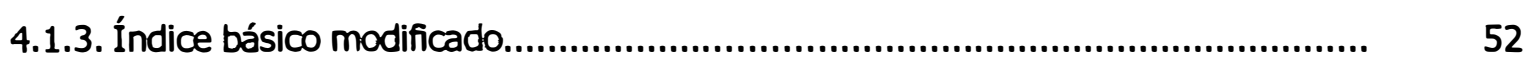

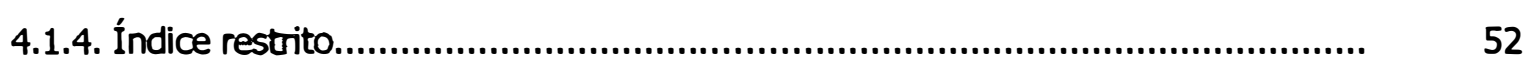

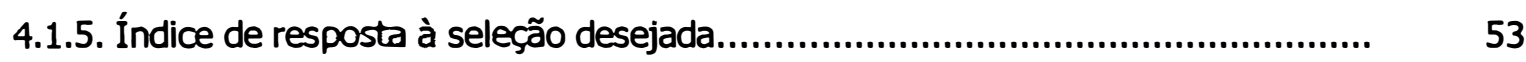

4.1.6. Considerações gerais.............................................................................. 53

4.2. Análises estatísticas dos experimentos do Ensaio Nacional de Milho Precoce

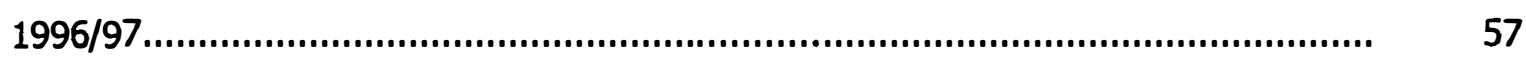

4.2.1. Análises de variância e obtenção das médias ajustadas.................................. 57

4.2.2. Análise de estabilidade........................................................................... 59

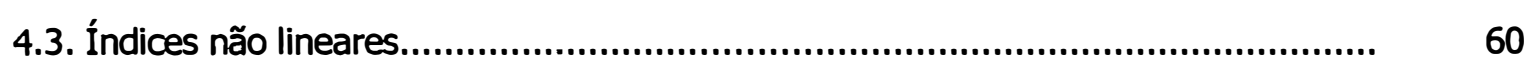

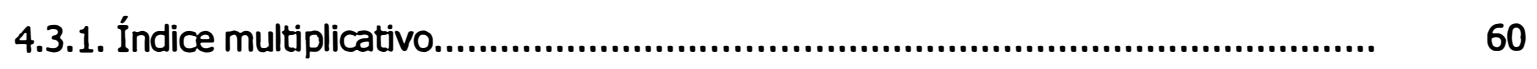

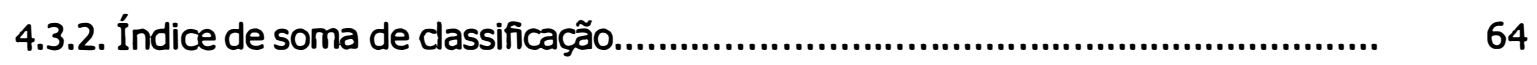

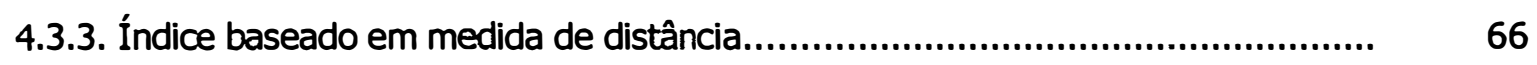

4.3.4. Comparaçães dos índices não lineares........................................................ 67

4.4. Índice para a seleção de cultivares............................................................. 70

4.4.1. Etapas necessárias para seu cálculo........................................................... 72

4.4.2. Comparação com os índices não lineares...................................................... 83

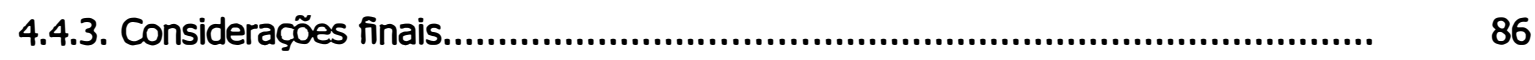

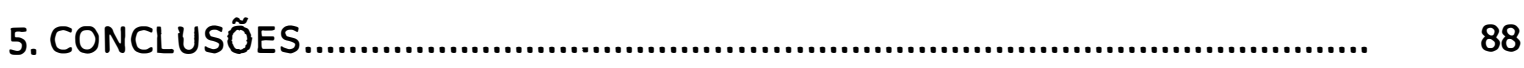

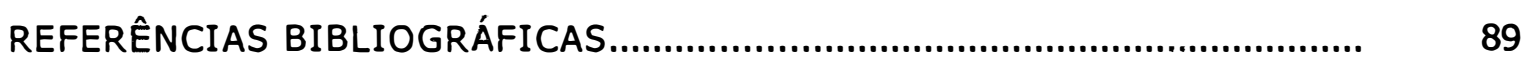

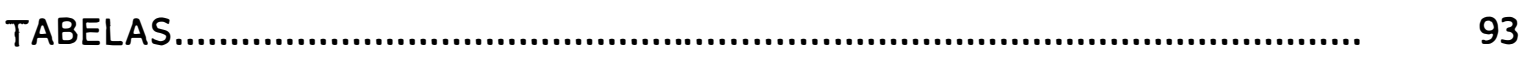




\section{ÍNDICE PARA A SELEÇÃO DE CULTIVARES}

Autor: ANTONIO AUGUSTO FRANCO GARCIA

Orientador: Prof. Dr. CLÁUDIO LOPES DE SOUZA JÚNIOR

\section{RESUMO}

Índices de seleção normalmente são combinações lineares de valores fenotípicos que permitem a realização de seleção para vários caracteres simultaneamente, promovendo o melhoramento das populações para o seu conjunto de características. Existem na literatura diversos tipos de índice, sendo os mais comumente usados os que possuem máxima correlação com o valor genotípico populacional. Contudo, todos eles visam maximizar a resposta à seleção para o conjunto considerado de caracteres, em programas de seleção recorrente. Para tanto, são necessárias estimativas de diversos parâmetros, como variâncias e covariâncias genéticas e fenotípicas, além de correlações entre caracteres. Além disso, é também necessário atribuir pesos econômicos aos caracteres considerados. Alguns outros índices foram desenvolvidos sob outro enfoque, sendo os principais o índice multiplicativo, o de soma de classificação e o de distância ao ideótipo. Por não necessitarem estimativas de parâmetros genéticos e fenotípicos, têm seu uso proposto também para a simples classificação dos genótipos, não necessariamente em programas de seleção recorrente.

O presente trabalho teve por objetivo verificar se esses índices não lineares são adequados à seleção de cultivares, ou genótipos em fase final de experimentação. Além disso, propôs-se também um novo índice para a seleção de cultivares, que não apresenta deficiências como a não realização de testes de médias e a impossibilidade de identificar genótipos com desempenho abaixo das exigências comerciais para dado caráter, sendo por isso vantajoso.

Como exemplo, foram utilizados os resultados do Ensaio Nacional de Milho Precoce 1996/97, conduzido pelo Centro Nacional de Pesquisas de Milho e Sorgo, da EMBRAPA. Nesse ensaio, foram obtidas as médias ajustadas para 49 híbridos, avaliados em nove locais contrastantes, para os caracteres peso de espigas ( $\mathrm{kg} / \mathrm{ha})$, umidade (\%), número de dias para florescimento, altura da planta $(\mathrm{cm})$, altura da espiga $(\mathrm{cm})$, prolificidade e porcentagem de 
plantas acamadas e quebradas. Foram calculados parâmetros de estabilidade e adaptabilidade para o caráter peso de espigas, os quais foram também incluídos nos índices.

O índice para a seleção de cultivares proposto tem as seguintes etapas de cálculo: agrupamento das médias e obtenção de recíprocos, definição dos níveis mínimos aceitáveis comercialmente para cada variável, transformação dos dados, definição do ideótipo, cálculo das distâncias a esse ideótipo, classificação dos indivíduos e seleção dos genótipos superiores. Os resultados mostroram que os índices não lineares revistos não são adequados à seleção de cultivares, por não priorizarem os caracteres mais importantes, por não permitirem o descarte dos genótipos com nível(eis) inferior(es) para alguma(s) variável(eis) e por não preverem a realização de testes de médias. Já o índice para a seleção de cultivares mostrou-se extremamente útil e muito superior aos demais. Porém, os níveis de probabilidade do agrupamento das médias devem ser escolhidos criteriosamente, devendo-se tomar probabilidades maiores para os caracteres mais importantes e menores para aqueles secundários e com menor amplitude de variação. Concluiu-se que, se os níveis de probabilidade forem adequadamente fixados, o índice para a seleção de cultivares proposto pode ser extremamente útil para auxiliar os melhoristas no processo de seleção de cultivares, quando diversas variáveis são consideradas. 


\title{
INDEX FOR THE SELECTION OF CULTIVARS
}

\author{
Author: ANTONIO AUGUSTO FRANCO GARCIA \\ Adviser: Prof. Dr. CLÁUDIO LOPES DE SOUZA JÚNIOR
}

\section{SUMMARY}

Generally, selection indices are linear combinations of phenotypic values which allow the simultaneous selection of several characters, and consequently the overall characteristics of a given population. There are several types of indices in the literature. The most common ones have maximum correlation with the population genotypic values. However, all of them aim to maximize the response to selection of the pool of characters within recurrent selections schemes. To use these indices it is necessary to know the estimates of several parameters, such as genetic and phenotypic variances and covariances, and correlations between pairs of characters. Moreover, one has to determine economic weights to be applied to the characters. Other indices developed in a different way, such as the multiplicative index, the sum of classifications index, and the distance to the ideotype index, do not need estimates of genetic and phenotypic parameters, and therefore can be also used for the classification of individual genotypes, not necessarily in a recurrent selection scheme.

In this study we aimed to assess if these non-linear indices would be suitable for the selection of cultivars or genotypes in the end of a breeding program. Additionaly we propose a new index, which does not have the common disadvantages of other non-linear indices. Multiple comparisons tests can be used, and, also, one could identy for a given genotype the traits that performed below than those required by commercial cultivars.

As an example, it was used the results from the Ensaio Nacional de Milho Precoce 1996/1997, carried out by the Centro Nacional de Pesquisas de Milho e Sorgo, EMBRAPA. From these data we calculated the adjusted means of 49 hybrids in nine different locations. The characters were ear weight $(\mathrm{kg} / \mathrm{ha})$, grain moisture $(\%)$, number of days to flowering, plant height $(\mathrm{cm})$, ear height $(\mathrm{cm})$, prolificacy, and percentage of broken and lodging plants. 
Parameters of stability and adaptability for ear weight were calculated and included in the indices.

The calculation of the proposed selection index has the following steps: grouping the means and obtaining the reciprocals, defining the minimum comercial value accptable for each variable, transforming the data, defining the ideotype, calculating the distances to this ideotype, classifying all the individuals and selecting the best genotypes. In our results we noticed that the reviewed non-linear indices were not suitable for cultivar selection. This was due to the fact that they do not prioritize the most important characters, do not allow to discard genotypes with low values in some variables, and can not be used for multiple comparisons. On the other hand, our cultivar selection index was very useful and outperformed the others. However, the probability levels to group the means should be carefully chosen. The most important characters should be assigned higher probabilities than the less important and less variable ones. Provided that the probability levels are correctly set, the proposed index will be very useful as a tool in cultivar selection with multiple variables. 


\section{INTRODUÇÃO}

Nos programas de melhoramento genético, freqüentemente obtêm-se medidas de diversos caracteres com a finalidade de praticar seleção para todos eles simultaneamente. Isto é importante pois a seleção para um ou poucos caracteres poder resultar em alteraçães desfavoráveis em outros, devido à presença de correlações genéticas entre eles. Abordagens matemáticas desta situação levaram ao desenvolvimento dos índices de seleção, que normalmente são obtidos como combinações lineares das medidas fenotípicas dos diversos caracteres, permitindo utilizar um único valor para efetuar a seleção de maneira mais eficiente.

A idéia inicial da aplicação de índices de seleção nos programas de melhoramento genético foi apresentada por Smith (1936), com base em trabalho de Fisher (1936). Este índice, conhecido como índice otimizado, sofreu posteriormente diversas modificações, sendo, no entanto, a maioria delas também baseada na obtenção de combinações lineares de valores fenotípicos obsenvados.

O objetivo de se empregar os índices de seleção é melhorar o valor genotípico da população sob seleção, ou seja, um conjunto de caracteres favoráveis. Tal qualidade é definida como uma função linear de valores genotípicos não observáveis de diversos caracteres, ponderados por um valor econômico relativo determinado pelo melhorista. A maioria dos índices é obtida a partir da maximização da correlação entre o valor genotípico e o índice, visando máxima eficiência na seleção.

Quando não se dispõe de boas estimativas dos parâmetros genotípicos e fenotípicos, o que impede o emprego dos índices otimizados, pode-se utilizar o índice básico, 
proposto por Brim et al. (1959), que é mais simples. Em outras situações, deseja-se maximizar a qualidade genotípica ao mesmo tempo em que se restringem as alterações em alguns caracteres, os quais não devem se alterar com a prática de seleção. Tal fato ocasionou o surgimento dos índices de seleção restritos (Kempthome \& Nordskog, 1959).

Considerando a dificuldade em atribuir pesos econômicos relativos, Pesek \& Baker (1969) propuseram que os índices sejam desenvolvidos especificando a resposta à seleção desejada para cada característica, surgindo assim os índices de resposta à seleção desejada. Tai (1977) modificou posteriormente este índice de modo a permitir sua aplicação quando alguns dos caracteres não têm alteração restrita.

Estes índices lineares, comuns na literatura, visam sobretudo melhorar gradativamente as freqüências de alelos favoráveis para o conjunto de caracteres de importância. Assim, inserem-se nos programas de seleção recorrente, permitindo a obtenção de populações com melhor valor genotípico. Como o material selecionado será recombinado, genótipos com dados caracteres em níveis inferiores aos aceitáveis comercialmente podem ser selecionados, desde que concentrem um número razoável de alelos favoráveis para outras características.

Uma outra situação encontrada, diferente da existente nos programas de seleção recorrente, é aquela em que se realizam experimentos em etapas avançadas dos programas de melhoramento genético, avaliando genótipos promissores (pré-comerciais) e utilizando-se cultivares comerciais como testemunhas. Neste caso, há a necessidade de comparar os novos genótipos com os materiais comerciais existentes no mercado, baseando-se em médias obtidas a partir de experimentos realizados em vários locais e anos. Após a realização dos experimentos, os melhores materiais poderão ser selecionados como cultivares comerciais. Atualmente, porém, há escassos relatos sobre como combinar a informação dos diversos caracteres num único valor, ou seja, num índice de seleção, facilitando a comparação e a classificação dos genótipos com base no conjunto de caracteres. Isto não pode ser feito pelo uso dos índices idealizados para emprego em programas de seleção recorrente, já que se deseja simplesmente identificar o(s) melhor(es) genótipo(s) para o conjunto de características, e não promover o aumento do valor genotípico de uma população; não haverá recombinação dos materiais superiores, como na seleção recorrente, e os genótipos selecionados devem estar dentro dos padrões comerciais mínimos exigidos para a espécie, para todos os caracteres. Logo, os índices aplicados neste caso devem prever o descarte de genótipos que não atendam a estas exigências mínimas. Portanto, métodos para a obtenção de índices que visem a 
maximização do valor genotípico, com ou sem a imposição de restriç̃̃es a alterações em alguns caracteres, não são adequados a tal situação.

Alguns autores apresentaram índices que não visam a melhoria do valor genotípico. Elston (1963) propôs um índice multiplicativo que considera todos os caracteres com o mesmo peso econômico. Tal índice é aplicado após transformação dos dados para cada caráter. Schwarzbach $(1972)^{1}$, citado por Wricke \& Weber (1986), sugeriu o emprego de medidas de distância, tais como a eudidiana e a de Mahalanobis, para classificar os genótipos para várias características simultaneamente, em função de sua proximidade com um genótipo ideal, definido pelo pesquisador. Mulamba \& Mock (1978) desenvolveram um índice no qual se efetua a soma do número de ordem que o genótipo apresenta para cada caráter mensurado; quanto menor o valor obtido, melhor a classificação. Em todos esses casos, não são necessárias estimativas de parâmetros genéticos, mas os índices não permitem o descarte de genótipos que não atendam exigências comerciais mínimas para algumas características. Além disso, nenhum deles considera se as diferenças entre as médias fenotípicas são significativas, não prevendo, portanto, a aplicação de testes de comparações múltiplas, que devem ser considerados nas análises estatísticas.

Nesse contexto, o presente trabalho tem por objetivo desenvolver um índice aplicável à seleção de cultivares, isto é, um índice para a classificação, identificação e seleção de genótipos superiores para todos os caracteres considerados. O emprego do índice deverá também permitir o descarte de genótipos com desempenho abaixo das exigências mínimas para dados caracteres, sem ser necessária a atribuição de valores econômicos relativos e a estimação de parâmetros genéticos. Além disso, foi feita comparação do novo índice com os propostos por Elston (1963), Schwarzbach (1972) $)^{1}$, citado por Wricke \& Weber (1986) e Mulamba \& Mock (1978).

\footnotetext{
1 SCHWARZBACH, E. Einige Anwendungsmöglichkeiten elektronischer Dateriverarbeitung (EDV) für die Beurteilung von Zuchimaterial. Arb. Tag. Oesterr. Pflanaenz. Gumpenstein: 277-87, 1972.
} 


\section{REVISÃO DE LITERATURA}

A seleção simultânea de vários caracteres tem sido abordada na literatura de diferentes formas: aplicação de seleção independente para os caracteres, seleção em tandem e o uso dos índices de seleção, sendo estes últimos os mais comumente usados (Figura 1). No caso da seleção independente de caracteres, toma-se a união das frações selecionadas para cada caráter; para a seleção em tandem, a intersecção delas. Para o índice de seleção, é selecionada uma fração delimitada por uma reta, cuja inclinação depende dos pesos atribuídos aos caracteres.

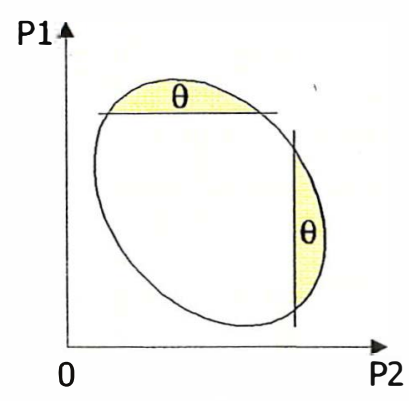

a

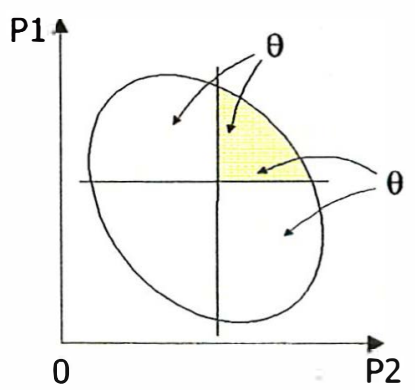

b

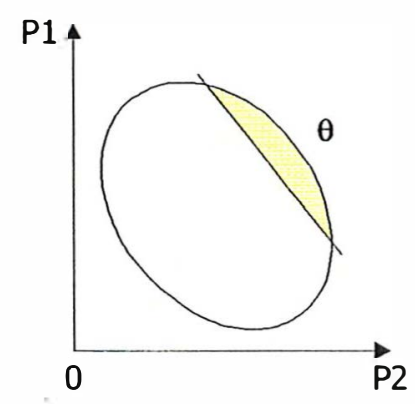

C

Figura 1. Representação esquemática da seleção para dois caracteres, P1 e P2, sendo $\theta$ (região colorida) a parte selecionada: a) seleção independente de caracteres, b) seleção em tandem, c) seleção com emprego de um índice de seleção linear. 
Um índice de seleção é uma combinação linear de valores fenotípicos, o qual resulta numa medida que concentra, num único valor, os méritos e deméritos de cada genótipo para vários caracteres. A seleção de caracteres com base em valores individuais independentes é aquela na qual os genótipos que apresentarem valores fenotípicos abaixo de determinados níveis são removidos da população. Já na seleção em tandem, um caráter é selecionado até que atinja um nível satisfatório, sendo o processo repetido subseqüentemente para os demais caracteres, visando a obtenção de uma população melhorada no seu conjunto.

A eficiência relativa deste três métodos foi investigada por Hazel \& Lush (1942), com base no ganho com seleção que proporcionam. Para tanto, considerou-se seleção truncada, distribuição normal para os valores fenotípicos e ausência de correlaģões entre caracteres. Supondo que o produto entre o valor econômico relativo, a herdabilidade e o desvio padrão fenotípico é igual para todos os caracteres, a resposta esperada para um ciclo de seleção com estes três métodos é

$$
\begin{aligned}
& R_{1}=n^{0,5} k a h^{2} \sigma_{p}, \text { para seleção com base em índice; } \\
& R_{2}=n k_{3} a h^{2} \sigma_{p}, \text { para seleção independente de caracteres; } \\
& R_{3}=k a h^{2} \sigma_{p}, \text { para seleção em tandem. }
\end{aligned}
$$

Nestas equações, $\sigma_{p}$ é o desvio padrão fenotípico, $h^{2}$ é o coeficiente de herdabilidade e $a$ é o valor econômico relativo; assim $a h^{2} \sigma_{P}$ tem mesmo valor para $R_{1}, R_{2}$ e $R_{3}$. A magnitude de $k$ (diferencial de seleção estandardizado) depende apenas da fração $p$ da população selecionada pelo uso do índice ou pela seleção em tandem; já $k_{3}$ é função da porção descartada $p^{1 / n}$ para cada um dos $n$ caracteres, no caso de seleção independente dos caracteres. Os autores concluíram que, sob tais condições, o uso do índice proporciona uma resposta à seleção $n^{0,5}$ vezes superior àquele com seleção em tandem, e que a seleção em níveis independentes apresenta ganho intermediário entre os dois. Conclusões semelhantes foram obtidas por Young (1961), Finney (1962) e Pesek \& Baker (1969). Baker (1986) afirma que, apesar das condições particulares empregadas nesse trabalho, ele oferece um forte argumento para o uso de índices de seleção em detrimento dos outros métodos. Além destas vantagens, os índices também podem ser utilizados para melhoramento de um único caráter, 
porém aproveitando suas correlações com outros caracteres e aumentando ainda mais a resposta à seleção (Baker, 1986), o que é mais uma justificativa para seu uso.

O primeiro índice de seleção disponível na literatura foi apresentado por Smith (1936), com desenvolvimento baseado na idéia apresentada por Fisher (1936). Muitas modificações foram propostas posteriormente, sendo que a maioria dos índices provém da solução do seguinte sistema de equações (Baker, 1986):

$$
P b=G a, \text { onde }
$$

$P=$ matriz formada por estimativas das variâncias e covariâncias fenotípicas;

$G=$ matriz formada por estimativas das variâncias e covariâncias genotípicas;

$a=$ vetor formado pelos pesos econômicos relativos;

$b=$ vetor formado pelos coeficientes do índice de seleção, que devem ser obtidos.

Os coeficientes do índice são obtidos facilmente a partir de $b=P^{-1} G a$, sendo $P^{-1}$ a inversa da matriz de variâncias e covariâncias fenotípicas, que possui posto completo.

Nesta revisão, será apresentada a forma como tais equações foram deduzidas, alguns outros índices delas originados, possíveis aplicações e usos dos índices. Outros enfoques, como a utilização dos índices não lineares, também serão revistos.

\section{1. Índices lineares}

\subsection{1. Índices otimizados}

Atribui-se a Smith (1936) o crédito pelo desenvolvimento de índices de seleção para o melhoramento simultâneo de vários caracteres. Este autor introduziu o conceito de valor genotípico de um genótipo, expresso como uma função linear dos valores genotípicos de vários caracteres. Seguindo sugestão de Fisher (1936), propôs-se que, uma vez que o valor genotípico não pode ser avaliado diretamente, ele deve ser estimado por uma função linear de valores fenotípicos observáveis. A partir deste conceito, foram desenvolvidos os índices de seleção otimizados. Este termo foi empregado a partir de sugestão posterior de Williams (1962a), para permitir sua diferenciação de modificações mais recentes aplicadas à idéia original. 
Para um grupo de $n$ caracteres com medidas fenotípicas $P_{j}$ disponíveis, $j=1, \ldots, n$, há um grupo correspondente de $n$ valores genotípicos, $\infty m$ valores $G_{j}$, $j=1, \ldots, n$, que deverá ser melhorado através de seleção aplicada em $P_{j}$. Desse modo, podem ser construídos dois índices como combinações lineares destes valores:

$$
\begin{aligned}
& I=b_{1} P_{1}+\ldots+b_{i} P_{i}+\ldots+b_{n} P_{n}=\sum_{j=1}^{n} b_{j} P_{j}, \text { fenotípico, } \\
& W=a_{1} G_{1}+\ldots+a_{i} G_{i}+\ldots+a_{n} G_{n}=\sum_{j=1}^{n} a_{j} G_{j}, \text { genotípico, onde }
\end{aligned}
$$

$P_{i}=$ valor fenotípico do i-ésimo caráter (mensurável);

$b_{i}=$ peso do caráter no índice de seleção, a ser obtido;

$G_{i}=$ valor genotípico do i-ésimo caráter (não mensurável);

$a_{i}=$ peso do valor genotípico do caráter.

Esta combinação linear $W$, de valores genotípicos não observáveis, é o valor genotípico. Os valores $a_{i}$ são os pesos ou valores econômicos relativos dos caracteres, que devem ser atribuídos pelo melhorista. Já $b_{i}$ são pesos estimados de modo a maximizar a resposta à seleção em $W$. A própria definição de valor genotípico permite verificar que este tipo de índice foi desenvolvido com enfoque no melhoramento de parâmetros populacionais, visando seu uso em programas de seleção recorrente.

Assumindo que os valores genotípicos e fenotípicos apresentem distribuição normal multivariada, de forma a existir uma regressão linear do valor genotípico $W$ œm alguma função linear dos valores fenotípicos, tem-se (Figura 2): 


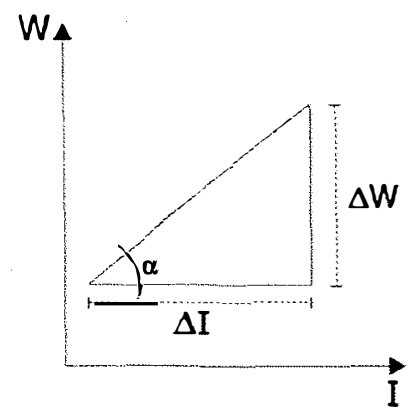

Figura 2. Associação linear entre o índice de seleção $I$ e a qualidade genotípica $W$.

Da Figura 2, tem-se:

$$
\operatorname{tg} \alpha=b_{W I}=\frac{\Delta W}{\Delta I}=\frac{W_{s}-W_{o}}{I_{s}-I_{o}}, \text { portanto, } \Delta W=b_{W I}\left(I_{s}-I_{o}\right), \text { onde }
$$

$b_{W l}=$ regressão linear do valor genotípico com o índice de seleção;

$\Delta W=$ alteração no valor genotípico;

$\Delta I=$ alteração no índice de seleção;

$W_{S}=$ valor genotípico da população selecionada;

$W_{O}=$ valor genotípico da população original;

$I_{S}=$ valor médio do índice na população selecionada;

$I_{O}=$ valor médio do índice na população original.

A resposta à seleção esperada em $W(\Delta W)$ com o uso do índice $I$, pode ser expressa como:

$$
\Delta W=\left(W_{s}-W_{o}\right)=b_{W I}\left(I_{s}-I_{o}\right)=\frac{C(W, I)}{V(I)} \cdot\left(I_{s}-I_{o}\right), \text { onde }
$$

$C(W, I)=$ covariância entre $W$ e $I$ e

$V(I)=$ variância dos $I$ 's dos genótipos.

Expressando $\Delta W$ em termos de seu desvio-padrão, tem-se (Baker, 1986): 


$$
\frac{\Delta W}{\sqrt{V(W)}}=\frac{\left(W_{S}-W_{O}\right)}{\sqrt{V(W)}}=\frac{C(W, I)}{\sqrt{V(W)} \sqrt{V(I)}} \cdot \frac{\left(I_{S}-I_{O}\right)}{\sqrt{V(I)}}=r_{W I} \frac{\left(I_{S}-I_{O}\right)}{\sqrt{V(I)}}=i \cdot r_{W I},
$$

sendo:

$V(W)$ = variância dos $W$ 's dos genótipos;

$i$ = diferencial de seleção estandardizado, para o índice de seleção;

$r_{W I}=$ coeficiente de correlação entre o valor genotípico e o índice.

Depreende-se dessa expressão que, para se maximizar a resposta à seleção em $W$, deve-se maximizar $r_{W 7}$, já que $i$ depende apenas da quantidade de genótipos selecionados. Originalmente, Smith (1936) sugeriu a maximização do produto entre o desviopadrão do índice e a regressão do valor genotípico sobre o índice, o que equivale a maximizar $r_{W I}$ (Baker, 1986). Isto foi feito por Hazel (1943), obtendo equações equivalentes. Outras possibilidades para o desenvolvimento de índices de seleção são (Lamkey, 1989):

i) a maximização do ganho genético esperado;

ii) a maximização da probabilidade de seleção correta;

iii) a minimização de $V(I-W)$, que é a variância da diferença entre $I$ e $W$.

Williams (1962b) mostrou que a maximização de $r_{W I}$ também maximiza a resposta esperada à seleção e a probabilidade de seleção correta, já que os últimos são funções monótonas crescentes da correlação, ou seja, são crescentes em qualquer que seja o intervalo considerado. A seguir, será apresentada apenas a obtenção de índices baseando-se na maximização de $r_{W I}$, de entendimento mais simples. Utilizando a alternativa iii, Wricke \& Weber (1986) chegaram aos mesmos resultados aqui apresentados, o que mostra a já citada equivalência dos procedimentos.

Uma outra forma de expressar a resposta à seleção $(R s)$ em $W$, é:

$$
R s=i \cdot r_{W I}=i \cdot \frac{C(W, I)}{\sqrt{V(W) \cdot V(I)}} .
$$

Utilizando a notação matricial, pode-se, sem perda de generalidade, assumir que os elementos $P_{i}$ (valor fenotípico do i-ésimo caráter) e $G_{i}$ (valor genotípico do i-ésimo caráter) 
sejam tomados como desvios de suas respectivas médias, sendo então representados pelos vetores $p^{\prime}=\left[\begin{array}{lll}p_{1} & \cdots & p_{n}\end{array}\right]$ e $g^{\prime}=\left[\begin{array}{lll}g_{1} & \cdots & g_{n}\end{array}\right]$, respectivamente, de modo que $E(p)=E(g)=\phi$, sendo $E(p)$ e $E(g)$ as esperanças matemáticas dos vetores $p$ e $g$ ， respectivamente.

Obtém-se então $E\left(p p^{\prime}\right)=P, E\left(p g^{\prime}\right)=C, E\left(g g^{\prime}\right)=G, b^{\prime} p=I$ e $a^{\prime} g=W ，$ onde:

$$
P=\left[\begin{array}{cccc}
V\left(p_{1}\right) & C\left(p_{1}, p_{2}\right) & \cdots & C\left(p_{1}, p_{n}\right) \\
C\left(p_{1}, p_{2}\right) & V\left(p_{2}\right) & \cdots & C\left(p_{2}, p_{n}\right) \\
\cdots & \cdots & \cdots & \cdots \\
C\left(p_{1}, p_{n}\right) & C\left(p_{2}, p_{n}\right) & \cdots & V\left(p_{n}\right)
\end{array}\right] \text { é a matriz de variâncias e covariâncias }
$$

fenotípicas;

$$
C=\left[\begin{array}{cccc}
C\left(p_{1}, g_{1}\right) & C\left(p_{1}, g_{2}\right) & \cdots & C\left(p_{1}, g_{n}\right) \\
C\left(p_{2}, g_{1}\right) & C\left(p_{2}, g_{2}\right) & \cdots & C\left(p_{2}, g_{n}\right) \\
\cdots & \cdots & \cdots & \cdots \\
C\left(p_{n}, g_{1}\right) & C\left(p_{n}, g_{2}\right) & \cdots & C\left(p_{n}, g_{n}\right)
\end{array}\right] \text { é a matriz de covariâncias entre os } p_{i}{ }^{\prime} \text { 's e os }
$$

$g_{i}$ 's, ou seja, entre os efeitos fenotípicos e genéticos;

$$
G=\left[\begin{array}{cccc}
V\left(g_{1}\right) & C\left(g_{1}, g_{2}\right) & \cdots & C\left(g_{1}, g_{n}\right) \\
C\left(g_{1}, g_{2}\right) & V\left(g_{2}\right) & \cdots & C\left(g_{2}, g_{n}\right) \\
\cdots & \cdots & \cdots & \cdots \\
C\left(g_{1}, g_{n}\right) & C\left(g_{2}, g_{n}\right) & \cdots & V\left(g_{n}\right)
\end{array}\right] \text { é a matriz de variâncias e covariâncias }
$$

genotípicas;

$$
\begin{aligned}
& b=\left[\begin{array}{c}
b_{1} \\
\vdots \\
b_{n}
\end{array}\right] \text { é o vetor dos pesos a serem estimados; } \\
& a=\left[\begin{array}{c}
a_{1} \\
\vdots \\
a_{n}
\end{array}\right] \text { é o vetor dos valores econômicos relativos. }
\end{aligned}
$$

Tem-se que: 


$$
\begin{aligned}
& C(I, W)=C\left(b^{\prime} p, a^{\prime} g\right)=C\left(b^{\prime} p, g^{\prime} a\right)=b^{\prime} C a, \\
& V(I)=V\left(b^{\prime} p\right)=C\left(b^{\prime} p, b^{\prime} p\right)=C\left(b^{\prime} p, p^{\prime} b\right)=b^{\prime} P b, \mathrm{e} \\
& V(W)=V\left(a^{\prime} g\right)=C\left(a^{\prime} g, a^{\prime} g\right)=C\left(a^{\prime} g, g^{\prime} a\right)=a^{\prime} G a .
\end{aligned}
$$

Então, deve-se maximizar $r_{W I}$, com a finalidade de conseguir máxima resposta à seleção no valor genotípico quando se utiliza o índice de seleção. Sabe-se que

$$
r_{W I}=\frac{C(I, W)}{\sqrt{V(I) \cdot V(W)}}=\frac{b^{\prime} C a}{\sqrt{b^{\prime} P b a^{\prime} G a}} .
$$

Equivalentemente, pode-se maximizar $\ln r_{W I}$, que é uma função monótona e crescente de $r_{W I}$ e é mais fácil de derivar:

$$
\begin{aligned}
& \ln r_{W I}=\ln \frac{b^{\prime} C a}{\sqrt{b^{\prime} P b a^{\prime} G a}}=\ln b^{\prime} C a-\ln \left(b^{\prime} P b a^{\prime} G a\right)^{-1 / 2}= \\
& =\ln b^{\prime} C a-\left(\frac{1}{2}\right) \ln b^{\prime} P b-\left(\frac{1}{2}\right) \ln a^{\prime} G a .
\end{aligned}
$$

Deste modo, os valores de $b$ que maximizam a correlação, podem ser obtidos derivando-se parcialmente a função com relação a $b$ e igualando a derivada a zero:

$$
\begin{aligned}
& \frac{\partial \ln r_{W I}}{\partial b}=\frac{C a}{b^{\prime} C a}-\left(\frac{1}{2}\right) \frac{2 P b}{b^{\prime} P b}=0, \therefore \\
& \frac{C a}{C(I, W)}=\frac{P b}{V(I)}, \text { ou } \\
& P b=C a \cdot \frac{V(I)}{C(I, W)} .
\end{aligned}
$$

Uma vez que há interesse apenas em valores relativos para os $b_{i}{ }^{\prime} s$, o termo constante $V(I) / C(I, W)$ pode ser eliminado, resultando no sistema de equações

$$
P b=C a \text {. }
$$


Para se calcularem os pesos do índice, deve-se conhecer as matrizes $P$ e $C$. As variâncias e covariâncias fenotípicas podem ser estimadas facilmente pelos métodos estatísticos usuais. Já para obtenção de $C$, delineamentos espećficos devem ser empregados. Wricke e Weber (1986) apresentaram os valores de $C$ para alguns casos mais comuns, apresentados a seguir.

Para o caso de clones, assumindo o modelo $P_{i}=G_{i}+E_{i}$, onde o fenótipo do genótipo $i\left(P_{i}\right)$ pode ser expresso como sendo resultado de um efeito genético $G_{i}$ e um ambiental $E_{i}$, obtém-se a covariância entre o efeito fenotípico do caráter $i$ e o genotípico do caráter $j$ :

$$
C\left(p_{i}, g_{j}\right)=C\left(P_{i}, G_{j}\right)=C\left(G_{i}, G_{j}\right)+C\left(E_{i}, G_{j}\right), \text { sendo }
$$

$P_{i}=$ valor fenotípico;

$G_{i}=$ valor genotípico;

$E_{i}=$ efeito não genético (ambiental).

Assumindo-se que não há covariância entre $E_{i}$ e $G_{i}$, decorre que $C\left(p_{i}, g_{j}\right)=C\left(G_{i}, G_{j}\right)$, o que significa que há a necessidade de estimar apenas a matriz $G$, de covariâncias genéticas. Para espécies alógamas, na ausência de epistasia, o modelo será $P_{i}=A_{i}+D_{i}+E_{i}$, onde $A_{i}$ e $D_{i}$ são os efeitos genéticos aditivos e dominantes no genótipo i. Logo,

$$
C\left(p_{i}, g_{j}\right)=C\left(P_{i}, A_{j}\right)=C\left(A_{i}, A_{j}\right)+C\left(D_{i}, A_{j}\right)+C\left(E_{i}, A_{j}\right)
$$

Tomando $C\left(D_{i}, A_{j}\right)=0$ e $C\left(E_{i}, A_{j}\right)=0$, deve-se então estimar a covariância aditiva entre os caracteres.

Assim sendo, o sistema de equações mais comumente utilizado para obtenção dos índices de seleção é:

$$
P b=G a, \text { sendo }
$$


$G=$ matriz formada pelas estimativas das variâncias e covariâncias genotípicas, referentes ao tipo de progênie considerado. Esta é a forma mais comum de representar o sistema de equações usado para obtenção do índice de seleção.

A solução é conseguida pela pré-multiplicação do sistema pela inversa da matriz de variâncias e covariâncias fenotípicas $P^{-1}$ :

$$
\begin{aligned}
& P^{-1} P b=P^{-1} G a, \therefore \\
& b=P^{-1} G a .
\end{aligned}
$$

O índice obtido desta forma é o índice otimizado de Smith (1936), que maximiza $r_{W T}$. Apenas os pesos relativos $b_{i}$ são importantes, podendo ser multiplicados por uma constante arbitrária qualquer, sem alterar seu uso. Verifica-se que, quando os pesos são estimados dessa forma, $V(I)=C(I, W)$.

Como na prática são empregadas estimativas dos parâmetros populacionais, estes índices foram denominados por Williams (1962a) de índices estimados, outros autores também chamam-no de índice de Smith-Hazel, já que Hazel (1943) obteve equagões equivalentes, difundindo seu emprego, principalmente no melhoramento animal. É óbvio que $\hat{P} \hat{b}=\hat{G} a$ e, portanto, $\hat{b}=\hat{P}^{-1} \hat{G} a$.

Após a apresentação da dedução do índice otimizado, fica evidente que seu emprego foi idealizado para melhor o valor genotípico de uma população, isto é, para ser empregado com o objetivo de aumentar os valores genotípicos dos genótipos que compõem uma população, melhorando-a geneticamente para todos os caracteres sob seleção. Assim, sua utilização visa aumento do conjunto de alelos favoráveis relacionados aos caracteres de interesse da população sob seleção. Selecionam-se os genótipos que mais contribuem para melhoria do valor genotípico populacional, independentemente de seu desempenho para caracteres individuais.

Em alguns casos, os valores econômicos relativos de alguns caracteres incluídos no índice podem ser tomados como zero. Tais caracteres, apesar de não terem importância econômica direta, podem auxiliar no aumento do valor genotípico populacional. Para tanto, modifica-se o termo à direita da igualdade eliminando-se os termos com $a_{i}=0$, não 
requerendo estimativas das variâncias e covariâncias genéticas entre eles para obtenção dos índices, reduzindo o número de cálculos (Baker, 1986).

Um procedimento prático para a obtenção de índices otimizados foi proposto por Henderson (1963). Consideram-se como caracteres primários aqueles que apresentam valor econômico relativo diferente de zero, sendo os demais denominados secundários, desde que apresentem alguma associação com os primários, justificando sua inclusão no índice. Obtém-se então um índice para cada caráter primário e, ponderando-se cada um deles pelo valor econômico desejado, calcula-se o índice otimizado. A principal vantagem deste método é que ele possibilita obter novos índices, mesmo que os pesos se alterem, sem necessidade de novos cálculos. Atualmente, com a disponibilidade de computadores com alta capacidade para realização de operações matemáticas, alterações nos pesos podern ser facilmente conseguidas.

Um dos problemas encontrados no emprego de índices deste tipo é a dificuldade em atribuir pesos econômicos $a_{i}$ adequados, pois, nitidamente, não é fácil se atribuir pesos relativos entre os caracteres (Wricke \& Weber, 1986).

Concluindo, verifica-se que o índice otimizado é perfeitamente adequado às situações existentes nos programas de seleção recorrente, onde se deseja efetuar o melhoramento da população para todos os caracteres importantes, embora exista dificuldade de ponderação. Genótipos com desempenho inferior para uma ou mais características poderão ser selecionados, desde que apresentem alelos favoráveis para os demais caracteres. Porém, essa não é a situação encontrada nos programas de desenvolvimento de cultivares, já que os genótipos com alguma característica cujo desempenho esteja abaixo dos níveis mínimos comerciais exigidos não podem ser selecionados. Além do mais, não haverá recombinação dos genótipos selecionados e não há estimativas dos parâmetros genéticos requeridos para o cálculo dos índices. Também não faz sentido supor a existência de valor genotípico que deva ser melhorado. Assim, outras abordagens dessa situação devem ser feitas.

\subsection{2. Índices básicos}

No caso onde é possível especificar o valor econômico relativo de cada caráter, mas não há boas estimativas dos parâmetros genotípicos e fenotípicos, pode-se empregar o índice sugerido inicialmente por Brim et al. (1959), denominado índice básico por Williams 
(1962a). Calcula-se um índice para cada genótipo, multiplicando-se os valores fenotípicos observados de cada caráter pelo seu respectivo valor econômico, somandoos posteriormente:

$$
I=a_{1} P_{1}+\ldots+a_{i} P_{i}+\ldots+a_{n} P_{n}, \text { sendo }
$$

$I$ = valor do índice básico;

$a_{i}=$ valor econômico relativo atribuído ao caráter $i$;

$P_{i}=$ valor fenotípico observado para o caráter $i$.

Sua aplicação é restrita aos casos onde se pode assumir que o fenótipo do caráter é uma boa aproximação do seu valor genotípico (Wricke e Weber, 1986).

É evidente que, nesse caso, $b=a, I=a^{\prime} p$ e $W=a^{\prime} g$, resultando

$$
\begin{aligned}
& V(I)=a^{\prime} P a ; \\
& V(W)=a^{\prime} G a ; \\
& C(I, W)=a^{\prime} C a ; \\
& r_{I W}=\frac{a^{\prime} G a}{\left.\sqrt{\left(a^{\prime} P\right.} a\right)\left(a^{\prime} G a\right)}=\sqrt{a^{\prime} G a} .
\end{aligned}
$$

O principal atributo deste índice é sua simplicidade de obtenção e interpretação, além de não requerer estimativas de parâmetros genéticos. Williams (1962a) mostrou que o índice básico pode ser vantajoso quando os pesos do índice otimizado apresentam grandes erros. Porém, pelas mesmas razões que para o índice otimizado e por ser apenas uma pequena modificação dele, também não é adequado para a seleção de genótipos experimentais, que poderão ser selecionados como cultivares.

\subsection{3. Índices básicos modificados}

Uma modificação nesse último procedimento foi feita por Smith et al. (1981), que propuseram que o valor fenotípico de cada caráter seja ponderado por sua herdabilidade $\left(h_{i}^{2}\right)$ e não pelo seu valor econômico. Esses autores concluíram que um índice baseado em estimativas de herdabilidade pode ser mais efetivo que o índice básico, caso $a_{i}$ tenha o mesmo valor para todos caracteres. 
No caso onde os $a_{i}$ 's não apresentam mesma magnitude, e os valores de $h_{i}^{2}$ variam muito de acordo com a característica, Baker (1986) sugeriu a combinação dos procedimentos de Smith et al. (1981) e Williams (1962a), através do uso de um índice no qual cada caráter $i$ seja ponderado por $w_{i}$, o produto entre sua herdabilidade e valor econômico relativo, ou seja, $w_{i}=a_{i} h_{i}^{2} .0$ índice é:

$$
I=w_{1} P_{1}+\ldots+w_{i} P_{i}+\ldots+w_{n} P_{n}
$$

Como $h_{i}^{2}$ e $a_{i}$ sabidamente variam de acordo com o caráter considerado, se os parâmetros genotípicos e fenotípicos forem estimados com boa precisão, tal índice pode ser muito útil para auxiliar a seleção (Baker, 1986).

Da mesma forma que o índice básico, não é possível utilizar os índices modificados para aumentar a resposta à seleção de caracteres primários, através do uso de caracteres correlacionados, o que é evidente, já que não se faz uso de matrizes de variância e covariância genéticas. Observa-se novamente que também não é possível aplicá-lo nas etapas finais dos programas de desenvolvimento de cultivares, pelas razões já expostas para os índices otimizado e básico.

\subsection{4. Índices restritos}

Este tipo de índice foi proposto por Kempthome \& Nordskog (1959), tendo posteriormente sofrido várias alteragões, como as de James (1968) e Cunningham et al. (1970). Basicamente, índices de seleção restritos são aqueles que consideram a resposta à seleção em um ou mais caracteres como sendo constante (ou zero), enquanto altera a média dos demais na direção desejada. Tal procedimento permite então alterar apenas os caracteres de interesse, mantendo os outros em níveis desejados, ou seja, com resposta restrita ou inalterada. 0 princípio usado para seu desenvolvimento consiste em se obterem pesos $b_{j}$ 's, de forma que a covariância seja zero entre o índice fenotípico $I$ e o grupo de caracteres $i$ que não se deseja alterar. Por exemplo, caso se deseje que o caráter $g_{1}$ não sofra alteração com a seleção, usase

$$
C\left(I, g_{1}\right)=0
$$


Uma forma de equacionar o problema é apresentada por Cunningham et al. (1970), através de uma modificação do sistema de equações original $P b=G a$ para

$$
\begin{aligned}
& {\left[\begin{array}{cc}
P & G_{i} \\
G_{i} & 0
\end{array}\right]\left[\begin{array}{c}
b \\
b_{d}
\end{array}\right]=\left[\begin{array}{l}
G \\
0
\end{array}\right][a] \Rightarrow\left[\begin{array}{c}
P b+G_{i} b_{d} \\
G_{i} b+0 b_{d}
\end{array}\right]=\left[\begin{array}{c}
G a \\
0
\end{array}\right], \text { ou seja, }} \\
& \left\{\begin{array}{l}
P b+G_{i} b_{d}=G a \\
G_{i} b \quad=0, \text { onde }
\end{array}\right.
\end{aligned}
$$

$G_{i}=$ jésima coluna da matriz de variâncias e covariâncias genotípicas, referente aos $i$ caracteres cuja resposta deve ser restrita.

Nota-se que os valores tomados para $b_{d}$ são tais que a covariância entre os pesos do índice e os valores fenotípicos destes $i$ caracteres seja zero $\left(G_{i} b=0\right)$, implicando em ausência de resposta para eles quando se realiza seleção com uso do índice restrito. Já $b$ é o mesmo vetor do índice otimizado, considerando-se a restrição.

As seguintes expressões podem ser utilizadas para a obtenção dos pesos (Wricke \& Weber, 1986):

$$
\begin{aligned}
& b=\left[I-P^{-1} G_{i}\left(G_{i}^{\prime} P^{-1} G_{i}\right)^{-1} G_{i}^{\prime}\right] P^{-1} G a, \text { sendo } I \text { a matriz identidade, e } \\
& b_{d}=\left(G_{i}^{\prime} P^{-1} G_{i}\right)^{-1} G_{i}^{\prime} P^{-1} G a .
\end{aligned}
$$

Os valores do vetor $b$ são usados como coeficiente do índice $I$, da maneira usual, e $b_{d}$ não é considerado.

Uma generalização desse procedimento é apresentada por Wricke \& Weber (1986). Pode-se impor $r \leq n$ restrições ao sistema ( $n=$ número de caracteres $=$ número de linhas $\mathrm{e}$ colunas de $C$ ), sendo cada uma delas uma combinação linear dos valores dos $g_{i}$ 's (restrição linearmente dependente). Por exemplo, podem-se obter os pesos que otimizem um índice de seleção com a seguinte restrição:

$$
\begin{aligned}
& w_{j 1} C\left(I, g_{1}\right)+w_{j 2} C\left(I, g_{2}\right)=k_{j}, \text { que pode ser escrita como } \\
& w_{j}^{\prime} C^{\prime} b=k_{j} .
\end{aligned}
$$


As soluções para tais sistemas são apresentadas por Mallard (1972). O sistema de equagões a ser resolvido é

$$
\begin{gathered}
{\left[\begin{array}{cc}
P & C W^{\prime} \\
W C^{\prime} & 0
\end{array}\right]\left[\begin{array}{l}
b \\
\lambda
\end{array}\right]=\left[\begin{array}{c}
C a \\
k
\end{array}\right], \text { ou }} \\
\left\{\begin{array}{rl}
P b+C W^{\prime} \lambda & =C a \\
W C^{\prime} b & =k
\end{array},\right. \text { onde }
\end{gathered}
$$

$W=$ matriz $r \times n$ de transformação, de posto $r \leq n$, definindo as $r$ restrições;

$\lambda=$ vetor auxiliar com $r$ variáveis auxiliares;

$k=$ vetor de $r$ valores, dado pelas equações de restrição $W C^{\prime} b=k$.

Sua solução é:

$$
\begin{aligned}
& \lambda=\left(W C^{\prime} P^{-1} C W^{\prime}\right)^{-1} W C^{\prime} P^{-1} C a-\left(W C^{\prime} P^{-1} C W^{\prime}\right)^{-1} k, \mathrm{e} \\
& b=P^{-1}\left(C a-C W^{\prime} \lambda\right) .
\end{aligned}
$$

Por exemplo, no caso de desejar restringir $g_{1}$, simplesmente toma-se $W=\left[\begin{array}{llll}1 & 0 & \ldots & 0\end{array}\right]$, e assim por diante, simplificando os cálculos.

Verifica-se que este tipo de índice é apenas uma modificação dos índices otimizados e, pelas mesmas razões já apresentadas, não é adequado à situação encontrada nas etapas finais dos programas de desenvolvimento de cultivares.

\subsection{5. Índices de resposta à seleção desejada}

Estes índices podem ser considerados como um caso especial dos índices restritos, tanto que alguns autores, como Baker (1986), não fazem distinção entre eles. Situam-se no caso onde há tantas restrições quanto caracteres considerados, ou seja, $r=n$. Sem perda de generalidade, assume-se que $W$ é a matriz identidade e, deste modo, o sistema restrito $W C^{\prime} b=k$ anterior será $C^{\prime} b=k$ (Wricke \& Weber, 1986). Considerando que a matriz $C^{\prime}$ é quadrada de dimensão $n \times n$ e posto completo, pois $r=n$, a solução é obtida por

$$
b=\left(C^{\prime}\right)^{-1} k
$$


Nota-se que não são necessárias estimativas de variâncias e covariâncias fenotípicas. $O$ índice mais conhecido deste tipo é o de Pesek \& Baker (1969), que consideraram $C=G$. Como $G$ é simétrica, $G=G^{\prime}$, então

$$
b=G^{-1} k \text {. }
$$

Com este índice, não é necessário atribuir pesos econômicos, mas se deve definir o genótipo desejado. Os pesos $b_{j}$ são tais que os valores genotípicos dos caracteres são melhorados na proporção definida no vetor $k$. Por exemplo, para três caracteres, se $k^{\prime}=\left[\begin{array}{lll}1 & 2 & 3\end{array}\right]$, o primeiro deles será melhorado em uma unidade, o segundo em duas e o terceiro em três, sem estandardização. Embora não seja necessária a atribuição de valores econômicos relativos, de certo modo, a definição dos valores para o ganho também é uma forma de ponderação, dificultando seu uso, assim como no caso do índice otimizado. Os pesos obtidos são tais que a seleção com base no índice priorizará os genótipos que proporcionarão a resposta à seleção mais próxima possível da desejada. Contudo, níveis inferiores em alguns caracteres podem ser compensados por outros com fenótipo em níveis adequados, não permitindo então que o índice seja usado nos programas de obtenção de cultivares, do mesmo modo que os anteriores. Além disso, ele também pressupõe um valor genotípico que deve ser melhorado, o que não faz sentido na situação considerada.

Outro caso foi considerado por Tai (1977) para $n$ caracteres, sendo $r$ deles restritos e $n-r$ com pesos econômicos atribuídos. Sem perda de generalidade, pode-se assumir que os restritos são os $r$ primeiros e os com peso econômico os $n-r$ últimos, $a_{1}$ são os pesos econômicos (desconhecidos) para os $r$ primeiros e $a_{2}$ os pesos econômicos (conhecidos) para os $n-r$ restantes. O sistema a ser resolvido, de modo a determinar $b$, é

$$
\left\{\begin{array}{l}
P b=C\left[\begin{array}{l}
a_{1} \\
a_{2}
\end{array}\right] . \\
W C^{\prime} b=k
\end{array}\right.
$$

\subsection{6. Índices gerais}

Hanson \& Johnson (1957), observando que cada índice de seleção é calculado com base numa população específica, testada num dado conjunto de ambientes, questionaram a 
possibilidade do uso de um índice geral, adotado para todo o programa de melhoramento. Os autores sugeriram que poderia ser mais eficiente combinar a informação de uma série de experimentos para obter um índice geral médio, desenvolvido de forma a maximizar a resposta à seleção com relação a todos os possíveis genótipos avaliados em todos os possíveis ambientes, sendo os coeficientes do índice obtidos também com base na qualidade genotípica. Uma vez que uma solução exata é impraticável, recomendou-se o uso de matrizes de variância e covariânda médias para a situação toda, obtendo-se, a partir delas, as estimativas desejadas. Procedimento semelhante foi sugerido por Caldwell \& Weber (1965). Obviamente, tais índices também se destinam ao uso em programas de seleção recorrente.

\section{2. Índices não-lineares}

\subsection{1. Índice multiplicativo}

Elston (1963) desenvolveu um índice, apresentado detalhadamente a seguir, que não requer o uso de pesos econômicos e estimativas de parâmetros genéticos. Tal índice, como os demais, dassifica os genótipos para todos os caracteres ao mesmo tempo, permitindo depois efetuar seleção exclusivamente com base em um único valor, com a vantagem de prescindir de estimativas e pesos, nem sempre existentes.

Por não necessitar de estimativas de parâmetros genéticos, além de não pressupor a existência de um valor genotípico populacional que deva ser melhorado, adapta-se tanto aos programas de seleção recorrente, como às etapas finais dos programas de obtenção de cultivares, o que não ocorre com os índices lineares apresentados. Todos os caracteres recebem mesma ênfase na seleção, sendo impossível atribuir-lhes qualquer peso.

Seu desenvolvimento baseia-se num princípio muito simples. Sabe-se que a fração dos genótipos selecionada com base num índice linear para dois caracteres é dada pela função linear com forma $a_{1} g_{1}+a_{2} g_{2}+\ldots+a_{p} g_{p}$, sendo $a_{i}$ os pesos econômicos. Porém, quando não é possível ou não se deseja atribuir tais pesos, pode-se obter uma função não linear que selecione uma região bastante aproximada desta última fração, a ser determinada com emprego do índice multiplicativo (Figura 3). 


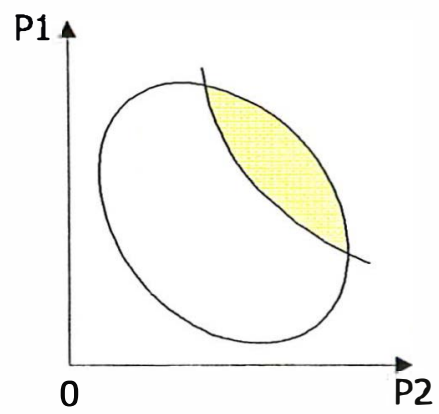

Figura 3. Região selecionada com emprego do índice multiplicativo de Elston (1963), para dois caracteres P1 e P2.

Os genótipos escolhidos com base nesse procedimento são aproximadamente os mesmos que os selecionados com o uso do índice linear, quando os pesos econômicos são iguais. Desse modo, buscou-se um procedimento alternativo que, ao invés de maximizar a correlação entre o valor genotípico populacional e o índice, como no caso dos índices lineares, sejam tomados aproximadamente os mesmos genótipos.

Para tanto, o autor supôs que as medidas de cada valor de $g_{i}$ possam ser aproximadas por sua medida fenotípica $p_{i},(i=1,2, \ldots, n$ caracteres). A região delimitadora aproxima-se de uma linha reta se os valores de $p_{i}$ estiverem expressos em unidades adequadas. Após obtenção das medidas, deve-se maximizar a função que delimite a área de interesse (Figura 3). Na prática, esse procedimento simples evita a necessidade de se estimarem parâmetros, devendo resultar, aproximadamente, na seleção dos mesmos genótipos que aqueles escolhidos com o índice linear. Há a vantagem adicional de tal índice poder ser empregado também em etapas avançadas dos programas de obtenção de cultivares, com a simples finalidade de classificar os genótipos.

Para ilustrar uma situação real, o autor apresentou um exemplo considerando a seleção de fêmeas de aves de corte, sendo $p_{1}$ o número de ovos postos por uma ave em um ano e $p_{2}$ o peso desta ave com dez semanas. Supondo que o melhorista deseje selecionar uma fração $\lambda$ das aves, de forma a maximizar simultaneamente $p_{1}$ e $p_{2}$ com mesma ênfase, deve-se descobrir qual função delimita a região de interesse. A função $p_{1}+p_{2}$ não é 
adequada, já que seus valores sofrerão pouca influência dos valores de $p_{2}$, porque este caráter é menos variável que $p_{1}$. Mas, se as medidas de $p_{1}$ forem $a$ vezes tão variáveis como as de $p_{2}$, pode ser empregado o índice $p_{1}+a p_{2}$, implicando na atribuição dos mesmos pesos às variáveis. Nota-se que a variância de cada caráter incluído no índice deve ser considerada, ou então, altemativamente, aplicar uma transformação que uniformize as variâncias.

O autor considerou também a possibilidade de descartar genótipos com desempenho no limite inferior para algum(ns) caráter(es). No exemplo, tem-se que $p_{1} \geq 0$, devendo o índice garantir que não sejam selecionados genótipos com $p_{1}=0$, ou seja, aves que não ponham nenhum ovo, independente do valor que $p_{2}$ assuma. De modo similar, $p_{2} \geq k$, onde $k$ é o limite inferior para o peso com dez semanas; se $p_{2}=k$, os genótipos não podern ser selecionados, independente do valor de $p_{1}$.

Com base nessas condições, considerando que o índice deve assumir seus maiores valores quando $p_{1}$ e $p_{2}$ forem máximos e garantindo que a fração selecionada seja aproximadamente a mesma que aquela obtida com emprego de índices lineares, propôs-se o uso da função multiplicativa $p_{1}\left(p_{2}-k\right)$, que pode ser escrita em sua forma geral como

$$
\prod_{i=1}^{n}\left(p_{i}-k_{i}\right)=\left(p_{1}-k_{1}\right)\left(p_{2}-k_{2}\right) . .\left(p_{n}-k_{n}\right), \text { onde }
$$

$k_{i}=$ limite inferior de $p_{i}$.

É evidente que, no exemplo, se $p_{1}=0$, a função assume valor zero, o mesmo correndo quando $p_{2}=k$; evita-se assim a seleção dos genótipos inferiores para qualquer uma das características. Logo, usando tal procedimento, os genótipos que possuam fenótipo igual ao menor valor para alguma(s) característica(s), automaticamente apresentarão valor zero para a função e, deste modo, apresentarão o menor valor possível para o índice (zero), não sendo selecionados.

Graficamente, para dois caracteres, as curvas delimitando os genótipos selecionados pertencem à família de curvas obtidas por

$$
p_{1}-k_{1}=\frac{A}{p_{2}-k_{2}}, \infty \mathrm{m} A>0 \text {, }
$$


que, geometricamente, são hipérboles retangulares com assíntotas em $p_{1}=k_{1}$ e $p_{2}=k_{2}$. A parte $\lambda$ selecionada da população é função de $A$; quanto menor a porção selecionada, mais este índice se aproxima dos lineares (Figura 4). Logo, sem necessidade de estimativas de parâmetros genéticos e fenotípicos, pode-se selecionar aproximadamente a mesma fração de genótipos que os índices lineares tomariam, havendo ainda o descarte dos genótipos com caracteres em níveis inferiores, pelo simples uso da função multiplicativa.

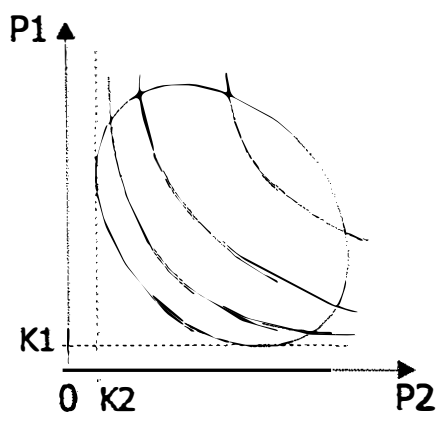

Figura 4. Família de curvas obtidas por $p_{1}-k_{1}=A /\left(p_{2}-k_{2}\right)$, sendo $A>0$. A região delimitada pelas curvas corresponde aos genótipos selecionados com emprego do índice de Elston (1963).

Verifica-se que, caso a transformação $p_{i}{ }^{\prime}=\log \left(p_{i}-k_{i}\right)$ seja aplicada a todos os caracteres, o índice multiplicativo será equivalente às funções lineares $\sum_{i=1}^{n} p_{i}{ }^{\prime}$, pela propriedade que o logaritmo possui de transformar produtos em somas. Imaginando que cada caráter possua um peso $a_{i}$ desconhecido, de modo que as medidas sejam $a_{1} p_{1}, \ldots, a_{n} p_{n}$, a aplicação do logaritmo resultará então em

$$
\sum_{i=1}^{n} \log a_{i} p_{i}=\sum_{i=1}^{n} \log p_{i}+\sum_{i=1}^{n} \log a_{i}
$$

graças a já mencionada propriedade dos logaritmos. Os pesos afetarão apenas o segundo termo e como $a_{i}$ é uma constante para todos os genótipos, este componente não altera a classificação dos genótipos. Observa-se que o sentido de peso de cada caráter é diferente neste tipo de índice, pois na verdade ele é um multiplicador da variabilidade que cada caráter 
apresenta e que, sendo uniforme para todos eles, evita ponderações quando se usa a função multiplicativa. Logo, mediante transformação adequada (logarítmica), consegue-se a mesma ênfase para todos os caracteres.

Em situações práticas, deve-se considerar que, além do fator de escala, as distribuições devem estar proximamente centradas, ou seja, expressas em unidades semelhantes, para que, ao se efetuarem as multiplicações, não exista diferença entre as unidades de medidas dos caracteres. Necessita-se extender o conceito do índice à expressão $p_{i}-k_{i}$ e não simplesmente a $p_{i}$, já que a simples diferença de unidades entre os caracteres pode causar grandes diferenças nos pesos que cada caráter recebe.

Finalmente, 0 autor conclui que $o$ índice

$$
\prod_{i=1}^{n}\left(p_{i}{ }^{\prime}-k_{i}^{\prime}\right)
$$

pode ser suficiente, para colocar os caracteres na mesma escala e ajustá-los para diferenças em suas variâncias. Caso uma única transformação logarítmica não seja suficiente, podese, teoricamente, aplicá-la tantas vezes quanto se deseja. $O$ valor de $k_{i}$ nada mais é que uma constante que, subtraída de cada $p_{i}$, permite que todas as variáveis estejam proximamente centrodas.

A obtenção do índice de seleção multiplicativo segue então os seguintes passos:

i) Tomam-se escalas para os diferentes caracteres de forma que os melhores genótipos sempre possuam os maiores valores. Para caracteres onde os menores valores são os desejados, muda-se a escala com a utilização dos recíprocos dos valores, ou ainda, multiplicando todos eles por -1 ;

ii) Caso as distribuições dos caracteres sejam diferentes, aplica-se uma transformação para uniformizá-las, pelo menos quanto ao número de modas. A distribuição pode ser avaliada através de histogramas simples;

iii) Para cada medida de cada caráter, subtrai-se o menor valor de ocorrência dentre elas, ou seja, obtém-se $\left(p_{i}-k_{i}\right)$, efetuando um ajuste da escala;

iv) Se os histogramas obtidos para os vários caracteres tiverem formas similares, calcula-se o índice 


$$
\prod_{i=1}^{n}\left(p_{i}-k_{i}\right)
$$

v) Caso a condição anterior não se verifique, subtrai-se o menor valor de $p_{i}{ }^{\prime}$ que ocorreu de cada valor $p_{i}{ }^{\prime}=\log \left(p_{i}-k_{i}\right)$, obtendo-se portanto $\left(p_{i}{ }^{\prime}-k_{i}{ }^{\prime}\right)$, após o que se calcula (ignorando o valor de $p_{i}{ }^{\prime}=-\infty$, que resulta para o valor zero)

$$
\prod_{i=1}^{n}\left(p_{i}^{\prime}-k_{i}^{\prime}\right)
$$

No caso de se desejar classificar todos os genótipos, mesmo os posicionados inferiormente, para impedir a ocorrência de índices com valor zero, não se deve tomar o menor valor de $p_{i}$ que ocorreu, mas sim

$$
k_{i}=\frac{n\left(\min p_{i}\right)-\left(\max p_{i}\right)}{n-1}, \text { onde }
$$

$n=$ número de genótipos.

De modo semelhante, caso necessário, toma-se

$$
k_{i}^{\prime}=\frac{n\left(\min p_{i}^{\prime}\right)-\left(\max p_{i}^{\prime}\right)}{n-1}
$$

Estes parâmetros $\left(k_{i}^{\prime} s\right)$ foram obtidos considerando que os $n$ valores de $p_{i}$ disponíveis sejam uma amostra aleatória de uma distribuição retangular (Elston, 1963). Seu uso é feito para evitar que o índice tenha valor zero quando o genótipo estiver no limite superior ou inferior para alguma variável. Finalmente, classificam-se os genótipos de acordo com o valor obtido com cálculo do índice.

O fato desse índice multiplicativo não requerer a obtenção de estimativas de parâmetros genéticos e nem supor a existência de um valor genotípico populacional, permite que ele seja aplicado tanto para selecionar genótipos em programas de seleção recorrente (como os lineares) como para simplesmente classificar os genótipos com respeito a diversos caracteres simultaneamente, sendo assim adequado às etapas finais dos programas de desenvolvimento de cultivares. 
Contudo, alguns problemas surgem em suas aplicações reais. Inicialmente, nota-se que, por ser multiplicativo, impede que o melhorista atribua qualquer peso arbitrário a algum(ns) caráter(es), já que multiplicar o valor de qualquer caráter por um peso significa apenas alterar a escala do índice e não priorizar um caráter sobre os demais. Isso pode ser um problema, pois em situações reais, embora exista dificuldade em atribuir pesos, muitas vezes isso é possível e desejável. Como exemplo, podemos citar o caráter produção, geralmente mais importante que os demais.

\subsubsection{Indice de soma de classificação}

O índice de soma de classificação, proposto por Mulamba \& Mock (1978), baseiase num principio simples: após classificação dos genótipos para cada um dos $P_{i}$ caracteres a serem incluídos no índice, usa-se o número de ordem obtido para cada um deles no cálculo do índice $I_{j}$, da seguinte forma:

$$
I_{j}=\sum n_{i j}, \text { sendo }
$$

$I_{j}=$ índice para o genótipo $j$;

$n_{i j}=$ número de classificação da variável $i$ para o genótipo $j$.

Obviamente, os melhores genótipos terão menores valores para $I_{j}$ e sua Classificação é facilmente realizada, sem necessidade de obtenção de parâmetros genéticos. Este índice transforma os dados de forma que todos os caracteres tenham mesma variância. Em função de suas propriedades, pode ser aplicado para classificar os genótipos das etapas finais dos programas de seleção de cultivares do mesmo modo que o índice multiplicativo; serve também para uso em seleção recorrente, mas com limitaçães. Por exemplo, os ganhos esperados com seleção não podem ser calculados, embora Crosbie et al. (1980) afirmem ser possível o uso de uma equação de predição do ganho esperado, também usada para o índice multiplicativo, resultando numa razoável forma de aproximação.

Tal índice não permite descartar genótipos com caracteres em níveis inferiores, o que praticamente inviabiliza o seu uso, já que nas etapas finais de seleção de cultivares alguns genótipos não devam ser selecionados por apresentarem caracteres com valores diferentes das exigências comerciais. Outro problema é a não consideração de que as diferenças entre as 
médias, nas etapas finais, não são necessariamente significativas; tal fato pode levar a interpretaģes errôneas quanto às reais diferenças entre os genótipos.

\subsection{3. Índices baseados em medidas de distância}

Um outro tipo de índice, que também não requer estimativas de parâmetros genéticos, foi apresentado por Schwarzbach (1972) ${ }^{1}$, citado por Wricke \& Weber (1986). Neste caso, pressupõe-se que os valores fenotípicos sejam boas aproximações dos genotípicos e se calculam, a partir das médias fenotípicas, distâncias de cada genótipo a um genótipo ideal, fixado pelo pesquisador para todos os $n$ caracteres considerados. Teoricamente, seu uso é possível, tanto nos programas de seleção recorrente como nas etapas finais dos programas de seleção de cultivares.

Podem-se empregar como medidas a distância eudidiana ou a distância generalizada de Mahalanobis, por exemplo. Para o genótipo $i$, com uso da distância eudidiana, o índice é:

$$
D_{i I}=\sqrt{\sum_{j=1}^{n} a_{j}\left(x_{i j}-x_{I j}\right)^{2}}, \text { sendo }
$$

$D_{i I}=$ distância euclidiana do genótipo $i$ ao genótipo ideal $I$;

$x_{i j}=$ fenótipo do caráter $j$ no genótipo $i$;

$x_{l j}=$ valor do genótipo ideal para o caráter $j$, (determinado pelo melhorista);

$a_{j}=$ peso atribuído ao caráter $j$, do mesmo modo que nos demais índices.

Exemplificando para o caso de três caracteres, pode-se representar a localização do genótipo $i$ e do ideótipo $I$ num espaço tridimensional (Figura 5), sendo a distância eudidiana entre os dois genótipos medida por

$$
d_{i I}=\sqrt{\sum_{j=1}^{3}\left(x_{i j}-x_{I j}\right)^{2}} .
$$

\footnotetext{
I SCHWARZBACH, E. Einige Anwendungsmöglichkeiten elektonischer Daterverorbeitung (EDV) für die Beurteilung von Zudiumoterial. Arb. Tag. Oestert. Pflanzenz. Gumpenstein: 277-87, 1972.
} 


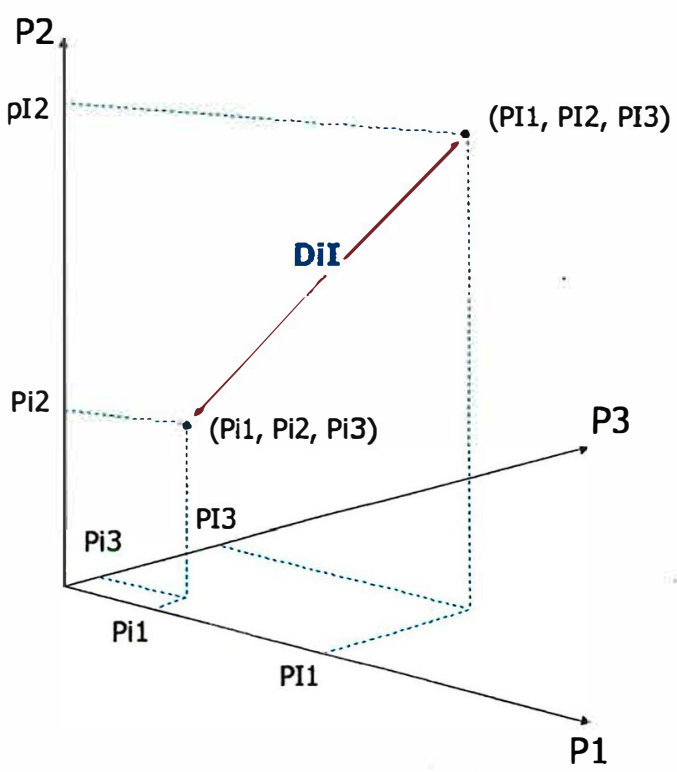

Figura 5. Representação tridimensional da localização de um genótipo $i\left(P_{i j}\right)$ e do ideótipo $I\left(P_{I j}\right)$ para três caracteres, $P_{1}, P_{2}$ e $P_{3}$. A distância euclidiana entre os genótipos foi representada por $D_{i I}$.

Generalizando, para qualquer número $n$ de caracteres medido, a distância euclidiana de cada genótipo $i$ ao ideótipo $I$ é

$$
d_{i I}=\sqrt{\sum_{j=1}^{n}\left(x_{i j}-x_{I j}\right)^{2}},
$$

sendo evidente que para tais casos não é possível uma representação gráfica. Esta distância, embora envolva um conceito simples, pode ser aplicada satisfatoriamente em muitos casos (Manly, 1994). Os genótipos superiores estarão mais próximos do ideótipo, sendo então selecionados. É óbvio que o cálculo das distâncias só pode ser feito se todos os dados estiverem na mesma escala.

Esse índice não permite que os genótipos que não satisfaçam às exigências mínimas do mercado sejam descartados. Além disso, não considera o fato de as médias fenotípicas não serem necessariamente estatisticamente diferentes, o que deveria ser levado em conta nos cálculos. Uma vantagem que apresenta sobre o índice de Elston (1963) é a possibilidade de se efetuarem ponderações. 


\subsection{4. Índices polinomiais}

Kempthome \& Nordskog (1959) mencionaram o eventual uso de uma função polinomial, e não uma linear, como um índice de seleção. Como exemplo, para dois caracteres, podese tomar $W$ como sendo a seguinte função polinomial (Wricke \& Weber, 1986):

$$
W=a_{1} g_{1}+a_{2} g_{2}+a_{11} g_{1}^{2}+a_{12} g_{12}+a_{22} g_{2}^{2}
$$

Basta escolher os pesos da mesma forma que para os índices lineares, tomando $g_{1}, g_{2}, g_{1}^{2}, g_{1} g_{2}$ e $g_{2}^{2}$ como caracteres, procedendo-se do mesmo modo que para o índice otimizado.

Outros índices não lineares podem ser obtidos utilizando-se razões entre duas variáveis, que com a aplicação de logaritmos tornam-se novamente lineares (Wricke \& Weber, 1986). No entanto, fica difícil para o melhorista justificar o uso de tal função, que é de difícil interpretação.

\subsection{Considerações gerais sobre os índices}

Nesto revisão, ficou evidenciado que, para a maioria dos índices, notadamente os lineares, é necessária a atribuição dos valores econômicos relativos dos caracteres, bem como dispor de estimativas das variâncias por caráter e covariâncias genotípicas entre caracteres. Isto dificulta sua aplicação na prática, já que os experimentos instalados para seleção nem sempre permitem a obtenção de tais estimativas (Baker, 1986) e pode haver dificuldades em se atribuir os pesos.

Índices lineares, desenvolvidos a partir das equaçōes de Smith (1936), requerem estimativas de: (1) variância genética de cada caráter, (2) correlagōes genotípicas entre os caracteres, (3) herdabilidade de cada caráter, (4) variâncias fenotípicas de cada caráter e (5) correlaģōes fenotípicas entre caracteres, o que certamente limita a sua aplicação. Hazel (1943) alertou que os índices desenvolvidos para uma população não podem ser aplicados a outras indistintamente, pois os valores econômicos e as estimativas de parâmetros genéticos podem diferir, requerendo sempre novas estimações para diferentes valores econômicos. Um problema adicional que surge é que as estimativas de parâmetros requeridas normalmente apresentam grandes erros de estimação, dificultando ainda mais o cálculo dos índices. 
Por pressuporem a existência de um valor genotípico populacional que deva ser melhorado, além de não preverem o descarte de genótipos com algum(ns) valor(es) abaixo das exigências mínimas de mercado, condui-se que os índices lineares não são adequados para dassificar genótipos nas etapas finais dos programas de obtenção de cultivares.

Os índices que mais se aproximam dessa situação são o de Elston (1963), o de Schwarzbach (1972) ${ }^{2}$ citado por Wricke \& Weber (1986) e o de Mulamba e Mock (1978). O primeiro considerou o problema de classificar genótipos com base em seus valores fenotípicos e propôs um índice multiplicativo, após transformação adequada, sem ponderações ou obtenção de estimativas de variâncias e covariâncias. O segundo usou distâncias em relação a um genótipo ideal, assumido pelo pesquisador, podendo ou não incluir pesos, mas também sem estimativas de parâmetros populacionais. O terceiro baseia-se simplesmente no número de dassificação apresentado pelos genótipos para cada variável. Contudo, nenhum deles considera a necessidade de descartar genótipos abaixo (ou acima) dos valores fenotípicos que um caráter deve exibir em função das exigências comerciais (ou agronômicas), muito embora o índice multiplicativo permita descartar genótipos com o menor valor. Outro ponto a ser levantado, que nenhum índice considera, é a possibilidade de realização de testes estatísticos para comparagões de médias, comumente realizados neste tipo de experimento.

Não se sabe da literatura como os melhoristas fazem para selecionar os genótipos nos programas de obtenção de cultivares. O mais provável é que eles façam uso de algum índice subjetivo, provavelmente semelhante à seleção em tandem, sem especificar os cálculos, atribuindo maior peso aos caracteres relacionados diretamente $œ \mathrm{~m}$ a produção. Além da dificuldade que tal processo apresenta, o grau de subjetividade e a dificuldade que sua aplicação representa torna a seleção de cultivares uma etapa extremamente laboriosa. Fica difícil para outros melhoristas repetirem os resultados da seleção, o que é desfavorável. Logo, o desenvolvimento de um índice que auxilie em tal etapa é plenamente justificável.

Com respeito à seleção recorrente, há inúmeros casos na literatura relatando o emprego principalmente dos índices de seleção lineares. Eagles \& Frey (1974), em aveia, verificaram que a resposta à seleção encontrada com o emprego do índice de seleção otimizado e com o índice básico apresentam resultados muito semelhantes. Isso é vantajoso, já que a

\footnotetext{
2 SCHWARZBACH, E. Einige Anwendungsmöglichkeiten elektonischer Datenverarteitung (EDV) für die Beurteilung von Zuchtonaterial. Arb. Tag. Oesterr. Pflanzenz. Gumpenstein: 277-87, 1972.
} 
obtenção do índice básico é bem mais simples. Resultados semelhantes foram apresentados por Elgin et al. (1970) em alfafa.

Rosielle \& Frey (1975) utilizaram o índice restrito em aveia, mostrando que é possivel utilizá-lo para limitar a resposta à seleção em caracteres secundários, mesmo na presença de correlações positivas.

Suwantaradon et al. (1975) avaliaram vários tipos de índice de seleção para o melhoramento simultâneo de sete características de linhagens $S_{1}$ de milho. Além do índice otimizado, eles usaram o índice básico e o de resposta à seleção desejada de Pesek \& Baker (1969). O índice otimizado e o básico forneceram resultados semelhantes, levando os autores a sugerirem a aplicação desse último. O índice modificado propiciou respostas em caracteres individuais proporcionais às respostas esperadas. Kauffmann \& Dudley (1979) realizaram um estudo semelhante para produção e concentração de proteína em milho, conduindo que o índice da resposta desejada foi o mais eficiente.

Radwan \& Momtaz (1975), estudando índices otimizados para uso em linho, concluíram que as respostas realizadas à seleção mostraram que aquela aplicada com base no índice foi mais eficiente que a seleção de caracteres individuais, na população como um todo.

Davis \& Evans (1977), avaliando 15 caracteres em feijão, conduíram que o índice básico pode ser até $73 \%$ tão eficiente quanto o otimizado. Além disso, dados de certos caracteres da planta podem ser até mais eficientes que os componentes de produção na construģa dos índices.

Crosbie et al. (1980) compararam vários tipos de índice de seleção para o melhoramento simultâneo para tolerância ao frio, em milho. Os resultados mostraram que o índice de Pesek \& Baker (1969) não foi satisfatório porque a resposta esperada foi pequena quando grandes aumentos foram especificados para alguns caracteres e pequenos para outros. $O$ índice otimizado e o básico aparentemente discordaram quanto às respostas à seleção. Finalmente, os autores concluíram que o melhor método pareceu ser o emprego do índice multiplicativo de Elston (1963).

Motto \& Perenzin (1982) avaliaram índices para a seleção simultânea de produção e teor protéico num sintético de milho, concluindo que o índice da resposta desejada de Pesek \& Baker (1969) foi muito útil nesse caso. St. Martin et al. (1982) usaram índices de seleção restritos para aumento da produção de grãos de milho, sem alterar a dureza, umidade, teor 
protéico e qualidade da proteína dos grãos. Conciuíram que o uso do índice deve ser acompanhado de um œerto julgamento subjetivo dos melhoristas, o que é desfavorável.

Sullivan \& Bliss (1983) usaram o índice da resposta desejada (Pesek \& Baker, 1969) para melhoramento da produção de grãos e concentração protéica, num programa de seleção recorrente de feijão, sugerindo modificações na metodologia de estimativas das variâncias e covariâncias ambientais, usando os parentais. Tal mudança resultou em melhores estimativas dos coeficientes dos índices.

Um índice extensivamente usado em programas de seleção recorrente de milho dos Estados Unidos, particularmente nos da Universidade de Iowa, é o índice de Smith et al. (1981). Nele, são usados como pesos os coeficientes de herdabilidade, ao invés de pesos econômicos. Os autores apresentam como principal vantagem desse índice o fato de os coeficientes de herdabilidade coincidirem com os pesos do índice otimizado no caso onde os caracteres são não correlacionados, simplificando os cálculos, já que as herdabilidades são rotineiramente computadas nos programas de melhoramento. Porém, isso pode não ocorrer sempre, podendo haver correlações elevadas entre caracteres. Outro problema que tal índice apresenta é o fato dele atribuir maior peso justamente aos caracteres mais fáceis de serem melhorados, por apresentarem maior herdabilidade. Supōese que isso seja errado, uma vez que os caracteres mais importantes, como produção de grãos, possuem as menores herdabilidades, devendo ser priorizados na seleção.

Após extensa revisão sobre o uso de índices de seleção em programas de seleção recorrente, Baker (1986) conduiu que não há resultados conclusivos sobre a validade do uso de índices de seleção usando produção e seus componentes, visando apenas o melhoramento da produção, explorando a correlação entre caracteres. Vários dos trabalhos revistos mostroram que o índice básico geralmente oferece resposta à seleção semelhante ao índice otimizado. Isso traz a vantagem de não ser necessário estimar variâncias e covariâncias nos cálculos e a desvantagem de não se poder usar caracteres secundários para realizar melhoramento de um caráter primário importante. Esse mesmo autor concluiu que os índices de seleção não são usados rotineiramente nos programas de seleção recorrente. 


\section{MATERIAL E MÉTODOS}

\subsection{Material}

Foram utilizados os resultados do Ensaio Nacional de Cultivares de Milho Precoce, referente ao ano agrícola 1996/97, a título de exemplo, para verificar a adequação do índice proposto a uma situação real. Deve-se ressaltar que, na prática, o número de genótipos pré comerciais avaliados nas etapas finais dos programas de desenvolvimento de cultivares deve ser muito maior que o encontrado em tais experimentos. Este ensaio é conduzido anualmente em diversas localidades, sob coordenação da EMBRAPA (Empresa Brasileira de Pesquisa Agropecuária), através do Centro Nacional de Pesquisa de Milho e Sorgo, localizado em Sete Lagoas, MG.

Foram tomados resultados de dez locais, escolhidos em diferentes regiões do país. Nem sempre os caracteres avaliados foram medidos em todos eles, sendo esta uma situação muito comum na prática (Tabela 1). Os experimentos foram instalados segundo o delineamento látice quadrado 7x7, de acordo com os prinćpios básicos da experimentação agrícola. No total, 49 cultivares foram avaliados: 94 HT 31 QPM, A 953, AG 5014, AGROMEN 2003, AGROMEN 2005, AGROMEN 2007, AGROMEN 2018, AGX 2573, AGX 5492, AGX 5542, AGX 5558, AGX 5674, AL 25 XII, AS 3466, C 435, C 435 G, C 491 W, C 505 B, C 505 C, C 625, CD 1723, CO 32, CO 34, CO 36, DINA 1000, DINA 270, DINA 657, EXCELLER, FT 9006, G 165 \$, G 167 S, G 176 S, HATÃ 3012, HD 9486, HD 951128, HD 9563, HT 951005, MASTER, P 3041, PL 320, PL 322, R \& G01, XL 345, XL 360, Z 64 E 74, Z 84 E 90, Z 84 E 98, Z 8440 e Z 8452. 
Tabela 1. Locais de instalação dos experimentos, siglas adotadas e caracteres avaliados: peso de espigas $(P E$, em $\mathrm{kg} / \mathrm{ha})$, umidade $(\mathrm{U}, \%)$, número de dias para florescimento (FLO, dias), altura da planta $(\mathrm{AP}, \mathrm{cm})$, altura da espiga $(\mathrm{AE}, \mathrm{cm})$, prolificidade $(\mathrm{PROL})$, número de plantas acamadas e quebradas (PAQ, \%).

\begin{tabular}{lccccccc}
\hline \multicolumn{1}{c}{ Local } & \multicolumn{1}{c}{ Caráter avaliado } & & \\
& PE & U & FLO & AP & AE & PROL & PAQ \\
\hline Ataliba Leonel, SP (Atali) & $\mathrm{X}$ & & $\mathrm{X}$ & $\mathrm{X}$ & $\mathrm{X}$ & $\mathrm{X}$ & $\mathrm{X}$ \\
Brasília, DF (Brasil) & $\mathrm{X}$ & $\mathrm{X}$ & $\mathrm{X}$ & $\mathrm{X}$ & $\mathrm{X}$ & $\mathrm{X}$ & $\mathrm{X}$ \\
Campo Alegre, MS (Caleg) & $\mathrm{X}$ & & & $\mathrm{X}$ & $\mathrm{X}$ & $\mathrm{X}$ & $\mathrm{X}$ \\
Capinópolis, SP (Capin) & $\mathrm{X}$ & & & $\mathrm{X}$ & $\mathrm{X}$ & $\mathrm{X}$ & $\mathrm{X}$ \\
Cascavel, PR (Cascav) & & $\mathrm{X}$ & & $\mathrm{X}$ & $\mathrm{X}$ & & \\
Goianésia, GO (Goian) & $\mathrm{X}$ & $\mathrm{X}$ & $\mathrm{X}$ & $\mathrm{X}$ & $\mathrm{X}$ & $\mathrm{X}$ & $\mathrm{X}$ \\
Rondonópolis, MT (Rondo) & $\mathrm{X}$ & $\mathrm{X}$ & & $\mathrm{X}$ & $\mathrm{X}$ & $\mathrm{X}$ & $\mathrm{X}$ \\
São Gabriel do Oeste, MS (Sgoes) & $\mathrm{X}$ & $\mathrm{X}$ & $\mathrm{X}$ & $\mathrm{X}$ & $\mathrm{X}$ & $\mathrm{X}$ & $\mathrm{X}$ \\
Sooretama, ES (Soore) & $\mathrm{X}$ & & $\mathrm{X}$ & $\mathrm{X}$ & $\mathrm{X}$ & $\mathrm{X}$ & $\mathrm{X}$ \\
Tangará da Serra, GO (Tang) & $\mathrm{X}$ & & & $\mathrm{X}$ & $\mathrm{X}$ & $\mathrm{X}$ & $\mathrm{X}$ \\
\hline
\end{tabular}

As parcelas constituíram-se de duas linhas de $5 \mathrm{~m}$, espaçadas entre si por 0,90 m, sendo que todos os experimentos tiveram três repetições. Em cada uma das parcelas dos respectivos locais, foram avaliados os seguintes caracteres: peso de espigas (PE, kg/ha), umidade nos grãos (U, \%), número de dias para florescimento (FLO, dias), altura da planta $(A P, c m)$, altura da espiga $(A E, c m)$, número de espigas e número de plantas por parcela, cuja razão originou a variável prolificidade (PROL), número de plantas acamadas e quebradas, que, somados, divididos pelo estande e multiplicados por 100, resultaram no número de plantas acamadas e quebradas, em porcentagem (PAQ, \%).

\subsection{Métodos}

\subsubsection{Análises de variância e estabilidade}

Em cada local, foram realizadas as análises de variância de acordo com o modelo matemático do delineamento látice quadrado (Cochran \& Cox, 1957): 


$$
y_{i j k}=m+g_{i}+b_{j(k)}+r_{k}+e_{i j k}, \text { em que }
$$

$y_{i j k}=$ observação referente ao genótipo $i$ no bloco $j$ da repetição $k$;

$m=$ média geral do experimento (constante);

$g_{i}=$ efeito do genótipo $i$;

$b_{j(k)}=$ efeito do bloco $j$ dentro da repetição $k$;

$r_{k}=$ efeito da repetição $k$;

$e_{i j k}=$ erro experimental associado à parcela $i j k$.

Todos os efeitos, com exceção do erro experimental, foram considerados como fixos. Foram estimadas as médias ajustadas de cada tratamento, em cada experimento, para a variável $\mathrm{PE}$, as quais foram usadas posteriormente para a análise de estabilidade deste caráter. As análises foram realizadas com os dados em suas unidades originais, exceto para a variável PAQ, transformada pelo uso da função $f(x)=\sqrt{x+0,5}$.

Em seguida, efetuou-se a análise de variância conjunta dos respectivos locais (Tabela 1) para todos os caracteres (PE, U, FLO, AP, AE, PROL e PAQ), de acordo com o modelo:

$$
y_{i j k l}=m+g_{i}+b_{j(k l)}+r_{k(l)}+l_{l}+(g l)_{i l}+e_{i j k l}, \text { sendo }
$$

$y_{i j k l}=$ observação referente ao genótipo $i$ no bloco $j$ da repetição $k$ no local $l$;

$m=$ média geral do experimento (constante);

$g_{i}=$ efeito do genótipo $i$

$b_{j(k l)}=$ efeito do bloco $j$ dentro da repetição $k$ no local $l$;

$r_{k l}=$ efeito da repetição $k$ no local $l$;

$l_{l}=$ efeito do local $l$;

$(g l)_{i l}=$ efeito da interação do genótipo $i$ com o local $l$;

$e_{i j k l}=$ erro experimental associado à parcela $i j k l$.

Todos os efeitos, com exceção do erro experimental, foram novamente considerados como fixos. Para a variável PE, foi incluída no modelo a covariável estande, de 
forma que a produção fosse também ajustada para este fator. Isto implicou no surgimento da fonte de variação adicional estande, além da redução de um grau de liberdade no resíduo (Steel \& Torrie, 1960).

Em seguida, estimaram-se as médias ajustadas, pelo método dos quadrados mínimos, para as variáveis $P E, U, F L O, A P, A E$, PROL e PAQ. Neste caso, as análises também foram realizadas com os dados em suas unidades originais, exceto para PAQ, transformada pela função $f(x)=\sqrt{x+0,5}$.

A partir dos resíduos intrablocos obtidos nas análises de variância conjunta, foram calculados os erros efetivos (Cochran \& Cox, 1957), usados posteriormente para os testes de médias requeridos pelo índice de seleção. Todas as análises estatísticas acima mencionadas foram realizadas utilizando-se o programa computacional SAS (Statistical Analysis System, SAS, 1992), através do procedimento conhecido como GLM (General Linear Models). O esquema da análise de variância conjunta encontra-se na Tabela 2.

Tabela 2. Esquema da análise de variância conjunta dos experimentos do Ensaio Nacional de Milho Precoce, ano agrícola 1996/97, com fontes de variação (FV), graus de liberdade (GL), somas de quadrados (SQ), quadrados médios (QM) e teste $F$.

\begin{tabular}{|c|c|c|c|c|}
\hline$\overline{F V}$ & GL & SQ & $\overline{Q M}$ & $\mathrm{~F}$ \\
\hline Local (I) & $1-1$ & $\mathrm{SQ}_{1}$ & $\mathrm{QM}_{1}=\mathrm{SQ}_{1} /(\mathrm{I}-1)$ & $\overline{\mathrm{QM}_{1} / \mathrm{QM}_{\mathrm{e}}}$ \\
\hline Repetiçao/Local (r/l) & $\mid(r-1)$ & $\mathrm{SQ}_{2}$ & $\mathrm{QM}_{2}=\mathrm{SQ}_{2} /(\mathrm{r}-1)$ & $\mathrm{QM}_{2} / \mathrm{QM}_{\mathrm{e}}$ \\
\hline Bloco/Repetição/Local (b/r/l) & $r(b-1)$ & $\mathrm{SQ}_{3}$ & $\mathrm{QM}_{3}=\mathrm{SQ}_{3} / \mathrm{r}(\mathrm{b}-1)$ & $\mathrm{QM}_{3} / \mathrm{QM}_{\mathrm{e}}$ \\
\hline Genótipos ajustados (g) & $g-1$ & $\mathrm{SQ}_{4}$ & $\mathrm{QM}_{4}=\mathrm{SQ}_{4} /(\mathrm{g}-1)$ & $\mathrm{QM}_{4} / \mathrm{QM}_{\mathrm{e}}$ \\
\hline Local x Genótipos & $(l-1)(g-1)$ & $\mathrm{SQ}_{5}$ & $\mathrm{QM}_{5}=\mathrm{SQ}_{5} /(\mathrm{l}-1)(\mathrm{g}-1)$ & $\mathrm{QM}_{5} / \mathrm{QM}_{\mathrm{e}}$ \\
\hline Erro intrabloco & $g l_{e}$ (difer.) & SQe & $\mathrm{QM}_{\mathrm{e}}=\mathrm{SQ}_{\mathrm{e}} / \mathrm{gl}_{\mathrm{e}}$ & \\
\hline
\end{tabular}

Para a variável $P E$, foi realizada uma análise de estabilidade envolvendo os nove locais onde ela foi avaliada (Tabela 1). Optou-se pelo emprego da metodologia de Eberhart \& Russell (1966), onde cada ambiente foi classificado como sendo favorável ou desfavorável em função da média apresentada pelo experimento nele instalado. Dispondo-se de 49 cultivares e nove locais, construiu-se uma tabela de dupla entrada contendo as médias ajustadas de cada 
cultivar em cada ambiente. O modelo de Eberhart \& Russell (1966) adotado utiliza o modelo de regressão linear:

$$
Y_{i j}=m_{i}+b_{i} I_{j}+d_{i j}, \text { em que }
$$

$Y_{i j}=$ média do cultivar $i$ no local $j$;

$m_{i}=$ média de todos os cultivares em todos os locais;

$b_{i}=$ coeficiente de regressão linear entre $Y_{i j}$ e $I_{j}$;

$I_{j}=$ índice ambiental referente ao ambiente $j$;

$d_{i j}=$ desvios da regressão linear.

Os valores do índice ambiental foram calculados a partir da diferença entre a média dos cultivares no ambiente $j$ e a média geral $m_{i}$. O coeficiente angular da reta de regressão $b_{i}$ entre o desempenho de cada genótipo e o índice de ambientes foi tomado como medida de adaptabilidade, e os desvios da regressão linear, medidos através do coeficiente de determinação $\left(R^{2}\right)$, foram tomados como medida da estabilidade de cada genótipo. Esta metodologia apresenta o problema de, normalmente, não identificar diferenças estatísticas entre os parâmetros calculados (Vencovsky \& Barriga, 1992). Deste modo, não foram realizados testes de significância para tais parâmetros, usando os valores encontrados diretamente no cálculo dos índices.

\subsubsection{Obtenção dos índices de seleção}

Uma vez que os índices de seleção lineares podem ser usados apenas nos programas de seleção recorrente, foram estimados apenas os índices de seleção cuja aplicação é, ao menos teoricamente, possível para a seleção de cultivares: índices de Elston (1963), de Schwarzbach (1972) ${ }^{1}$, citado por Wricke \& Weber (1986), de Mulamba \& Mock (1978) e o índice para a seleção de cultivares, proposto nesta tese.

Para tanto, foram considerados os caracteres resultantes das análises de variância, a saber: $P E, U, F L O, A P, A E, P R O L$ e $P A Q$, além dos parâmetros resultantes da análise de

\footnotetext{
1 SCHWARZBACH, E. Einige Anwendungsmöglichkeiten elektronischer Daterverarbeitung (EDV) für die Beurteilung von Zuctitnaterial. Arb. Tag. Oesterr. Pflanzenz. Gumpenstein: 277-87, 1972.
} 
estabilidade, quando possível: a adaptabilidade $(b)$ e a estabilidade $\left(R^{2}\right)$. Assim, totalizaram-se nove variáveis, sendo que nem sempre foi possível incluir todas elas nos cálculos, sendo então usadas apenas aquelas pertinentes ao respectivo índice.

\subsubsection{1. Índice multiplicativo}

Este índice, proposto por Elston (1963), foi aplicado às médias ajustadas das análises de variância conjuntas dos caracteres $P E, U, F L O, A P, A E, P R O L$ e $P A Q$, e também ao valor do parâmetro de estabilidade $\left(\mathbf{R}^{2}\right)$. Não foi possível aplicá-lo ao parâmetro $b$, uma vez que o índice só permite a otimização da seleção de genótipos extremos (superiores ou inferiores) e, neste caso, o valor ideal da variável é 1,0 (ampla adaptabilidade). Foram seguidos os seguintes passos:

1) Tomaram-se escalas para os diferentes caracteres de forma que os melhores genótipos sempre possuíssem os maiores valores. Para tanto, obtiveram-se os reáprocos dos valores medidos para os caracteres U, FLO, AP, AE e PAQ. Com tal transformação, esses caracteres passaram a apresentar valores menores que a unidade, o que já ocorreu originalmente para PROL e $\mathrm{R}^{2}$. Como valores menores que 1,0 apresentam logaritmos negativos, e a transformação a ser aplicada é a logarítmica, multiplicou-se cada variável com valor menor que a unidade por uma constante que elevasse a escala de mensuração do respectivo caráter a valores maiores que 1,0. Após as multiplicagões, os caracteres obtidos foram: PE, $(1 / \mathrm{U}) \times 10^{2},(1 / \mathrm{FLO}) \times 10^{2},(1 / \mathrm{AP}) \times 10^{3},(1 / \mathrm{AE}) \times 10^{3}, \mathrm{PROL} \times 10,(1 / \mathrm{PAQ}) \times 10, \mathrm{R}^{2}$ $x 10$. Vale lembrar que estes fatores de escala foram posteriormente eliminados ao se realizar a subtração dos valores de $k_{i}$.

ii) Aplicou-se a transformação logarítmica a todas as $i$ variáveis, visando tornar as distribuigões uniformes. Em outras palavras, calculou-se $p_{i}{ }^{\prime}$, o logarítmo de cada variável $i$, sendo que não apareceram valores negativos para $p_{i}{ }^{\prime}$, graças as multiplicações por constantes.

iii) Para cada $p_{i}{ }^{\prime}$, subtraiu-se o valor de $k_{i}{ }^{\prime}=\left[n\left(\min p_{i}^{\prime}\right)-\left(\max p_{i}^{\prime}\right)\right] /[n-1]$, obtendo-se $\left(p_{i}{ }^{\prime}-k_{i}{ }^{\prime}\right)$, onde $n$ é o número de genótipos. 
iv) Como os histogramas obtidos para os vários caracteres não apresentaram formas similares, calculou-se $p_{i}{ }^{\prime \prime}=\log \left[\left(p_{i}{ }^{\prime}-k_{i}{ }^{\prime}\right) \cdot 10^{4}\right]$. Novamente, a constante $10^{4}$ foi usada para evitar valores negativos nos logaritmos, ou seja, em $p_{i}{ }^{\prime \prime}$.

v) Subtraiu-se $k_{i}^{\prime \prime}=\left[n\left(\min p_{i}{ }^{\prime \prime}\right)-\left(\max p_{i}^{\prime \prime}\right)\right] /[n-1]$ de cada valor de $p_{i}{ }^{\prime \prime}$, resultando em $\left(p_{i}{ }^{\prime \prime}-k_{i}{ }^{\prime \prime}\right)$. As distribuições foram comparadas através de histogramas e se mostraram semelhantes, não necessitando nova aplicação da transformação.

vi) Calcularam-se os valores do índice multiplicativo $\prod_{i=1}^{8}\left(p_{i}{ }^{\prime \prime}-k_{i}^{\prime \prime}\right)$ para os 49 genótipos, efetuando-se classificação deles com base no valor obtido pelo índice, sendo que os melhores genótipos foram aqueles que apresentaram os maiores valores para ele.

\subsubsection{2. Índice de soma de classificação}

Neste caso, de acordo com as recomendações de Mulamba \& Mock (1978), foram dassificados os genótipos para os caracteres $P E, U$, FLO, AP, AE, PROL, PAQ e $R^{2}$, sendo que cada genótipo recebeu um número de dassificação para cada variável, adotando-se o critério de sempre utilizar o valor 1 para o melhor valor da respectiva variável, e assim sucessivamente. Desse modo, os genótipos com valor de dassificação 1 foram aqueles com maiores valores para as variáveis $\mathrm{PE}, \mathrm{PROL}$ e $\mathrm{R}^{2}$ e os com menores valores para $U$, FLO, AP, AE e PAQ. Não foi possível incluir o parâmetro $b$, já que ele não deve ser maximizado ou minimizado, como prevê o índice, mas sim permitir a melhor classificação dos genótipos com valor mais próximo possível da unidade.

Após obtenção dos números de classificação de cada genótipo, foram calculados os índices de cada um deles, da seguinte forma:

$$
I_{j}=\sum n_{i j} \text {, sendo }
$$

$I_{j}=$ indice para o genótipo $j$;

$n_{i j}=$ número de classificação da variável $i$ para o genótipo $j$.

Foram considerados como melhores os genótipos com menores valores de $I_{j}$. 


\subsubsection{3. Índice baseado em medida de distância}

Este índice, proposto por Schwarzbach (1972) ${ }^{1}$, citado por Wricke \& Weber (1986), foi calculado para as médias ajustadas das análises conjuntas dos experimentos do Ensaio Nacional. Foram calculadas, a partir das médias fenotípicas ajustadas, distâncias de cada genótipo a um genótipo ideal, definido para as variáveis $\mathrm{PE}, \mathrm{U}, \mathrm{FLO}, \mathrm{AP}, \mathrm{AE}, \mathrm{PROL}, \mathrm{PAQ}, b$ e $R^{2}$.

Inicialmente, estas variáveis foram estandardizadas, com base nas suas respectivas médias e desvios padrão, calculados entre os 49 genótipos. Depois, definiu-se o ideótipo como sendo o genótipo formado pelo maior valor dos caracteres $P E, P R O L$ e $R^{2}$, menor valor para U, FLO, AP, AE e PAQ e valor 1,0 para $b$. Em seguida, calcularam-se as distâncias euclidianas entre cada genótipo e este ideótipo, pelo uso da fórmula

$$
D_{i l}=\sqrt{\sum_{j=1}^{9}\left(x_{i j}-x_{l j}\right)^{2}} \text {, em que }
$$

$D_{i I}=$ distância euclidiana entre o genótipo $i$ e o ideótipo $I$;

$x_{i j}=$ medida do caráter $j$ no genótipo $i$;

$x_{l j}=$ valor definido para o ideótipo $I$, referente ao caráter $j$.

Então, procedeu-se a classificação dos genótipos com base na distância que apresentaram do ideótipo, sendo considerados melhores aqueles cujas distâncias foram as menores.

\footnotetext{
'SCHWARZBACH, E. Einige Anwendungsmöglichkeiten elektronischer Daterveranteitung (EDV) für die Beurteilung von Zuchtmaterial. Arb. Tag. Oesterr. Pflanzenz. Gumpenstein: 277-87, 1972.
} 


\subsection{3. Índice para a seleção de cultivares}

\subsubsection{Etapas para o cálculo do índice}

\section{a) Agrupamento de médias e obtenção de recíprocos}

Na situação proposta para estudo, já se dispõe de experimentos com precisão suficiente para a realização de testes estatísticos de comparação de médias. Muitos testes para comparações múltiplas de médias estão disponíveis na literatura, sendo os mais comumente usados o de Tukey (1949), Duncan (1955), Dunnet (1955), Scheffé (1959) e D.M.S. (diferença mínima significativa) (Steel \& Torrie, 1960). Cada um deles possui diferentes abordagens, considerações sobre o Erro Tipo I, graus de liberdade do resíduo, presença de testemunhas nos experimentos, etc. Contudo, há uma certa dificuldade no agrupamento dos genótipos, em função da presença de classes sobrepostas.

Visando facilitar a interpretação dos resultados, Scott e Knott (1974) propuseram um teste que permite agrupar as médias na análise de variância sem a ocorrência de sobreposição de classes, resultando na obtenção de grupos homogêneos. Por apresentar tal facilidade, esse teste foi adotado no presente trabalho para as médias ajustadas da análise de variância, sendo usado como testador o quadrado médio do erro efetivo. Cada grupo homogêneo obtido pôde ser representado por um único valor e, no presente caso, optou-se por substituir os valores individuais dos genótipos dentro de um mesmo grupo pela média de tal grupo. Isto permitiu que o cálculo da distância com relação ao ideótipo fosse feito considerando as diferenças estatísticas entre os genótipos, o que não seria possível com o uso de algum teste que formasse classes com sobreposição.

Realizou-se o teste de agrupamento de Scott \& Knott (1974) considerando diferentes níveis de probabilidade de erro Tipo I, resultando no cálculo de dois índices para a seleção de cultivares. 0 primeiro deles, denominado Índice 1 , adotou níveis de probabilidade com valores 0,$01 ; 0,10 ; 0,05 ; 0,05 ; 0,05 ; 0,07$ e 0,03 para as variáveis $P E, U, F L O, A P, A E$, PROL e PAQ, respectivamente. $O$ outro, denominado Índice 2 , adotou níveis 0,$05 ; 0,001$; 0,$001 ; 0,01 ; 0,01 ; 0,001$ e 0,01 , para os mesmos caracteres. Não se realizou nenhum teste para $b$ e $\mathrm{R}^{2}$. 
Uma vez realizado o agrupamento das médias dos caracteres, os valores originais foram transformados de forma que, para todas as variáveis, sempre os valores de interesse do melhorista fossem os maiores. Para tanto, obteve-se o recíproco dos caracteres $U, F L O, A P, A E$ e PAQ, pois estes são caracteres para os quais a seleção é feita para buscar os menores valores. Obtidos os recíprocos, todos eles puderam ser selecionados de modo a tomar os maiores valores com o objetivo da seleção. Exceção foi feita ao parâmetro $b$, já que a seleção tem como objetivo tomar os genótipos com valores o mais próximo possível do valor 1,0 , considerado ideal (Vencovsky \& Barriga, 1992).

A respeito do teste de Scott \& Knott (1974), nota-se que os autores propuseram um critério para julgar se os grupos obtidos numa análise de agrupamentos convencional são significativos, num dado nível de probabilidade de erro tipo I. Partindo de um grupo de $k$ médias, que devem ser agrupadas (no caso, $k=49$ ), denominadas $y_{1}, y_{2}, \ldots, y_{k}$, com $y_{i} \cap N\left(\mu_{i}, \sigma^{2}\right)$ e de uma estimativa independente $s^{2}$ da variância comum, com $\left(v s^{2}\right) / \sigma^{2} \cap \chi_{v}^{2}$, da forma usual, sendo $v$ o número de graus de liberdade do resíduo e $\chi_{v}^{2}$ a distribuição de qui-quadrado com $v$ graus de liberdade, testa-se a igualdade entre as médias com um teste $F$ na análise de variância. Nos casos em que esta condição não se verifica, utiliza-se então o teste da razão de verossimilhança para verificar a homogeneidade dos grupos.

Sendo $B_{o}$ o máximo valor da soma de quadrados entre grupos, obtido entre todas possíveis partições dos $k$ tratamentos em dois grupos, e $\hat{\sigma}_{o}^{2}$ a estimativa de máxima verossimilhança de $\sigma^{2}$ quando todos $\mu_{i}$ 's são assumidos como iguais, ou seja,

$$
\hat{\sigma}_{o}^{2}=\frac{\left[\sum_{1}^{k}\left(y_{i}-\bar{y}\right)^{2}+v s^{2}\right]}{k+v},
$$

realiza-se o teste da razão de verossimilhança $B_{o} / \hat{\sigma}_{o}^{2}$ para a hipótese de nulidade $H_{o}: \mu_{i}=\mu,(i=1, \ldots, k)$ contra a hipótese alternativa $H_{a}$ de que $\mu_{i}$ é igual a $m_{1}$ ou $m_{2}$ ， que representam as médias (desconhecidas) dos dois grupos formados. Tal teste equivale a 
rejeitar $H_{o}$ se a razão $B_{o} / \hat{\sigma}_{o}^{2}$ for grande, ou seja, se a variância resultante da partição for muito maior que a variância do acaso.

A significância da razão de verossimilhança é testada utilizando-se (Scott \& Knott, 1974)

$$
\lambda=\frac{\pi}{2(\pi-2)} B_{o} / \hat{\sigma}_{o}^{2}
$$

cuja distribuição pode ser aproximada por uma distribuição de qui-quadrado com $v_{o}$ graus de liberdade.

O cálculo de $\lambda$ necessitou da obtenção da partição dos tratamentos para a qual a soma de quadrados entre grupos é máxima (ou, equivalentemente, mínima dentro dos grupos). Para obtenção destas somas de quadrados, adotou-se o método de agrupamentos proposto por Edwards \& Cavalli-Sforza (1965), aplicado a médias univariadas $y_{i}, y_{2}, \ldots, y_{k}$, seguindo sugestão do artigo de Scott \& Knott (1974). No caso, foram utilizadas as médias ajustadas oriundas das análises de variância conjuntas de cada caráter. A partição testada pela razão de verossimilhança permitiu verificar a existência dos grupos postulados pela hipótese altemativa $H_{a}$. Fisher (1958) mostrou que é suficiente estudar somente $k-1$ partições das $2^{k-1}-1$ possíveis, bastando para tanto ordenar as médias em função de sua magnitude, e proceder a divisões sucessivas em grupos, o que foi feito no presente caso.

O método de Edwards e Cavalli-Sforza (1965) se inicia com a melhor divisão das médias em dois grupos, baseado na soma de quadrados entre grupos, o que é feito subseqüentemente dentro de cada novo grupo formado. $O$ processo de subdivisão foi realizado até que os grupos fossem julgados homogêneos, pela aplicação do teste $\lambda$, utilizando-se os erros efetivos das análises de variância, referentes a cada caráter, como resíduo. Após tal análise, cada média passou a pertencer a um dado grupo, sendo que médias dentro do mesmo grupo foram assumidas como estatisticamente iguais, de acordo com o nível de significância adotado no qui-quadrado. 


\section{b) Definição dos níveis mínimos aceitáveis $\left(N_{i}\right)$ para cada caráter}

Normalmente, os genótipos que serão selecionados como possíveis cultivares devem apresentar níveis mínimos de desempenho para cada caráter, sendo que aqueles que produzam valores inferiores (ou superiores, dependendo do caso) a estes níveis mínimos não podem ser selecionados, pois não serão aceitos pelo mercado consumidor. No caso do milho, considerado no exemplo, tais níveis foram fixados com base na média que o experimento apresentou, uma vez que não houve presença de testemunhas. Assim sendo, fixou-se o desempenho mínimo exigido para os genótipos selecionados para os caracteres:

i) PE: no mínimo, œm produção estatisticamente igual à média do experimento;

ii) U: não se assumiu nenhum valor como referência para descarte;

iii) FLO: ciclo no mínimo estatisticamente igual ou inferior à média do experimento;

iv) AP e AE: não possuir altura estatisticamente superior à média do experimento;

v) PROL: não apresentar valor estatisticamente inferior à média do experimento;

vi) PAQ: não devem ser selecionados genótipos cuja taxa de plantas acamadas e quebradas seja superior à média do experimento;

vii) $b$ : deve ser no mínimo igual a 0,80 para não caracterizar seleção de genótipos adaptados aos piores ambientes;

viii) $R^{2}$ : valores de estabilidade no mínimo iguais à média do experimento.

Vale ressaltar que estes valores foram fixados arbitrariamente, apenas como exemplo. Numa situação real, podem ser alterados de acordo com a necessidade do pesquisador.

\section{c) Transformação dos dados}

As médias fenotípicas $\left(P_{i}\right)$ de cada caráter $i$ foram transformadas de acordo com a seguinte expressão:

$$
P_{i}^{\prime}=\frac{P_{i}-N_{i}}{s_{i}}, \text { sendo }
$$


$P_{i}^{\prime}=$ média transformada do caráter $i$;

$P_{i}=$ média para o caráter $i$, após o agrupamento e a obtenção dos recíprocos;

$N_{i}=$ nível mínimo de desempenho exigido para o caráter $i$, ou seja, valor fenotípico mínimo que pode ser aceito. Tais valores foram definidos no item b e, uma vez que as variáveis que se desejam minimizar foram transformadas pelos recíprocos, $N_{i}$ é sempre o nível mínimo;

$s_{i}=$ desvio padrão do caráter $i$.

Após a definição dos $N_{i}$ 's e alteração da escala dos caracteres (ítens a e b), calculou-se o valor de $s_{i}$ para cada caráter. A seguir, aplicou-se a transformação às médias agrupadas e não aos valores individuais, que foram substituídos pelas médias do respectivo grupo, já que assumiu-se que elas não diferem entre si no nível de significância adotado. Logo, cada valor de $P_{i}$, é na verdade a média do grupo a que pertence o valor. Os valores de $N_{i}$ que foram subtraídos também consideraram a eventual presença de significância entre as médias; por exemplo, ao se desejar subtrair a média do experimento, verificou-se a qual grupo ela pertencia, sendo então a média desse grupo usada como valor de $N_{i}$. No caso de não haver um nível mínimo exigido, usou-se o $N_{i}$ como a média do menor grupo. Em suma, verificou-se a qual grupo pertencia o valor de $N_{i}$ a ser subtraído e, então, utilizou-se a média desse grupo no cálculo.

Essa transformação assemelha-se muito à estandardização, exceto pelo fato de que o valor subtraído não é necessariamente a média amostral. Deste modo, as variáveis estarão agora expressas em unidades de desvio padrão, não estando, contudo, centradas na média, e sim nos valores usados para o descarte. Genótipos pertencentes ao mesmo grupo terão mesmo valor para uma dada variável. Para os genótipos que apresentaram valores negativos para pelo menos uma variável após a transformação, pôde ser sugerido o descorte, por não atenderem às exigências mínimas de desempenho para tal variável, sendo estatisticamente inferiores (ou superiores) aos níveis fixados.

\section{d) Definição do ideótipo}

Definiu-se como ideótipo o genótipo usado como referencial para a seleção, sendo formado pelo melhor valor de todos os caracteres avaliados no experimento. Provavelmente, tal 
material inexiste no conjunto considerado, sendo que sua obtenção é o objetivo principal do melhorista.

Assim, no exemplo, considerou-se como ideótipo o genótipo com valor igual à média do maior grupo para todos os caracteres, uma vez que, mesmo aqueles que devem ser minimizados foram transformados pelo emprego dos recíprocos, sendo feitas excecões para a variável $b$, cujo valor ideal foi tomado como sendo 1,0 e não o maior ou menor valor, bem como $R^{2}$, onde foi usado o maior valor encontrado. Tal ideótipo foi usado como ponto de referência para dassificação dos genótipos.

\section{e) Cálculo das distâncias ao ideótipo}

O emprego de medidas de distâncias permite que genótipos com medidas semelhantes para o conjunto de caracteres considerados estejam próximos uns dos outros. Este conceito foi considerado, já que, no índice desenvolvido, tem-se interesse na seleção dos genótipos mais próximos do ideótipo fixado pelo melhorista.

Muitas medidas de distância estão disponíveis na literatura, sendo aplicadas aos mais diferentes casos (Manly, 1994). No presente trabalho, aplicou-se apenas a distância eudidiana média, de fácil interpretação e perfeitamente adequada ao trabalho. Considerou-se apenas as distâncias entre os genótipos e o ideótipo definido, pois isto é suficiente para classificar os genótipos.

No presente caso, dispõe-se de 49 genótipos, para os quais tem-se medidas para $p$ caracteres, $X_{1}, X_{2}, \ldots, X_{p}$ (no caso, $p=9$ ). Para cada genótipo $i(i=1, \ldots, 49$ ), tais medidas foram denotadas como $x_{i 1}, x_{i 2}, \ldots, x_{i p}$.

A distância eudidiana entre o genótipo $i$ e o ideótipo $I$ é definida como o comprimento do segmento de reta que une a extremidade dos vetores, os quais representam cada genótipo no espaço de dimensão $n$ ( $n=p=9$, no caso). Em outras palavras, é a distância entre os dois pontos que representam espacialmente os genótipos (Manly, 1994).

A medida de distância que foi efetivamente usada nesta tese foi a distância eudidiana média, que é derivada da distância euclidiana. No seu cálculo, a soma das diferenças ao quadrado é dividida pelo número de caracteres envolvidos (Bussab et ail., 1990): 


$$
d m_{i I}=\sqrt{\frac{\sum_{j=1}^{p}\left(x_{i j}-x_{I j}\right)^{2}}{p}} .
$$

Tal medida é apenas um reescalonamento da distância eudidiana, possuindo as mesmas propriedades que ela. Entretanto, possui como vantagem adicional o fato de poder ser usada na ausência de dados para alguma(s) variável(is), já que a distância de cada genótipo ao ideótipo será dividida pelo número respectivo de caracteres considerado. Pela observação de $d m_{i I}$, que é uma soma de desvios ao quadrado, fica claro que a unidade em que as observações são medidas apresenta grande influência na distância e que isto causa uma indesejável ponderação, com maior peso para os caracteres cuja unidade de medida seja de maior magnitude. A variância de cada caráter também influi no cálculo das distâncias. No entanto, tal problema foi resolvido pela transformação que foi aplicada aos dados, onde se garantiu que todos os caracteres tivessem a mesma influência na distância.

\section{f) Classificação dos indivíduos e seleção dos genótipos superiores}

Após a aplicação de todos os passos descritos, efetuou-se a classificação dos genótipos com base na distância que apresentaram com relação ao ideótipo. Os genótipos foram classificados em ordem crescente de distância. Para aqueles que apresentaram valor negativo nos dados transformados para alguma(s) variável(eis) foi sugerido o descarte. Finalmente, foi recomendada a seleção dos genótipos superiores, descontando-se os eventuais descartes. 


\section{RESULTADOS E DISCUSSÃO}

\section{1. Índices lineares}

Grande parte dos índices reportados na literatura destinam-se, exclusivamente, ao uso em programas de seleção recorrente. Para melhor ilustrar esta utilização, será apresentado um exemplo hipotético, fundamentalmente para mostrar como os índices de seleção lineares são calculados, além de ressaltar a diferença entre seu uso em programas de seleção recorrente e na seleção de genótipos em fases finais dos programas de desenvolvimento de cultivares. O número de genótipos e caracteres considerados será inferior àqueles que se tem normalmente nos programas de melhoramento, uma vez que o objetivo será apenas demonstrar o motivo pelo qual tais índices não podem ser utilizados para a seleção de cultivares.

Sejam dez genótipos hipotéticos de uma espécie vegetal qualquer, autógama ou alógama, oriundos de uma população que deva ser melhorada para três caracteres conjuntamente: produção de grãos, altura da planta e teor protéico. Foram simuladas as estimativas de diversos parâmetros genéticos e fenotípicos, imaginando uma espécie vegetal que produza, em média, cerca de $3000 \mathrm{~kg} / \mathrm{ha}$ de grãos, tenha altura por volta de 1,0 m e apresente teor protéico nos grãos de cerca de 10\% (Tabelas 3 e 4). Os genótipos serão selecionados, $\infty \mathrm{m}$ base em seu desempenho para o conjunto de caracteres, e recombinados, originando variabilidade para o próximo ciclo seletivo, œmo é usual em programas de seleção recorrente. A maioria dos índices de seleção encontrados na literatura é desenvolvida 
justamente para permitir máxima eficiência neste processo, ou seja, permitir a máxima resposta à seleção para o conjunto de caracteres da população.

É evidente que esta não é a situação existente nas etapas finais dos programas de melhoramento, já que os cultivares selecionados não serão recombinados, mas sim entrarão no processo de multiplicação e comercialização. Nesse caso, dezenas, ou até centenas de materiais, são avaliados em experimentos com repetições, tomando-se medidas para vários caracteres. Deseja-se efetuar uma classificação desses genótipos considerando o conjunto de caracteres e então selecionar os melhores, que poderão se tornar cultivares. Normalmente, o modelo matemático usado nas análises estatísticas é fixo, impossibilitando sequer a obtenção das estimativas que são requeridas para cálculo dos índices lineares; tampouco faz sentido supor a existência de valores genotípicos populacionais que devam ser melhorados.

Tabela 3. Valores genéticos e fenotípicos para dez genótipos (progênies) extraídos de uma população sob seleção recorrente, para uma espécie vegetal hipotética.

\begin{tabular}{cccc}
\hline & \multicolumn{3}{c}{ Médias fenotípicas } \\
\cline { 2 - 4 } Genótipo & Produção $(P, \mathrm{~kg} / \mathrm{ha})$ & Altura $(\mathrm{A}, \mathrm{m})$ & Teor protéico $(\mathrm{T}, \%)$ \\
\cline { 2 - 4 } 1 & 3503 & 1,08 & 8,1 \\
2 & 3470 & 1,05 & 11,0 \\
3 & 3322 & 0,91 & 9,0 \\
4 & 3188 & 0,91 & 9,5 \\
5 & 3060 & 1,03 & 9,6 \\
6 & 2912 & 1,00 & 10,0 \\
7 & 2708 & 0,90 & 10,3 \\
8 & 2651 & 0,96 & 12,0 \\
9 & 2608 & 0,94 & 8,3 \\
10 & 2477 & 0,93 & 11,4 \\
\hline
\end{tabular}


Tabela 4. Parâmetros genotípicos e fenotípicos para produção $(P, \mathrm{~kg} / \mathrm{ha})$, altura $(A, m)$ e teor protéico $(T, \%)$, numa população de uma espécie vegetal hipotética.

\begin{tabular}{|c|c|c|c|}
\hline \multirow[b]{2}{*}{ Parâmetro } & \multicolumn{3}{|c|}{ Caráter } \\
\hline & Produção ( $P, \mathrm{~kg} / \mathrm{ha})$ & Altura $(A, m)$ & Teor protéico $(T, \%)$ \\
\hline Média & 2989,9 & 0,97 & 9,92 \\
\hline Variância genética & 100,00 & 0,0831 & 0,6080 \\
\hline Variância fenotípica & 245,00 & 0,1005 & 1,0100 \\
\hline Herdabilidade (médias) & 0,35 & 0,73 & 0,51 \\
\hline \multirow[t]{3}{*}{ Valor econômico relativo $\left(a_{i}\right)$} & 0,001 & $-5,0$ & 4,0 \\
\hline & \multicolumn{3}{|c|}{ Pares de caracteres } \\
\hline & $P-A$ & $P-T$ & $A-T$ \\
\hline Correlação genética & 0,32 & $-0,50$ & 0,0 \\
\hline Covariância genética & 0,9225 & $-3,8987$ & 0,0 \\
\hline Correlação fenotípica & 0,44 & $-0,68$ & $-0,27$ \\
\hline Covariância fenotípica & 2,1833 & $-10,6968$ & $-0,0860$ \\
\hline
\end{tabular}

\subsection{1. Índice otimizado}

Os valores econômicos relativos para o cálculo deste índice foram atribuídos de forma que um aumento de $1000 \mathrm{~kg} / \mathrm{ha}$ na produção de grãos tenha o mesmo valor econômico que uma diminuição de $0,20 \mathrm{~m}$ no porte e um aumento de $0,25 \%$ no teor protéico $\left(a_{1}=1 / 1000=0,001 ; a_{2}=1 /-0,20=-5,0 ; a_{3}=1 / 0,25=4,0\right)$. Isso significa que foram dados pesos econômicos relativos de $a_{1}=0,001$ para $1 \mathrm{~kg} / \mathrm{ha}$ de aumento na produção de grãos, $a_{2}=-5,0$ para a redução de $1 \mathrm{~m}$ no porte e $a_{3}=4,0$ para aumento de $1 \%$ no teor protéico. A forma aqui empregada de atribuição de pesos é a mais comumente utilizada, onde se determinam quais alterações nos caracteres terão mesmo valor econômico, obtendo-se, então, os $a_{i}$ 's (Baker, 1986) (Tabela 4). Nota-se que tal atribuição dos pesos é subjetiva e nem 
sempre fácil de ser realizada, o que dificulta o emprego do índice pelos melhoristas em situações reais.

As equações relativas aos índice, $P b=G a$, resultaram:

$\left[\begin{array}{ccc}245,00 & 2,1833 & -10,6968 \\ 2,1833 & 0,1005 & -0,0860 \\ -10,6968 & -0,0860 & 1,0100\end{array}\right]\left[\begin{array}{l}b_{1} \\ b_{2} \\ b_{3}\end{array}\right]=\left[\begin{array}{ccc}100,00 & 0,9225 & -3,8987 \\ 0,9225 & 0,0831 & 0,0 \\ -3,8987 & 0,0 & 0,6080\end{array}\right]\left[\begin{array}{c}0,001 \\ -5,0 \\ 4,0\end{array}\right]$.

Os pesos usados no índice são:

$$
\left[\begin{array}{l}
b_{1} \\
b_{2} \\
b_{3}
\end{array}\right]=\left[\begin{array}{ccc}
245,00 & 2,1833 & -10,6968 \\
2,1833 & 0,1005 & -0,0860 \\
-10,6968 & -0,0860 & 1,0100
\end{array}\right]^{-1}\left[\begin{array}{c}
-20,1073 \\
-0,4146 \\
2,4281
\end{array}\right]=\left[\begin{array}{c}
0,0739 \\
-3,2394 \\
2,9107
\end{array}\right] .
$$

Após obtenção dos $b_{i}{ }^{\prime}$ s, calculou-se, para cada genótipo, o valor do índice, em função da média fenotípica que apresentou para os caracteres produção de grãos, altura e teor protéico, usando a combinação linear

$$
I=(0,0739) P_{1}-(3,2394) P_{2}+(2,9107) P_{3} \text {. }
$$

Os genótipos foram então classificados com base no valor que apresentaram para o índice, possibilitando efetuar posteriormente seleção truncada para os valores superiores. Conforme apresentado, esta combinação linear é tal que maximiza o ganho no valor genotípico, real interesse do melhorista. Por exemplo, para 0 genótipo 1 , $I=(0,0739)(3503)-(3,2394)(1,08)+(2,9107)(8,1)=278,87$, utilizando as médias fenotípicas de $P_{1}, P_{2}$ e $P_{3}$, nas suas unidades originais.

Uma dificuldade de interpretação que pode surgir refere-se ao aparente menor peso atribuído para o caráter produção de grãos $\left(b_{1}=0,0739\right.$, enquanto $b_{2}=-3,24$ por exemplo). Na verdade, isso não ocorreu, pois os caracteres usados no cálculo do índice estão em unidades diferentes, compensando as diferenças nos pesos. Os valores usados em $P_{1}$ têm ordem de grandeza muito superior aos usados em $P_{2}$ e $P_{3}$, que por sua vez também têm unidades diferentes. Ao calcular o índice, tais diferenças de unidades compensam as diferenças existentes nos pesos, adequando-os a cada caráter. A melhor forma de verificar como os pesos calculados relacionam-se entre si seria após efetuar uma estandardização dos dados. 


\subsection{2. Índice básico}

Tal índice pode ser facilmente obtido. Considerando os mesmos pesos econômicos usados no índice otimizado, aplicados aos dados da Tabela 3, tem-se diretamente que $I=0,001 P_{1}-5,0 P_{2}+4,0 P_{3}$. Novamente, deve-se ressaltar que o caráter produção de grãos não recebeu o menor peso, como aparenta, já que as médias fenotípicas usadas em seus cálculos estão em unidades diferentes, compensando variagões nos pesos.

\subsection{3. Índice básico modificado}

Este tipo de índice tem a forma $I=w_{1} P_{1}+\ldots+w_{i} P_{i}+\ldots+w_{n} P_{n}$. No presente caso (Tabelas 3 e 4$), \quad w_{1}=a_{1} h_{1}^{2}=0,001(0,35)=0,00035, \quad w_{2}=a_{2} h_{2}^{2}=-5,0(0,73)$ $=-3,65$ e $w_{3}=a_{3} h_{3}^{2}=4,0(0,51)=2,04$. Portanto, $I=0,00035 P_{1}-3,65 P_{2}+2,04 P_{3}$.

Caso os parâmetros genotípicos e fenotípicos sejam estimados com boa precisão, tal índice pode ser muito útil para auxiliar na seleção, principalmente porque $h_{i}^{2}$ e $a_{i}$ sabidamente variam de acordo com o caráter considerado (Baker, 1986).

\subsection{4. Índice restrito}

Imaginando que no exemplo considerado não se deseja alterar a altura das plantas, tem-se:

$$
\begin{aligned}
& I=\left[\begin{array}{lll}
1 & 0 & 0 \\
0 & 1 & 0 \\
0 & 0 & 1
\end{array}\right], P^{-1}=\left[\begin{array}{ccc}
245,00 & 2,1833 & -10,6968 \\
2,1833 & 0,1005 & -0,0860 \\
-10,6968 & -0,0860 & 1,0100
\end{array}\right]^{-1}, G_{2}=\left[\begin{array}{c}
0,9225 \\
0,0831 \\
0,0
\end{array}\right], \\
& G=\left[\begin{array}{ccc}
100,00 & 0,9225 & -3,8987 \\
0,9225 & 0,0831 & 0,0 \\
-3,8987 & 0,0 & 0,6080
\end{array}\right], \text { e assim }\left(G_{2}^{\prime} P^{-1} G_{2}\right)^{-1}=[13,4215], \therefore
\end{aligned}
$$




$$
\begin{aligned}
& b=\left\{\left[\begin{array}{lll}
1 & 0 & 0 \\
0 & 1 & 0 \\
0 & 0 & 1
\end{array}\right]-\left[\begin{array}{ccc}
245,00 & 2,1833 & -10,6968 \\
2,1833 & 0,1005 & -0,0860 \\
-10,6968 & -0,0860 & 1,0100
\end{array}\right]^{-1}\left[\begin{array}{c}
0,9225 \\
0,0831 \\
0,0
\end{array}\right]\left[\begin{array}{lll}
13,4215]
\end{array}\right][0,9225 \quad 0,0831 \quad 0,0]\right\} . \\
& =\left[\begin{array}{ccc}
245,00 & 2,1833 & -10,6968 \\
2,1833 & 0,1005 & -0,0860 \\
-10,6968 & -0,0860 & 1,0100
\end{array}\right]^{-1}\left[\begin{array}{ccc}
100,00 & 0,9225 & -3,8987 \\
0,9225 & 0,0831 & 0,0 \\
-3,8987 & 0,0 & 0,6080
\end{array}\right]\left[\begin{array}{c}
0,001 \\
-5,0 \\
4,0
\end{array}\right] \\
& =\left[\begin{array}{c}
0,0689 \\
-0,7645 \\
3,0683
\end{array}\right] \text {. }
\end{aligned}
$$

Logo, o índice restrito será $I=0,0689 P_{1}-0,7645 P_{2}+3,0683 P_{3}$.

\subsection{5. Índice de resposta à seleção desejada}

Para realização dos cálculos, assumiu-se que o ganho desejado é de $1000 \mathrm{~kg} / \mathrm{ha} \mathrm{na}$ produção de grãos, $-0,20 \mathrm{~m}$ na altura das plantas e $0,25 \%$ no teor protéico (mesmos valores econômicos usados no índice otimizado). Assim, $k^{\prime}=\left[\begin{array}{lll}1000 & -0,20 & 0,25\end{array}\right]$ e os coeficientes são:

$$
\begin{aligned}
& b=\left[\begin{array}{ccc}
100,00 & 0,9225 & -3,8987 \\
0,9225 & 0,0831 & 0,0 \\
-3,8987 & 0,0 & 0,6080
\end{array}\right]^{-1}\left[\begin{array}{c}
1000 \\
-0,20 \\
0,25
\end{array}\right]=\left[\begin{array}{c}
15,50 \\
-174,48 \\
99,81
\end{array}\right], \text { e, conseqüentemente: } \\
& I=15,50 P_{1}-174,48 P_{9}+99,81 P_{3} .
\end{aligned}
$$

\subsubsection{Considerações gerais}

A classificação que todos os índices lineares forneceram para os dez genótipos do exemplo hipotético encontra-se na Tabela 5. Verifica-se que o caráter que mais influiu nos valores obtidos com emprego do índice otimizado foi a produção, indicando que este foi o caráter que recebeu maior peso econômico. Isso foi possível de se verificar pois os genótipos da Tabela 3 estavam classificados em ordem decrescente de produção, ordem esta que, com exceção do $1^{\circ}$ e $2^{\circ}$ colocados, manteve-se inalterada após o uso do índice. Além disso, a correlação entre o índice e a produção de grãos foi $r=0,99$. 
Tabela 5. Cálculo do índice de seleção otimizado $\left(I_{o}\right)$, índice básico $\left(I_{b}\right)$, índice básico modificado $\left(I_{b m}\right)$, indice restrito $\left(I_{r}\right)$ e índice de resposta à seleção desejada $\left(I_{r s d}\right)$ para os genótipos do exemplo hipotético. O número entre parênteses é a classificação de acordo com o índice empregado.

\begin{tabular}{cccccc}
\hline Genótipo & $I_{o}$ & $I_{b}$ & $I_{b m}$ & $I_{r}$ & $I_{r s d}$ \\
\hline 1 & $278,87^{(2)}$ & $30,50^{(10)}$ & $13,81^{(10)}$ & $265,26^{(2)}$ & $59916,5^{(1)}$ \\
2 & $284,97^{(1)}$ & $42,22^{(3)}$ & $19,82^{(3)}$ & $271,91^{(1)}$ & $54699,7^{(2)}$ \\
3 & $268,70^{(3)}$ & $34,77^{(8)}$ & $16,20^{(8)}$ & $255,69^{(3)}$ & $52230,5^{(3)}$ \\
4 & $260,23^{(4)}$ & $36,64^{(6)}$ & $17,17^{(6)}$ & $248,00^{(4)}$ & $50203,4^{(4)}$ \\
5 & $250,67^{(5)}$ & $36,31^{(7)}$ & $16,90^{(7)}$ & $239,40^{(5)}$ & $48208,5^{(5)}$ \\
6 & $241,00^{(6)}$ & $37,91^{(5)}$ & $17,77^{(5)}$ & $230,46^{(6)}$ & $45959,6^{(6)}$ \\
7 & $227,12^{(8)}$ & $39,41^{(4)}$ & $18,67^{(4)}$ & $217,40^{(8)}$ & $42845,0^{(7)}$ \\
8 & $227,68^{(7)}$ & $45,85^{(1)}$ & $21,90^{(1)}$ & $218,65^{(7)}$ & $42120,7^{(8)}$ \\
9 & $213,79^{(9)}$ & $31,11^{(9)}$ & $14,41^{(9)}$ & $204,35^{(10)}$ & $41088,4^{(9)}$ \\
10 & $213,16^{(10)}$ & $43,43^{(2)}$ & $20,73^{(2)}$ & $204,85^{(9)}$ & $39369,1^{(10)}$ \\
\hline
\end{tabular}

O genótipo classificado em primeiro lugar com o índice otimizado não foi o mais produtivo, mas sim aquele que apresentou melhor desempenho para os três caracteres conjuntamente, de modo a melhorar a qualidade genotípica da população. Caso algum dos genótipos apresentasse, por exemplo, altura acima de valores comercialmente aceitáveis, ele poderia ser selecionado se suas médias fenotípicas para outros caracteres fossem tais que compensassem tal deficiência, tanto que o genótipo 2, melhor classificado no caso, apresentou altura bem acima da média, em $9^{\circ}$ lugar (Tabela 3). É óbvio que este índice não deve ser aplicado em situações semelhantes às encontradas nos programas de seleção de cultivares, onde os melhores genótipos não serão recombinados, pois não se trata de uma população cuja valor genotípico deva ser melhorado. Além disso, um índice adequado à tal situação não deve permitir que materiais com desempenho comercial inferior (ou superior) aos níveis comerciais mínimos para algum(ns) caráter(es) seja(m) selecionado(s).

Nota-se ainda que 0 índice otimizado pode ser aplicado perfeitamente aos programas de seleção recorrente, onde se deseja efetuar melhoramento da população para o conjunto gênico, apesar desta dificuldade de ponderação. Os genótipos com desempenho 
inferior para um ou mais caracteres poderão ser selecionados, desde que apresentem alelos favoráveis para os demais caracteres, de forma a compensar tal deficiência. Claramente, esta não é a situação encontrada na seleção de cultivares, pois os genótipos com alguma característica cujo desempenho esteja abaixo (ou acima) dos níveis mínimos comerciais exigidos não podem, de forma alguma, ser selecionados, pois o mercado consumidor não aceitaria materiais muito diferentes dos já existentes. Cbviamente, não haverá recombinação dos genótipos selecionados para geração de variabilidade, além de não haver disponibilidade de estimativas dos parâmetros genéticos requeridos nos cálculos.

Com relação ao índice básico, observa-se que houve grande alteração na dassificação dos genótipos em relação ao índice otimizado, já que a correlação entre os dois foi negativa $(r=-0,26)$. Isso pode causar dúvidas para o melhorista sobre qual índice adotar, pois pode haver discrepâncias sobre quais genótipos selecionar. Fica claro que, se as estimativas de parâmetros fenotípicos estiverem muito distantes das genotípicas, haverá grande diferença entre o índice otimizado e o básico. Esse índice básico apresentou alta correlação com o caráter teor protéico $(r=0,99)$, sendo esta mais uma razão pela qual ele diferiu muito do otimizado (Tabela 5). Novamente, por ser uma simples modificação do índice otimizado, também não pode ser aplicado para a seleção de cultivares.

A classificação dos genótipos proporcionada pelo índice básico modificado é igual à do índice básico e eles mostram uma elevada correlação entre si $(r=0,99)$, o que mostra a estreita relação entre eles (Tabela 5). Novamente, observa-se que também não é possível aplicar o índice básico modificado na seleção de cultivares, pelas razões já expostas para os índices otimizado e básico: impossibilidade de descarte dos genótipos com caracteres inferiores aos exigidos comercialmente, inexistência de valor genotípico a ser melhorado, necessidade de estimativas de parâmetros genéticos.

O índice restrito é uma simples modificação do índice otimizado, devida à imposição de restrições, tanto que eles mostraram alta correlação entre si $(r=0,99)$. Pelas mesmas razões que para o otimizado, não se adapta à situação encontrada na seleção de cultivares. A classificação dos genótipos que ele proporciona é praticamente igual àquela do índice otimizado, confirmando a estreita relação entre eles (Tabela 5).

Com respeito ao índice da resposta à seleção desejada, nota-se que a classificação que ele proporciona também se assemelha muito àquela oferecida pelo índice otimizado e pelo restrito, refletindo a grande semelhança entre eles, principalmente porque, no caso, atribuiu-se 
mesmo peso às variáveis (Tabela 5). Da mesma forma que os demais índices lineares, este também não pode ser usado para a seleção de cultivares, mas sim em programas de seleção recorrente.

As correlações entre todos os índices são apresentadas na Tabela 6, onde pode ser mais facilmente visualizada a grande semelhança entre os índices otimizado, restrito e da resposta à seleção desejada, e entre o básico e o básico modificado. Isso decorre dos princípios envolvidos no desenvolvimento de tais índices, conforme apresentado na revisão de literatura. Nota-se que eles podem indusive levar a diferentes resultados na seleção, em função de alguns deles apresentarem correlações negativas.

Tabela 6. Matriz de correlações entre os índices de seleção otimizado $\left(I_{o}\right)$, básico $\left(I_{b}\right)$, básico modificado $\left(I_{b m}\right)$, restrito $\left(I_{r}\right)$ e de resposta à seleção desejada $\left(I_{r s d}\right)$.

\begin{tabular}{ccccc} 
& \multicolumn{1}{c}{$I_{b}$} & $I_{b m}$ & $I_{r}$ & $I_{r s d}$ \\
\cline { 2 - 4 }$I_{0}$ & $-0,2588$ & $-0,2925$ & 0,9998 & 0,9625 \\
$I_{b}$ & & 0,9991 & $-0,2416$ & $-0,4353$ \\
$I_{b m}$ & & $-0,2756$ & $-0,4679$ \\
$I_{r}$ & & & 0,9595 \\
\hline
\end{tabular}

Depreende-se do que foi apresentado que nenhum índice de seleção linear discutido se presta à seleção de cultivares, ou seja, de genótipos nas fases finais dos programas de melhoramento genético. Isso advém do fato de eles terem sido idealizados para a aplicação em programas de seleção recorrente, pois pressupõem a existência de um valor genotípico populacional a ser melhorado, não existente naquela situação.

Os dois melhores genótipos selecionados pelo índice otimizado são 02 e 0 1, sendo que o segundo deles jamais poderia se tornar cultivar, pois apresenta o pior teor protéico entre todos os genótipos. Estes mesmos genótipos também são os dois melhores colocados com emprego dos índices restrito e da resposta à seleção desejada, sendo que o número 1 não poderia ser cultivar, pelo baixo teor protéico apresentado, conforme discutido. Já para os 
índices básico e básico modificado, os dois melhores genótipos são os de número 10 e 3, sendo que $\circ 10$ jamais seria cultivar, por apresentar a menor produção dentre todos eles; o genótipo 3 tem baixo teor protéico ( $8^{\circ}$ lugar), também impedindo que ele se tome um cultivar (Tabelas 3 e 5). Isso reitera o fato desses índices não servirem para a seleção de cultivares.

Além disso, os índices não consideram o descorte de genótipos que tenham desempenho inferior ao exigido comercialmente para algum(ns) do(s) caracter(es) avaliados, pois levam em conta a contribuição de cada genótipo no melhoramento da população como um todo. No caso da seleção de cultivares, sequer faz sentido imaginar a existência de tal população, quanto mais selecionar genótipos com performance diferente da exigida pelo mercado. Outro fato desconsiderado pelos índices discutidos é que eles não consideram a possibilidade de realização de testes estatísticos de comparação de médias, os quais são necessários para a seleção de cultivares.

A grande diferença entre as classificagões obtidas com os diferentes tipos de índices, aliada à dificuldade de ponderações econômicas, subjetivas e nem sempre fáceis de serem executadas, torna custoso, ao melhorista, escolher qual índice aplicar. Deve-se mencionar que as estimativas dos parâmetros exigidos para os cálculos, na maioria das vezes, não são facilmente obtidas e possuem grandes erros de estimaço, inerentes ao processo estatístico escolhido para tanto, como por exemplo o método dos momentos, comumente usados na estimação dos componentes de variância. Isso dificulta a utilização dos índices lineares, mesmo em programas de seleção recorrente.

\subsection{Análises estatísticas dos experimentos do Ensaio Nacional de Milho Precoce 1996/97}

\subsubsection{Análises de variância e obtenção das médias ajustadas}

Os resultados das análises de variância mostram que ocorreram diferenças significativas entre os genótipos para todos os caracteres (1\%), o que indica que testes de média podem ser realizados para verificar como as médias diferiram entre si (Tabela 7). Podese deduzir que haverá grande diferença na classificação dos genótipos quando ocorrer a aplicação dos índices, por serem eles bastante diferentes entre si. Para todos os caracteres, houve diferença significativa entre os locais, bem como interação significativa entre locais e 
genótipos. Porém, optou-se por realizar um estudo da estabilidade apenas para o caráter peso de espigas (PE), que é o mais importante. De forma geral, todos os testes $F$ realizados para os quadrados médios foram significativos, exceto para blocos/repelições/locais, nos caracteres umidade nos grãos (U) e número de dias para florescimento (FLO) e para repetição/local para FLO. Isso indicou grande efeito de todas as fontes de variação consideradas nos modelos, para todos os caracteres. Os erros efetivos foram sempre superiores aos erros intrabloco, exceto para o caráter FLO, onde eles foram iguais. Os coeficientes de variação de todos os caracteres avaliados estiveram em níveis aceitáveis, variando de 3,49\% (FLO) a 48,38\% para a porcentagem de plantas acamadas e quebradas (PAQ). Este último valor, embora seja elevado mesmo após a transformação dos dados, encontra-se dentro dos valores normalmente observados nas situações comuns à experimentação agrícola para esta variável, a qual é relativamente difícil de mensurar. Para o caráter mais importante, $P E$, o coeficiente de variação foi de 9,19\%, encontrando-se dentro dos limites aceitáveis da experimentação agrícola, indicando boa condução dos experimentos.

As médias ajustadas de todos os caracteres avaliados foram usadas posteriormente para o cálculo dos índices de seleção, sendo que as médias do caráter PE de cada local foram usadas para a análise de estabilidade, por ser ele o caráter mais importante (Tabelas 8, 9 e 10). Para PE, as médias ajustadas da análise conjunta variaram de 6.842,9 $\mathrm{kg} / \mathrm{ha}$ (híbrido A 953) a 9.531,0 kg/ha (híbrido C $505 \mathrm{C}$ ), estando dentro das faixas normalmente encontradas para este caráter. Os valores de umidade (U) apresentaram uma pequena amplitude de variação, entre $14,51 \%$ e $17,4 \%$, com média 15,6\%. O mesmo ocorreu para FLO, variando entre 56,7 e 60,5 dias, com média 58,3 dias. Já para o porte, verificou-se que o caráter altura da planta (AP) apresentou média de 202,7 cm, variando de 189,6 a 229,9 cm; a altura da espiga (AE) teve média de 103,3 cm e amplitude de variação de 91,2 a 126,6 cm. O caráter prolificidade (PROL) variou pouco, de 0,98 a 1,22, com média 1,04. Finalmente, PAQ variou de 3,3\% a 15,5\%, com média de $8,7 \%$ (na sua unidade original, antes da transformação $\sqrt{x+0,5})($ Tabela 8$)$. Com relação ao caráter $P E$, nos nove locais onde ele foi avaliado, os coeficientes de variação entre eles variou de 5,63\% (Brasília, DF) a 12,34\% (Tangará da Serra, GO), estando dentro dos limites aceitáveis da experimentação agronômica (Tabelas 9 e 10). Com relação as médias dos locais para PE, elas variaram entre $5.262,6 \mathrm{~kg} / \mathrm{ha}$ (Capinópolis, SP) e 10.605,6 kg/ha (Brasília, DF). 


\subsubsection{Análise de estabilidade}

Neste caso, foram utilizadas as médias ajustadas do caráter PE dos nove locais em que ela foi avaliada, para aplicação da metodologia de Eberhart \& Russell (1966) (Tabelas 9 e 10). Tal análise só foi realizada para o caráter $\mathrm{PE}$, por ser ele o mais importante de todos. Assim sendo, para cada híbrido, foi calculado o coeficiente angular da reta de regressão $(b)$ entre o desempenho de cada genótipo (média ajustada de PE) e o índice de ambientes, sendo que tal parâmetro foi tomado como medida de adaptabilidade. Além disso, foram também obtidos os desvios desta regressão linear, que foram avaliados através do coeficiente de determinação $\left(R^{2}\right)$. Este coeficiente foi usado como medida da estabilidade de cada genótipo. Não foram realizados testes de significância para as estimativas dos dois parâmetros, pois, normalmente, os valores de $b$ não mostram diferença significativa do valor 1,0 e os desvios da regressão normalmente não são significativos (Vencovsky \& Barriga, 1992). Deste modo, se testes fossem realizados, os parâmetros calculados seriam pouco informativos. Os valores calculados encontram-se na Tabela 11.

Verifica-se que os valores de adaptabilidade variaram numa faixa muito ampla, de 0,704 a 1,390, mostrando que existem híbridos adaptados aos piores ambientes (menores valores de $b$ ), exigentes (maiores $b$ 's) e com boa adaptabilidade ( $b$ com valores próximos da unidade). A estabilidade variou de pequena $\left(R^{2}=0,6601\right)$ a muito boa $\left(R^{2}=0,9739\right)$, também numa ampla faixa de variação. Esta grande variabilidade permite prever que haverá grande diferença entre os híbridos, quando forem aplicados índices de seleção incluindo esses parâmetros. $O$ valor usado como referência para $b$ foi 1,0, pois, como ele é um coeficiente de regressão linear, indica quanto o comportamento do cultivar se modifica em função da alteração do ambiente e, deste modo, tal valor indica que uma unidade de melhoria ambiental representa uma unidade de resposta no genótipo. Para os desvios da regressão $\left(R^{2}\right)$, os melhores genótipos são aqueles que pouco se distanciam da reta de regressão, tendo, portanto, comportamento mais previsível (estável) e, conseqüentemente, maior valor de $R^{2}$.

Quando possível, os parâmetros calculados, $b$ e $\mathrm{R}^{2}$, também foram usados para classificar os genótipos com uso dos índices, como será apresentado. Logo, para cada híbrido, havia nove variáveis, sendo sete fenotípicas (PE, U, FLO, AP, AE, PROL e CD) e duas sendo parâmetros calculados a partir dos dados $\left(b \quad \mathrm{e}^{2}\right)$. Nota-se a grande dificuldade em se classificarem os 49 híbridos para as nove variáveis conjuntamente (Tabelas 8 e 11), sem uso de algum índice de seleção. 


\section{3. Índices não lineares}

\subsection{1. Índice multiplicativo}

O índice multiplicativo proposto por Elston (1963) não requer a obtenção de estimativas de parâmetros genéticos e nem supõe a existência de um valor genotípico populacional. Isto permitiu que fosse sugerida sua aplicação com a simples finalidade de classificar os genótipos com respeito a diversos caracteres simultaneamente, como é o caso da seleção de cultivares. Logo, pode ser aplicado ao caso em estudo, ao menos teoricamente.

A seguir, serão apresentados os resultados da aplicação do índice multiplicativo aos dados fenotípicos do Ensaio Nacional de Milho Precoce (Tabelas 8 e 11). Não foi possível induir o parâmetro de adaptabilidade $(b)$ nos cálculos, uma vez que o índice só permite a inclusão de variáveis as quais se desejam maximizar ou minizar e, nesse caso, o valor desejado é 1,0 (materiais com ampla adaptabilidade), intermediário. Esta é uma desvantagem desse índice, já que outras variáveis com tal característica, ou seja, valores diferentes dos extremos, também não podem ser incluídas. Deste modo, parâmetros cuja seleção seja estabilizadora, como por exemplo aquela realizada para os caracteres dias para maturação, altura das plantas intermediária para possibilitar colheita mecânica, etc, não podem ser incluídos no índice. A impossibilidade de descartar valores abaixo ou acima de determinados extremos é também uma grande limitação deste índice; na prática, os melhoristas normalmente estão interessados em descartar valores aquém ou além de dados limites.

Todos os passos para seu cálculo foram seguidos, de acordo com Elston (1963) e os procedimentos descritos no item Material e Métodos. Foram necessárias duas transformações logarítmicas para que as distribuições de todas as variáveis fossem semelhantes. Para nenhuma das variáveis se supôs que algum dos genótipos com valor nos níveis mínimos ou máximos fosse descartado, ou seja, ao invés de subtrair de cada valor a maior ou menor ocorrência da variável, foram subtraídos valores de $k_{i}$ de forma que não se tivesse zero como resultado. Isso foi conseguido utilizando-se $k_{i}=\left[n\left(\min p_{i}\right)-\left(\max p_{i}\right)\right] /[n-1]$, que é obtido baseado na distribuição teórica de uma amostra aleatória com distribuição retangular (Elston, 1963).

A transformação aplicada foi eficiente em uniformizar as distribuigões de todos os caracteres, estando de acordo com o artigo original, que afirma que duas transformações 
devem ser suficientes para uniformizar as distribuições, pelo menos quanto ao número de modas. Tal fato é verificado pelo exame da Figura 7 , onde se observa que as distribuições são, de fato, muito semelhantes, o que implicou que todos os caracteres tivessem o mesmo peso no cálculo do índice.

Visou-se o aumento dos caracteres PE, PROL e $R^{2}$, e a diminuição de U, FLO, AP, $A E$ e $C D$, para os quais foram utilizados recíprocos. Os valores após as duas transformagães logarítimicas, denominados $p_{i}{ }^{\prime \prime}-k_{i}{ }^{\prime \prime}$, bem como o índice calculado e as classificạōes, encontram-se na Tabela 12. Como mencionado, não foi possível induir o parâmetro $b$, cujo valor ideal é intermediário $(1,0)$.

Após as transformações logarítmicas, foram então calculados os índices multiplicativos referentes a cada genótipo. Seus valores variaram de 0,00 a 29,01, com média 13,5; quanto maior o valor do índice, melhor o genótipo. Vale lembrar que, com emprego desse índice, os valores de $I_{m}$ são as únicas informações que o melhorista terá a disposição para classificar os genótipos, o que evidentemente impossibilita estudar o que ocorreu com cada caráter individualmente.

Para facilitar, os valores do índice foram agrupados aos dados originais, permitindo visualizar o que realmente ocorreu, sendo que o caráter PAQ foi mostrado em sua unidade original (\% de plantas acamadas e quebradas em relação ao estande), embora os cálculos realizados para a obtenção do índice tenham sido feitos com esta variável transformada por $\sqrt{x+0,5}$ (Tabela 13).

Por se tratar de um índice multiplicativo, sem qualquer possibilidade de ponderação, ocorreu que caracteres mais importantes, como PE, tivessem o mesmo peso na classificação que os demais. Na prática, os melhoristas jamais aceitariam isso, uma vez que a variável citada, pelo menos no exemplo, é a mais importante. Mesmo em outras espécies, sempre é possível intuir que, ao menos teoricamente, em alguns casos, deve haver necessidade de algum tipo de ponderação.

Um exame da classificação dos genótipos com base no índice permite verificar que sua validade parece ser maior para uso em programas de seleção recorrente. Dentre os dez primeiros colocados, encontramos os genótipos com as classificoçães para produção com números 19, 6, 3, 14, 37, 20, 10, 5, 4 e 25, para PE. Obviamente, os melhoristas não aceitariam que todos esses materiais fossem recomendados para cultivo. Os genótipos 
classificados em $1^{\circ}$ e $2^{\circ}$ lugares para PE posicionaram-se apenas em $45^{\circ}$ e $24^{\circ}$ lugares, respectivamente, o que não seria aceito para um índice que realizasse a seleção de cultivares.
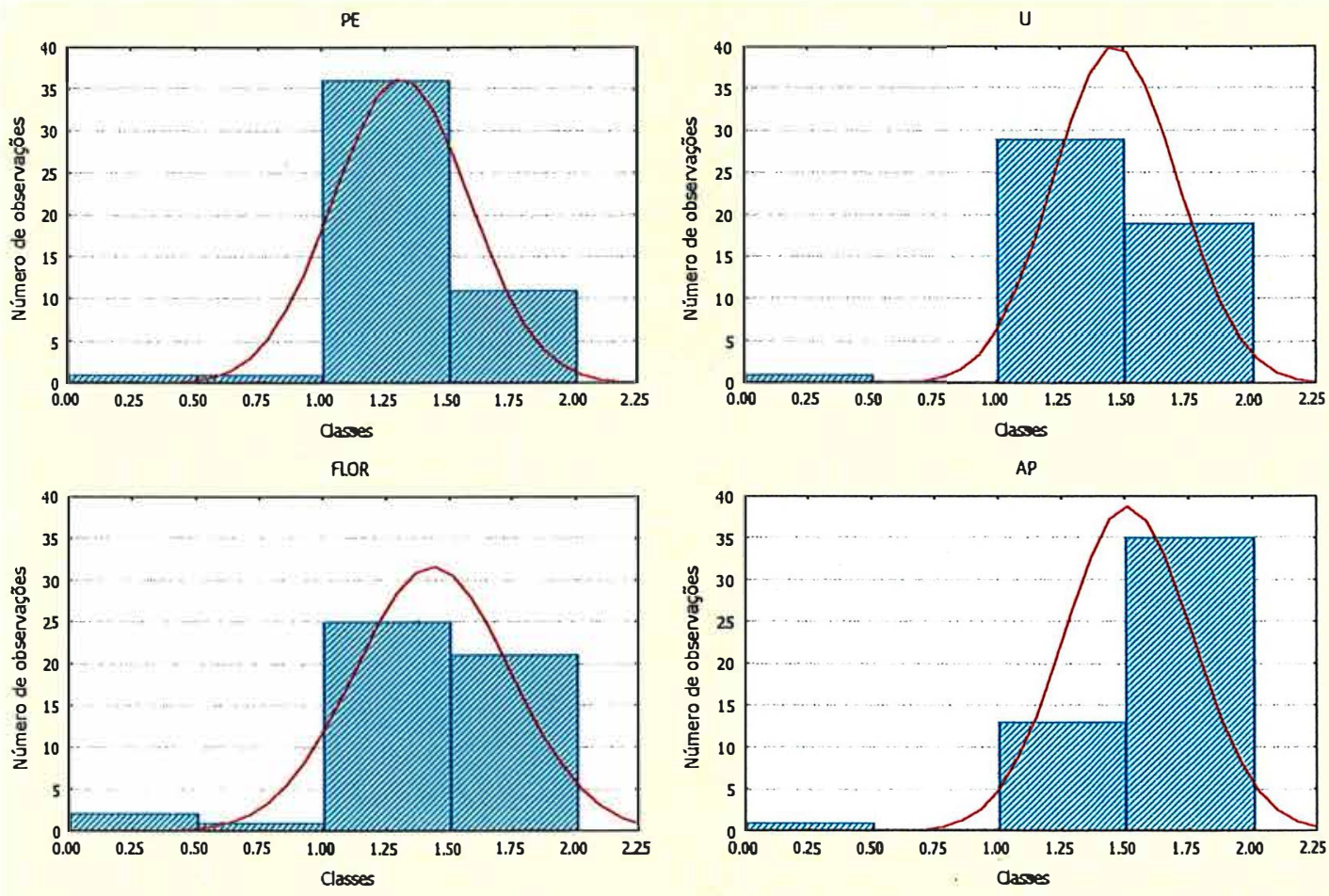

AE
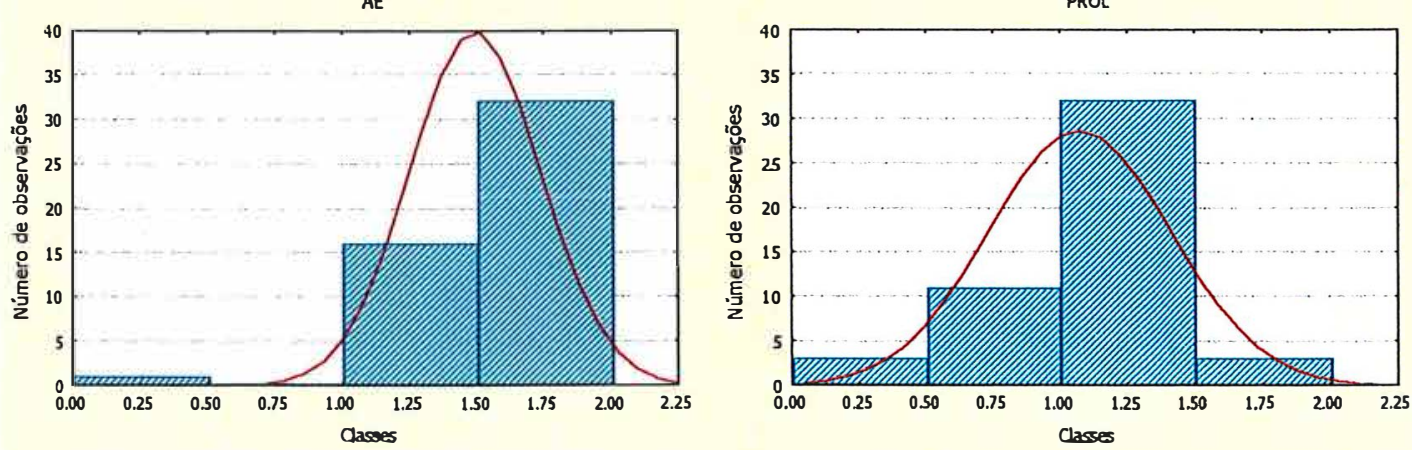

PAQ
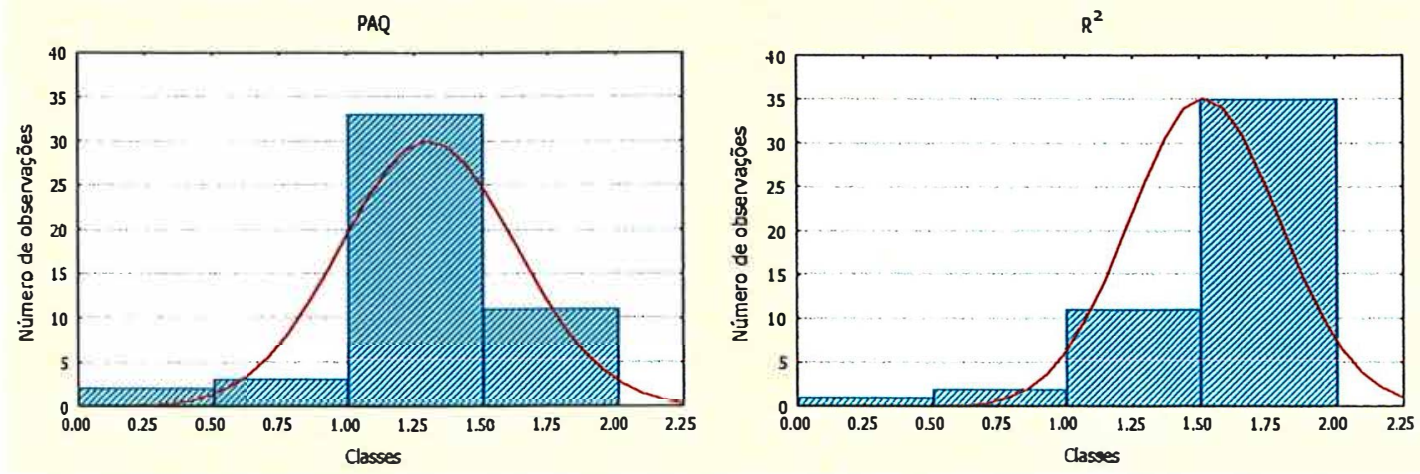

Figura 7. Histogramas com a distribuição de $p_{i}^{\prime \prime}-k_{i}^{\prime \prime}$ das variáveis $\mathrm{PE}, \mathrm{U}, \mathrm{FLO}, \mathrm{AP}, \mathrm{AE}, \mathrm{PROL}, \mathrm{PAQ}$ e $\mathrm{R}^{2}$. 
É possível definir que os genótipos com valor máximo ou mínimo para algum(ns) atributo(s) não sejam selecionados. Mas, na situação real, é mais provável que o melhorista deseje definir valores abaixo (ou acima) dos quais os genótipos sejam descartados, e não simplesmente os maiores ou menores valores. É mais comum ocorrer a imposição de faixas de variação e não apenas limites extremos. Por exemplo, podese desejar que os genótipos com produção estatisticamente inferior a das testemunhas comerciais sejam descartados em função de exigências do mercado consumidor. Outro caso seria impedir a seleção de materiais com altura acima da média das variedades disponíveis no mercado, e assim por diante. Tal situação não é abordada no índice multiplicativo, que só permite o descarte dos valores extremos. Caso

fosse utilizado $k_{i}$ maior que o valor mínimo, teríamos números negativos para $p_{i}-k_{i} \mathrm{e}$ haveria problemas na obtenção do índice e dos logaritmos. Vale lembrar que o produto de dois números negativos é positivo, o que pode causar grandes distorções no índice e na classificação dos genótipos.

A forma como os resultados foram apresentados, mesmo que confrontados com os dados originais (Tabela 13), impede saber se, no grupo de selecionados, existe material que deva ser descartado devido a alguma(s) variável(eis). Logo, o fato do índice não apresentar maiores subsídios para o melhorista julgar o resultado da classificação é uma grande desvantagem, visto que distorções podem ocorrer sem que se tome conhecimento. Por exemplo, o híbrido classificado em $1^{\circ}$ lugar pelo o índice multiplicativo, XL 345, tem PE apenas em $19^{\circ}$ lugar, $U$ em $18^{\circ}$ lugar e PAQ em $18^{\circ}$, o que implica que ele jamais seja recomendado como cultivar pelos melhoristas. Será que o híbrido C $435 \mathrm{G}, 6^{\circ}$ dassificado pelo índice e que apresenta AE classificada na $37^{\mathrm{a}}$ posição, não deve ser descartado por estar com tal valor acima das exigências mínimas? Ou ainda, será que o híbrido G $165 \$ 10^{\circ}$ colocado, por apresentar FLO na $39^{a}$ posição, não se caracteriza como material tardio, devendo ser excluído do conjunto avaliado? Outro caso pode ser o do híbrido $Z 84 \mathrm{E} 98,2^{\circ}$ colocado, que tem U classificada em $45^{\circ}$ lugar; será que tal valor não é excessivamente alto? Essas questões e muitas outras, que podem ser facilmente formuladas, não estão respondidas, dificultando ao melhorista selecionar adequadamente os melhores materiais. Os genótipos classificados nos cinco primeiros lugares para $\mathrm{PE}$, caráter mais importante, estão colocados em $45^{\circ}, 24^{\circ}, 3^{\circ}, 9^{\circ}$ e $8^{\circ}$ lugares, respectivamente. Isto não seria aceito em situações reais, dada a grande importância de PE. Os genótipos mais produtivos poderiam ser descarbos simplesmente por não fazerem parte do grupo melhor classificado com uso do índice, o que não deve ocorrer quando a seleção visa a obtenção de cultivares. 
Possivelmente, o fato de todos os caracteres terem o mesmo peso foi a causa da classificação dos híbridos não ter validade prática para os melhoristas. Isto já era previsto, uma vez que o índice multiplicativo, embora não exija estimativas de parâmetros genéticos como os índices lineares, foi idealizado para selecionar aproximadamente os mesmos genótipos que os lineares (Figura 8). Logo, é perfeitamente adequado à seleção recorrente, e não a de cultivares.

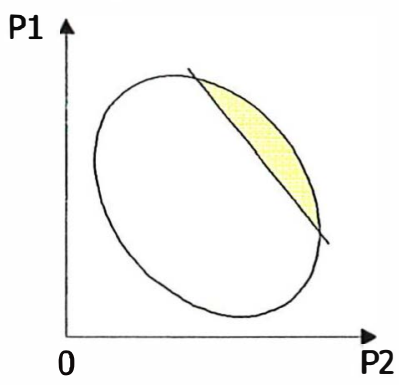

(a)

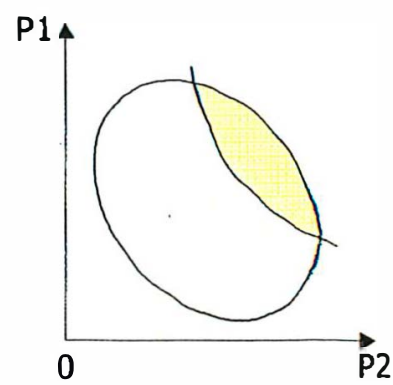

(b)

Figura 8. Região selecionada pelo emprego do índice linear otimizado (a) e pelo índice multiplicativo (b), ambos com mesmo peso para os caracteres $\mathrm{P} 1$ e P2.

Outro ponto a ser levantado é sobre as reais diferenças entre as variáveis, já que o índice não prevê a realização de testes de médias. As diferenças entre as médias fenotípicas de cada variável podem não ser estatisticamente significativas e, uma vez que estes experimentos permitem a realização de testes de comparação de médias, isto deveria ser levado em conta. Usando-se o índice diretamente nas médias, pode-se incorrer no erro de considerar como diferentes médias que, na verdade, são iguais estatisticamente. A existência de diferença significativa entre as médias deve ser considerada na seleção de cultivares.

Concluindo, muito embora o índice multiplicativo tenha sido recomendado também com a simples finalidade de classificar os genótipos, ele mostra sérias restrições quanto ao seu uso nos programas de seleção de cultivares.

\subsubsection{Indice de soma de classificação}

O índice de soma de classificação (Mulamba \& Mock, 1978) foi obtido simplesmente somando os valores de classificação para cada caráter de cada genótipo (Tabela 14). Optou-se por apresentar a variável $P A Q$ em suas unidades originais, já que a transformação aplicada não alteraria os valores do índice. Os valores encontrados variaram entre 107 e 297, com média 200. 
Observando a Tabela 14, verifica-se que entre os dez primeiros colocados, temos os híbridos com valores classificados para PE nas posiçōes 19, 14, 6, 49, 5, 7, 3, 37, 39 e 20. Tal fato jamais seria aceito pelos melhoristas, uma vez que o último colocado $\left(49^{\circ}\right)$ para este caráter, o híbrido A 953, está entre o grupo selecionado ( $4^{\circ}$ lugar). Evidentemente, isto ocorreu porque outros seus atributos são favoráveis, como U ( $1^{\circ}$ lugar), FLO ( $3^{\circ}$ lugar) e PAQ ( $3^{\circ}$ lugar). Talvez com exceção daqueles com PE em $6^{\circ}, 5^{\circ}$ e $7^{\circ}$ lugares, os demais não seriam recomendados como cultivares. De fato, isto é aceito em programas de seleção recorrente, onde valores desfavoráveis em alguns caracteres podem ser compensados por valores adequados em outros. Não se aceita isso, contudo, na seleção de cultivares, uma vez que os materiais devem ser recomendados para plantio e nenhum caráter pode estar fora dos níveis mínimos aceitáveis, como é o caso. Os cinco híbridos mais produtivos (maior $\mathrm{PE}$ ) estão classificados nas posições 28, 40, 7, 21 e 5, respectivamente, após o emprego do índice. $01^{\circ} \mathrm{e}$ - $2^{\circ}$ colocados para PE, os híbridos C 505 C e C 505 B, sequer seriam recomendados como cultivares, por estarem na $28^{\mathrm{a}}$ e $40^{\mathrm{a}}$ posições, respectivamente; isso mostra que ele não pode ser usado para a seleção de cultivares.

O índice não permite descartar genótipos com caracteres em níveis inferiores, o que praticamente inviabiliza o seu uso, já que no caso considerado tais genótipos não devem jamais ser selecionados. Vale lembrar que o resultado da aplicação do índice de soma de classificação fornece apenas os valores de $I_{j}$, impedindo verificar quais os valores apresentados para as variáveis dos genótipos selecionados e descartados, o que é outra desvantagem do índice. A apresentação de todos os valores foi feita para estudar o que ocorreu, mas não seria esse o resultado que o melhorista teria à disposição.

A utilização desse índice é muito simples, não necessitando sequer ajustar as unidades das variáveis, como no caso do índice multiplicativo. Como não são usados os valores fenotípicos diretamente e sim um número associado a cada um deles, é evidente que a variância é a mesma para todas variáveis, evitando transformação de dados. Desconhece-se, contudo, se as diferenças entre as médias são ou não significativas, o que pode levar a interpretações errôneas quanto às reais diferenças entre os genótipos. Por exemplo, os híbridos XL 345 e C 625 mostraram mesmos valores para a variável AP (197 om), mas com números de classificação diferentes, implicando em valores diferentes para o índice (Tabela 14). Para outras variáveis, isso também pode ter ocorrido, sem que o melhorista tenha conhecimento sobre a 
significância das diferenças entre as médias. Assim, pode-se concluir que este índice não seria indicado para a seleção de cultivares.

\subsection{3. Índice baseado em medida de distância}

Este tipo de índice, proposto por Schwarzbach $(1972)^{1}$, citado por Wricke \& Weber (1986), foi calculado para as médias ajustadas das análises conjuntas dos experimentos do Ensaio Nacional, após elas terem sido estandardizadas.

Foram calculadas as distâncias euclidianas entre cada genótipo $i$ e o genótipo ideal $I\left(d_{i I}\right)$, definido como sendo aquele com maior valor para os caracteres PE, PROL e $\mathrm{R}^{2}$, menor para U, FLO, AP, AE, PROL e PAQ e com valor 1,0 para $b$. O fato de permitir a inclusão de variáveis cujos valores não sejam os extremos, mas sim qualquer valor de interesse do melhorista, uma vez que o ideótipo é fixado por ele, é uma vantagem que ele apresenta sobre os índices multiplicativo e de soma de classificação, que impediram a inclusão de $b$. Por não fazer pressuposiğões sobre a existência de um valor genotípico populacional a ser melhorado, além de não necessitar de estimativas de parâmetros genéticos, pode, ao menos teoricamente, ser usado para a seleção de cultivares.

Embora os dados tenham sido estandardizados, optou-se por apresentar os resultados com os dados originais, incluindo seus números de ordem. Nenhum peso foi atribuído a qualquer caráter, muito embora isso seja possível para este índice, o que é uma vantagem sobre o multiplicativo e o de soma de classificação (Tabela 15). Os valores apresentados para a distância euclidiana variaram de 5,73 a 10,55, com média 7,48. Vale lembrar que o melhorista teria à disposição, após uso do índice, apenas os valores da distância euclidiana, sem tomar conhecimento dos valores apresentados pelos genótipos selecionados para todos os caracteres de interesse, não podendo julgar se a seleção foi ou não bem realizada. Observando-se os resultados, nota-se que entre os dez primeiros genótipos classificados estão aqueles com número de classificação $6,37,3,19,5,14,10,20,4$ e 24, para $P E$, caráter mais importante. Desses materiais, com exceção talvez daqueles com classificação $3,4,5$ e 6, os demais, de modo algum, seriam recomendados como cultivares, o que invalida 0

\footnotetext{
1 SOHWARZBACH, E. Einige Anwendungsmöglichkeiten elektronischer Daterverarbeitung (EDV) für die Beurteilung von Zuctionaterial. Arb. Tag. Oesterr. Pflanzenz. Gumpenstein: 277-87, 1972.
} 
índice para tal finalidade. Além disso, não há como saber se as diferenças entre as médias usadas nos cálculos são diferentes entre si, como por exemplo entre $\circ 10^{\circ}$ e $14^{\circ}$ material quanto a PE (híbridos C 625 e G 167 S). Esse tipo de dúvida dificulta seu uso na prática. Mesmo que se optasse pelo uso de algum peso na expressão da distância euclidiana para PE, mais importante, isso nem sempre é fácil de realizar.

Os genótipos com o $1^{\circ}$ e $2^{\circ}$ valores de PE posicionaram-se em $44^{\circ}$ lugar (C $505 \mathrm{C}$ ) e $26^{\circ}$ lugar (C 505 B), respectivamente, que não são colocações razoáveis para caráter tão importante. Jamais seria aceito que o $2^{\circ}$ colocado de acordo com $d_{i I}$ tivesse PE apenas na 37 colocação. Desse modo, tal forma de agrupar os valores de todos os caracteres num índice não é adequada à seleção de cultivares.

Outro problema encontrado nos resultados (Tabela 14) refere-se ao fato do índice não permitir o descarte de genótipos que não satisfaçam às exigências mínimas do mercado. Será que, por exemplo, o genótipo localizado em $1^{\circ}$ lugar não apresenta $R^{2}$ abaixo de um nível mínimo aceito comercialmente? Ou o $3^{\circ}$ colocado, valor de FLO superior ao desejado? A não elucidação desse tipo de questão ao melhorista dificulta ainda mais o uso desse índice.

\subsubsection{Comparações dos índices não lineares}

Pelo exposto, ficou claro que nenhum dos índices de seleção não lineares apresentados é adequado à seleção de cultivares. Resta a dúvida se eles poderiam ser aplicados em programas de seleção recorrente. $O$ único deles que buscou se relacionar com os índices lineares, onde há uma boa base teórica garantindo sua validade, foi $\circ$ índice multiplicativo. Contudo, ele apenas aceita a situação onde todos os caracteres têm o mesmo peso, que é um caso particular; pode ser que isso limite sua aplicação, mesmo para a seleção recorrente.

Teoricamente, o índice de soma de classificação poderia ter uso em programas de seleção recorrente, onde eventuais valores desfavoráveis em alguns atributos podem ser compensados por outros caracteres em níveis melhores. Fica difícil, entretanto, afirmar sua validade nesse caso, uma vez que a base teórica empregada em seu desenvolvimento não o relaciona com nenhum outro índice. Comparando-o com o índice multiplicativo, verificamos que eles apresentam uma baixa correlação $(r=-0,61)$, negativa porque o índice multiplicativo toma os maiores valores e o índice de soma de classificação os menores; contudo, pode-se chegar a 
resultados bem diferentes quando eles são usados. Os cinco melhores genótipos selecionados pelo índice multiplicativo são XL 345, Z 84 E 98, Z 8452, C 625 e HD 9563; já para o de soma de classificação, XL 345, C 625, Z 84 E 98, A 953 e AGX 5558. Apenas três deles seriam selecionados com os dois índices, mostrondo que a correlação não tem grande valor preditivo (Figura 9).

O índice da distância ao ideótipo, com aplicação sugerida em programas de seleção recorrente, apresentou alta correlação $(r=-0,83)$ com o índice multiplicativo, negativa em função do escalonamento, além de uma alta correlação positiva com o índice de soma de dassificação $(r=0,78)$ (Figuras 10 e 11). Os cinco melhores genótipos selecionados com o índice de distância ao ideótipo foram Z 84 E 98, HD 9563, Z 8452, XL 345 e AGX 5558, sendo que quatro deles também seriam selecionados com o índice multiplicativo, mostrando que a magnitude da correlação serve para realizar predições. Já com o índice de soma de dassificação, somente três seriam selecionados em comum. Isso é conseqüência da maior correlação entre o índice multiplicativo e o de distância ao ideótipo, mais semelhantes entre si. O índice de soma de classificação deve envolver princípios diferentes em seu desenvolvimento, levantando à dúvida sobre sua validade, mesmo em programas de seleção recorrente, dada a diferença que apresenta em relação aos demais.

Algumas considerações podem ainda ser feitas. Será que esses três índices lineares servem realmente para a seleção recorrente? Para que isso fosse verdade, de algum modo a correlação genética entre os caracteres deveria ser considerada, uma vez que está se buscando o melhoramento de uma população como um todo. De forma geral, um índice de seleção deve permitir a dassificação correta dos genótipos, considerando diversos caracteres simultaneamente. Tal dassificação deve ser bem feita, para que seja realizada a seleção dos genótipos superiores para um conjunto de caracteres. Na seleção recorrente, os genótipos selecionados dificilmente mostrarão bons valores para todos os caracteres, invalidando o uso de índices adequados a tal situação para a seleção de cultivares. $O$ único desses índices que tem um princípio de desenvolvimento semelhante aos dos índices específicos para seleção recorrente é o multiplicativo. Como ele correlacionou-se melhor apenas com o da distância ao ideótipo, eventualmente, apenas estes dois podem efetivamente ser aplicados à seleção recorrente. Já para a seleção de cultivares, pouquíssimos genótipos serão tomados e, como existem limitações sobre os níveis mínimos dos caracteres, um índice de seleção deve ser especificamente desenvolvido para tal caso, uma vez que ficou evidente que nenhum deles é adequado. 


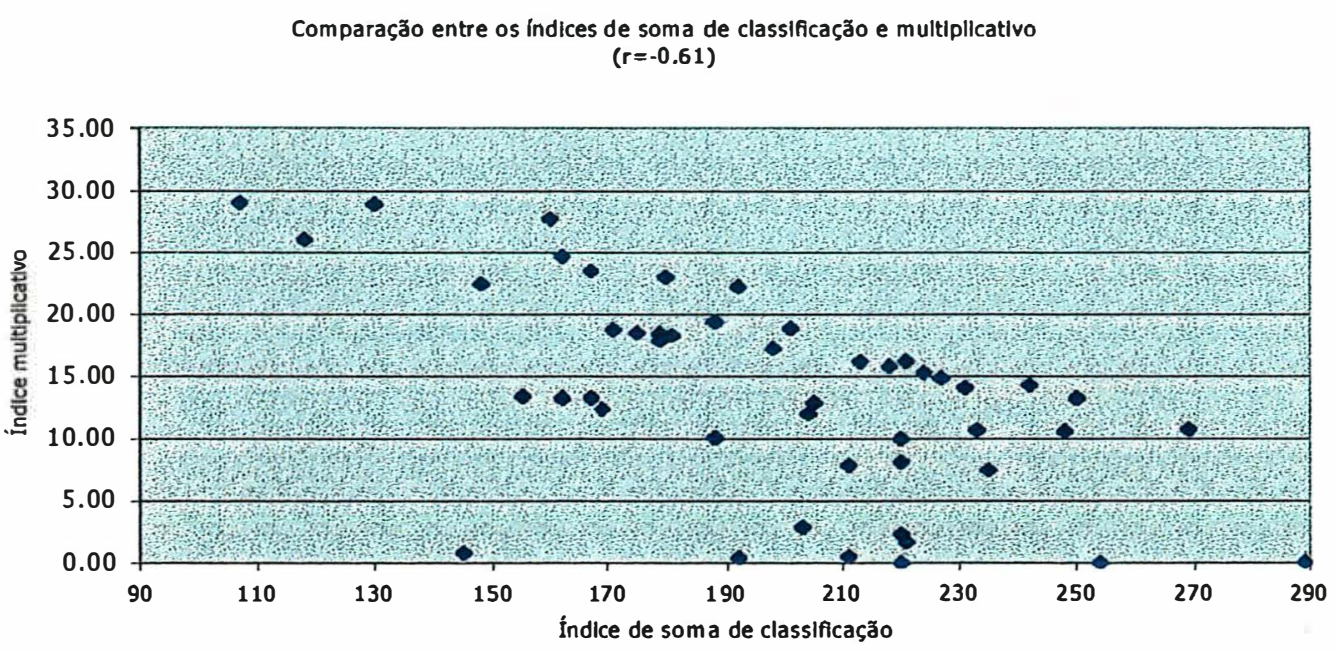

Figura 9. Correlação entre os índices soma de classificação e multiplicativo.

Comparação entre os índices multiplicativo e de distância ao ideótipo $(r=-0.83)$

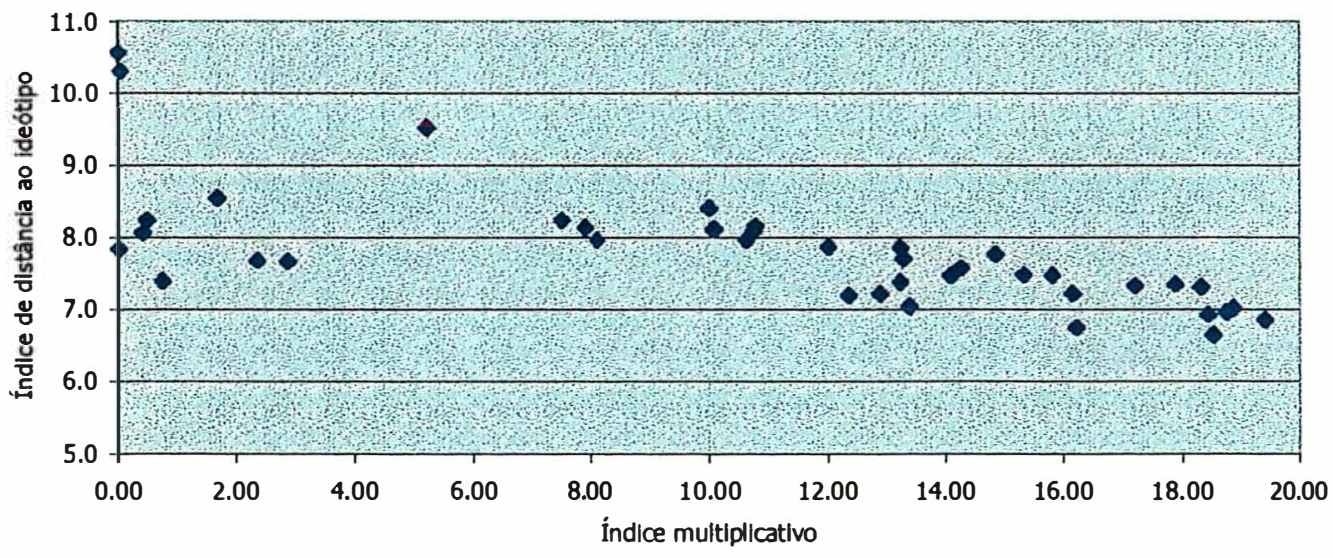

Figura 10. Correlação entre o índice multiplicativo e o de distância ao ideótipo. 


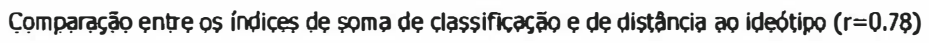

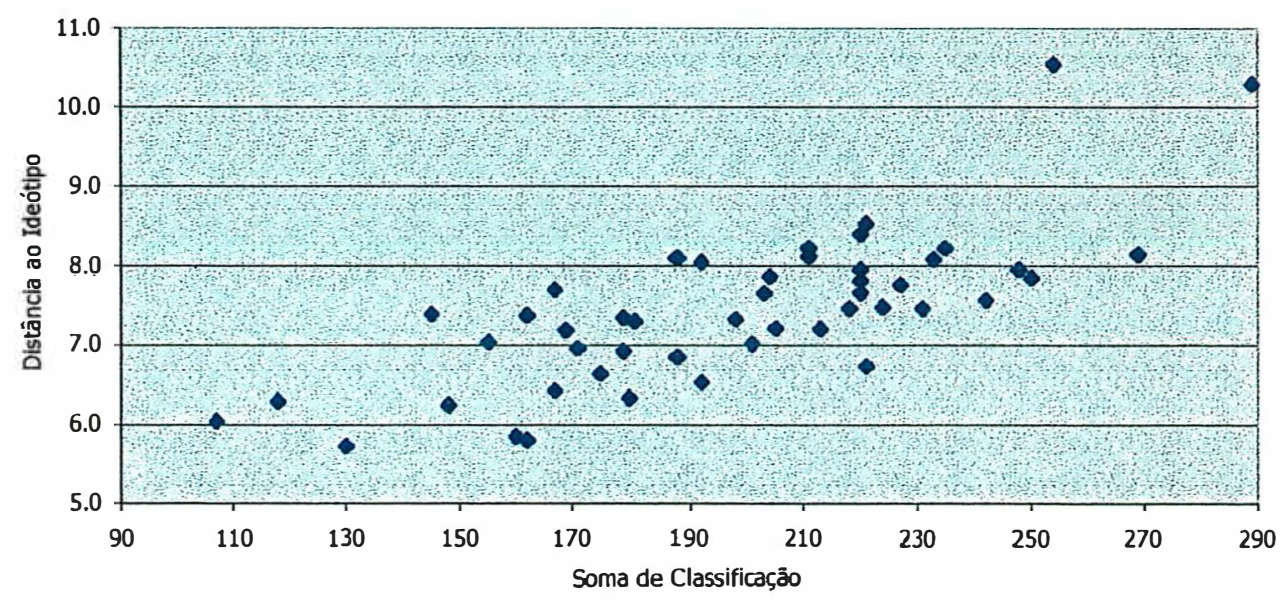

Figura 11. Correlação entre o índice baseado em distância ao ideótipo e soma de classificação.

\section{4. Índice para a seleção de cultivares}

Foi apresentado e discutido na revisão de literatura que a resposta à seleção conseguida com o emprego dos índices lineares tende a ser superior à obtida com outras formas de seleção, quando se considera vários caracteres conjuntamente. Dessa forma, o presente índice foi desenvolvido de modo a buscar selecionar, aproximadamente, os mesmos genótipos que aqueles da região selecionada pelos índices lineares, garantindo a correta classificação dos genótipos. No entanto, um novo enfoque foi dado, uma vez que a situação considerada é diferente daquela apresentada nos programas de seleção recorrente, para a qual foi idealizado o emprego dos índices lineares. Procedimento semelhante foi adotado por Elston (1963), com um índice multiplicativo.

Assim, sem procurar maximizar uma correlação inexistente entre o valor genotípico populacional e o índice de seleção, buscou-se tomar a fração $\theta$ adequada dos genótipos. $O$ princípio empregado para garantir a seleção dos genótipos da fração desejada foi semelhante 
ao apresentado por Schwarzbach (1972)', citado por Wricke \& Weber (1986), muito embora este trabalho não tenha definido a fração selecionada.

Foi definido como ideótipo um genótipo ideal, provavelmente inexistente no conjunto de genótipos, como sendo aquele que apresenta a melhor média fenotípica para todos os caracteres medidos nos experimentos. Por exemplo, tomando-se três caracteres, como altura, produção de grãos e ciclo vegetativo, o ideótipo será o genótipo que apresente maior produção, menor porte (no caso de plantas baixas serem as requeridas pelo melhorista) e ciclo de $x$ dias (determinado pelo melhorista). Este ideótipo é usado como ponto de referência para a seleção, conforme será apresentado. Num exemplo com duas variáveis, em que o ideótipo seja definido como aquele genótipo que apresenta maior valor para ambas, pode-se representálo graficamente como (Figura 6):

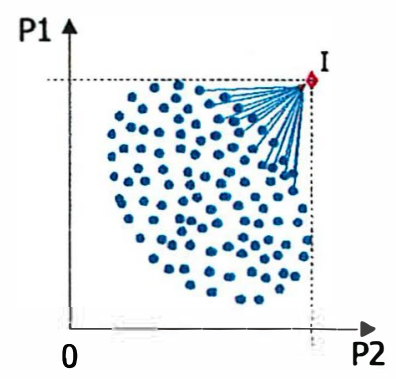

Figura 6. Ideótipo (I) e genótipos selecionados com base na distância que apresentam com relação a ele, para dois caracteres, P1 e P2.

Usando então uma medida de distância entre os genótipos avaliados e o ideótipo, a fração $\theta$ pode ser tomada como aquela formada pelo conjunto de genótipos que mais se aproximam do ideótipo, já que este material é aquele que, numa última análise, é desejado pelo melhorista.

${ }^{1}$ SCHWARZBACH, E. Einige Anwendungsmöglichkeiten elektronischer Datenverarbeitung (EDV) für die Beurteilung von Zuchtmaterial. Arb. Tag. Oesterr. Pflanzenz. Gumpenstein: 277-87, 1972. 


\subsubsection{Etapas necessárias para seu cálculo}

\section{a) Agrupamento de médias e obtenção de recíprocos}

Com a finalidade de testar a significância das diferenças entre as médias fenotípicas dos genótipos, foi aplicado o teste de Scott e Knott (1974) às médias ajustadas (Tabela 8), utilizando como testador o quadrado médio do erro efetivo (Tabela 7). Os testes foram realizados considerando diferentes níveis de probabilidade de erro Tipo I, a saber: 0,01; 0,$10 ; 0,05 ; 0,05 ; 0,05 ; 0,07$ e 0,03 para as variáveis PE, U, FLO, AP, AE, PROL e PAQ, respectivamente, obtendo-se posteriormente o índice denominado de Índice 1 . Outro conjunto de probabilidades de erro tipo I foi 0,$05 ; 0,001 ; 0,001 ; 0,01 ; 0,01 ; 0,001$ e 0,01 , para os mesmos caracteres, com obtenção do Índice 2 . Não se realizou nenhum teste para $b$ e $\mathbf{R}^{2}$, conforme já discutido. Em função das exigências da análise de variância, o caráter PAQ foi usado nos testes e nos índices após a transformação $\sqrt{x+0,5}$, sendo apresentado nesto unidade.

Os resultados dos testes, com os diferentes níveis de significância, estão apresentados nas Tabelas 16 e 17, para os Índices 1 e 2, respectivamente. Os números para designar cada grupo foram tomados de forma que 0 número 1 sempre indicasse 0 valor favorável, ou seja, o objetivo de seleção do melhorista. Desta forma, ele foi associado as maiores médias para os caracteres PE e PROL, e as menores médias para os demais.

Para os níveis de significância do Índice 1, obtiveram-se quatro grupos homogêneos para $\mathrm{PE}$, quatro para $U$, dois para FLO, cinco para AP, seis para $A E$, cinco para PROL e quatro para PAQ. Para o Índice 2, obtiveram-se cinco grupos homogêneos para PE, dois para $U$, dois para FLO, cinco para AP, cinco para AE, cinco para PROL e quatro para PAQ. É evidente que, de forma geral, quanto menor a precisão exigida, maior o número de grupos formados; em outras palavras, quanto menor o nível de significância adotado, menor o número de grupos formados, pois exige-se que as diferenças entre os grupos sejam realmente elevadas para que sejam assumidas como significativas. Por exemplo, para PE com nível 0,01 foram obtidos quatro grupos; já para o nível 0,05, que indica menor precisão exigida para assumir que duas médias são diferentes, foram formados cinco grupos. Porém, isto nem sempre ocorre, em função da distribuição de qui-quadrado adotada no teste. Por exemplo, o caráter PAQ formou quatro grupos nos níveis de significância 0,03 e 0,01. 
Com nível 0,10, o caráter $U$ formou quatro grupos; já com 0,001, apenas dois. 0 caráter FLO formou dois grupos tanto com probabilidade de erro tipo I de 0,05 quanto com 0,001, confirmando que, em função do agrupamento das médias, diferentes níveis de probabilidade podem resultar nos mesmos grupos. Fato semelhante ocorreu com AP nos níveis 0,05 e 0,01. Contudo, para $A E$, o número de grupos diminuiu de cinco para quatro ao se elevar a precisão exigida de 0,05 para 0,01 de probabilidade. Para o caráter PROL, o número de grupos formados com probabilidade de erro tipo I de 0,07 foi cinco; já para probabilidade 0,001 , foi quatro. Para o caráter PAQ, o número de grupos foi quatro para as probabilidades 0,03 e 0,01 .

Conforme pode-se verificar pelos resultados (Tabelas 16 e 17), esse teste não permite a formação de classes sobrepostas, sendo que apenas um número está associado a cada média. Essa vantagem do teste de Scott \& Knott (1974) foi discutida e defendida por Gates e Bilbro (1978), num trabalho em que os autores compararam os grupos formados com o teste de Duncan (1955) e com o teste em questão. Esses autores citaram como principal desvantagem do teste o grande número de cálculos realizados para sua aplicação, no entanto, com a atual disponibilidade de computadores, tal problema inexiste.

Após a obtenção dos grupos, foram obtidos os reciprocos das médias ajustadas dos caracteres cuja seleção é para buscar os menores valores, sem alterar o número dos grupos. Isto foi feito para os caracteres U, FLO, AP, AE e PAQ, pois estes são caracteres para os quais a seleção visa os menores valores. Como regra geral, adota-se que os caracteres que devem ser aumentados sejam usados na unidade original, enquanto que, para aqueles cujos valores devem ser reduzidos, empregam-se os recíprocos. Os resultados encontram-se nas Tabelas 18 e 19.

\section{b) Definição dos níveis mínimos aceitáveis $\left(N_{i}\right)$ para cada caráter}

Estes níveis para descarte, citados no item Materiais e Métodos, foram fixados arbritariamente, apenas como exemplo, normalmente baseando-se na média do experimento, já que não havia a presença de testemunhas nos ensaios. Vale lembrar que eles podern ser fixados de acordo com a real necessidade do pesquisador. $O$ uso de testemunhas comerciais pode auxiliar muito na escolha de tais níveis, bastando verificar se o material selecionado não apresenta valores significativamente diferentes dos materiais normalmente cultivados, para caracteres de interesse. 
Para o caráter PE, assumiu-se que os genótipos selecionados devem, no mínimo, ter produção estatisticamente igual à média do experimento. Para o Índice 1, como a média pertence ao grupo 3 , tomou-se $N_{i}$ como sendo a média do grupo 3 , de modo que $N_{i}=7.669$. Para o Índice 2, a média também pertence ao grupo 3, mas, no caso, por ter número diferente de grupos, $N_{i}=8.225$. Estes valores de $N_{i}$ estão expressos em unidades de desvio padrão, em função da transformação que foi realizada.

Com relação ao caráter $1 / U$, não se assumiu nenhum valor como referência para descarte e, deste modo, para o Índice 1, adotou-se a média do menor grupo (4, no caso), resultando $N_{i}=0,0576$. Para o Índice 2 , também se usou a média do menor grupo (2), com $N_{i}=0,0630$.

Para o caráter FLO, optou-se por selecionar apenas os genótipos com ciclo estatisticamente igual ou inferior à média do experimento. Usando 1/FLO e sabendo que para os Índices 1 e 2 as médias do experimento estão no grupo 2, tem-se que $N_{i}=0,0170$, igual para os dois índices, já que os grupos formados são os mesmos. Com respeito ao caráter AP, deseja-se descartar os genótipos com porte superior à média do experimento. Usando 1/AP, verificou-se que a média está no grupo 2 para os dois Índices, ambos com $N_{i}=0,0050$. 0 descarte para o caráter $A E$ foi tomado de forma que não fossem selecionados genótipos com altura superior à média experimental, localizada no grupo 2 para ambos Índices (1/AE), com valores coincidentes: $N_{i}=0,0097$. O mesmo procedimento foi usado para o caráter PROL, cujas médias se localizaram no grupo 4 nos dois casos, com $N_{i}=1,04$ para o Índice $1 \mathrm{e}$ $N_{i}=1,02$ para o Índice 2 . Novamente, o mesmo procedimento foi aplicado para o caráter PAQ (1/PAQ), com média no grupo 2 para os Índice 1 e 2 , com mesmo valor, pois formaram os mesmos grupos: $N_{i}=0,4865$. Para o ceficiente de regressão $b$, atribuiu-se que ele deve ser no mínimo igual a $0,80, \operatorname{logo}, N_{i}=0,80$. Finalmente, adotou-se valores de $\mathrm{R}^{2}$ no mínimo iguais à média do experimento, ou seja, $N_{i}=0,8639$, nos dois índices. 


\section{c) Transfomação dos dados}

Após o emprego dos recíprocos e a definição dos $N_{i}$ 's, foram calculados os valores do desvio padrão de cada caráter $\left(s_{i}\right)$, que obviamente são iguais nos dois índiœes, resultando: $s_{P E}=535,843, s_{1 / U}=0,00242, s_{1 / F L O}=0,000248, s_{1 / A P}=0,000183$, $s_{1 / A E}=0,000577, s_{P R O}=0,0415, s_{1 / C D}=0,119, s_{b}=0,158$ e $s_{R 2}=0,075$.

As médias fenotípicas $\left(P_{i}\right)$ de cada caráter $i$ (ou seu recíproco) foram então transformadas de acordo com a seguinte expressão:

$$
P_{i}^{\prime}=\frac{P_{i}-N_{i}}{s_{i}} \text {, sendo }
$$

$P_{i}^{\prime}=$ média transformada do caráter $i$;

$P_{i}=$ média original para o caráter $i$ (ou seu recíproco);

$N_{i}=$ nível mínimo de desempenho exigido para o caráter $i$;

$s_{i}=$ desvio padrão do caráter $i$.

Um ponto importante a ser ressaltado é que tal transformação não foi aplicada a cada média individual, mas sim às médias dos respectivos grupos. Assim, todos híbridos do mesmo grupo no teste de Scott \& Knott (1974) apresentaram mesmo valor após a transformação, conforme observado nas Tabelas 20 e 21 . Esta é uma grande diferença deste índice com relação aos demais, pois, após a aplicação do teste, médias iguais terão valores iguais (média do grupo) e, conseqüentemente, mesma importância no momento da classificação dos genótipos. Teoricamente, dois genótipos cujas médias fenotípicas estejam no mesmo grupo para todos os caracteres, são estatisticamente iguais, devendo apresentar mesma classificação após o emprego do índice. Isso dá ao melhorista a garantia de que os genótipos com classificą̧̃o diferente devem ter pelo menos um caráter em que sejam diferentes, evitando assim os problemas apresentados pelos outros índices.

Após tal transformação, muito semelhante à estandardização, é possível saber quais genótipos devem ser descartados em função dos níveis mínimos adotados, bastando para isso examinar quais caracteres transformados apresentaram valores negativos, não atendendo então às exigências mínimas de desempenho do respectivo caráter. Isto pode ser visualizado 
para diversos caracteres nas Tabelas 20 e 21, sendo muito simples para o melhorista identificar um genótipo que deve ser descartado, além de identificar a causa de tal ato, ou seja, valores negativos indicando que o genótipo está fora da exigência comercial para dada característica.

O que motivou a escolha desta transformação foi que, na verdade, ao se subtrair os mesmos valores de $N_{i}$ de todos os genótipos, para o caráter $i$, está se efetuando uma translação de eixos, fazendo com que os genótipos que tenham desempenho superior às exigências mínimas, localizem-se no $1^{\circ}$ quadrante do plano cartesiano. Como a translação não altera a distância eudidiana média entre os genótipos e o ideótipo, basta verificar quais genótipos não estão no $1^{\circ}$ quadrante, para então descartá-los. Obviamente, tal representação gráfica não é possível, por se tratar do espaço n-dimensional (exceto se a seleção for, no máximo, para três caracteres).

\section{d) Definição do ideótipo}

O ideótipo é o genótipo formado pelos melhores valores apresentados para todas as variáveis avaliadas. Desta forma, apresenta os maiores valores de PE, PROL e $R^{2}$ e os menores de $U, \mathrm{FLO}, \mathrm{AP}, \mathrm{AE}$ e PAQ. Além disso, tem também $b=1,0$ (ampla adaptabilidade). Pela realização do teste de agrupamento de médias de Scott \& Knott (1974), cada valor das variáveis do ideótipo está localizado dentro de algum grupo homogêneo. Assim, optou-se por usar para formar o ideótipo as médias dos grupos que contêm os melhores valores. Como os agrupamentos tiveram resultados diferentes para os Índices 1 e 2, os ideótipos também diferiram.

Para o Índice 1, cujo agrupamento para os caracteres foi apresentado na Tabela 16, tem-se que o ideótipo foi formado pela média dos genótipos do grupo 1 para todos os caracteres, pois estes são os grupos que contém a melhor média, seja ela a maior, como no caso de PE e PROL, ou a menor, como para U, FLO, AP, AE e PAQ. O ideótipo apresentou então os seguintes valores (médias do grupo 1): $9195 \mathrm{~kg} / \mathrm{ha}$ para $P E, 14,9 \%$ para $U, 57,3$ dias para FLO, 196 cm para AP, 97 cm para AE, 1,22 para PROL e 1,55 para PAQ transformadas por

$\sqrt{x+0,5}$ (correspondendo a $1,90 \%$ na unidade original), além de $b=1,0$ e $\mathrm{R}^{2}=0,9739$ (maior valor).

O mesmo ocorreu para o Índice 2, com agrupamento de médias apresentado na Tabela 17. O ideótipo também foi constituído pelas médias do grupo 1 , que contém os 
melhores valores para todos os caracteres, como no caso anterior. Uma vez que neste índice os agrupamentos mostroram diferenças em relação ao Índice 1, o ideótipo também apresentou diferenças: $9531 \mathrm{~kg} / \mathrm{ha}$ para PE, 14,9\% para U, 57,3 dias para FLO, $196 \mathrm{~cm}$ para AP, $97 \mathrm{~cm}$ para AE, 1,22 para PROL e 1,55 para PAQ (1,90\% na unidade original), além de $b=1,0$ e $R^{2}=0,9739$ (maior valor).

Essa forma de apresentar o ideótipo facilita o entendimento de sua definição. Ocorre porém que, nesta fase do cálculo do índice, diversos cálculos já foram realizados, como o agrupamento das médias, a obtenção de recíprocos e a transformação dos dados. Desse modo, fica mais fácil definir o ideótipo a ser efetivamente usado na obtenção do índice de seleção, empregando-se os dados já transformados. Usou-se então nos cálculos o ideótipo definido como sendo aquele genótipo formado sempre pela média do maior grupo, para as todas as variáveis, já que após as transformaçoes e obtenção dos recíprocos, tem-se a garantia de que os valores de interesse estão sempre nos grupos com as maiores médias, pois trabalhase com as variáveis $\mathrm{PE}, 1 / \mathrm{U}, 1 / \mathrm{FLO}, 1 / \mathrm{AP}, 1 / \mathrm{AE}$, PROL e 1/PAQ. Fica claro porque foram obtidos os recíprocos dos caracteres cuja seleção é feita para diminui-los: o ideótipo pode ser definido como sendo a média do maior grupo, encontrado para cada variável, após as transformações, independente do caráter considerado. A única exceção é feita para os caracteres que, a exemplo do parâmetro $b$, tenham como objetivo da seleção valores espećíicos (no caso, $b=1,0)$.

Assim sendo, os valores do ideótipo efetivamente usados para as variáveis $P E$, 1/U, 1/FLO, 1/AP, 1/AE, PROL e 1/PAQ, respectivamente, foram: 2,848; 4,229; 1,656; 0,703; 1,103; 4,410 e 1,389, para o Índice 1, e 2,438; 1,837; 1,656; 0,703; 1,103; 4,723 e 1,389 para o Índice 2. Estas são as médias dos grupos que apresentam os maiores valores, após a obtenção dos rećprocos e transformação dos dados, podendo ser obtidos diretamente como a média do grupo 1 para os resultados encontrados nas Tabelas 20 e 21, para os índices 1 e 2, respectivamente. As diferenças que ocorreram entre os valores transformados e aqueles nas unidades originais se devem as diferenças ocorridas no agrupamento de Scott \& Knott (1974). Por exemplo, o caráter $U$ teve mesmo valor do ideótipo na unidade original para os dois índices, mas apresentou diferenças no ideótipo transformado, graças ao diferente número de grupos formados nos dois índices (Tabelas 16 e 17). Os ideótipos também são diferentes para os dois índices em função do agrupamento. Para as variáveis $b$ e $R^{2}$, o ideótipo transformado apresentou valores de 1,000 e 1,458, respectivamente, igual nos dois índices já que estes 
parâmetros não foram agrupados. Vale ressaltar que todos esses valores do ideótipo apresentados, e que foram efetivamente usados nos cálculos do índice, estão expressos em unidades de desvio padrão, devida à transformação aplicada.

\section{e) Cálculo das distâncias euclidianas médias em relação ao ideótipo}

As distâncias euclidianas médias, calculadas entre cada híbrido e o ideótipo, têm valores apresentados nas Tabelas 22 e 23 para os Índices 1 e 2, respectivamente. Não foi aplicado nenhum tipo de ponderação na expressão da distância, sendo que a influência da unidade das observações foi eliminada pela transformação dos dados.

Observa-se que se dispõe agora de um critério, baseado num único valor, para classificar os genótipos em ordem de interesse: os mais próximos do ideótipo são aqueles que devem ser selecionados e recomendados para plantio comercial e/ou instalação de experimentos com menor número de tratamentos e maior número de repetições e ambientes, e, conseqüentemente, maior precisão experimental.

Verifica-se ainda que é fácil notar quais são os caracteres que estão abaixo dos níveis mínimos de desempenho exigidos, fixados pelo pesquisador. Para tanto, basta observar quais os genótipos que apresentam valores negativos, o que significa que, para tais variáveis, não pertencem ao primeiro quadrante, devendo então ser descartados.

\section{f) Classificação e seleção dos genótipos superiores}

Nas Tabelas 24 e 25 tem-se a classificação final dos 49 híbridos, após o emprego dos Índices 1 e 2, respectivamente. Efetua-se, para cada índice, a classificação em ordem decrescente, usando para tanto a distância eudidiana média. É claro que os valores apresentados para a distância euclidiana média para um determinado híbrido, no Índice 1, são diferentes daquela apresentada para o mesmo híbrido no Índice 2 , já que os agrupamentos são diferentes, assim como os ideótipos. Para facilitar a interpretação e o uso do índice pelo melhorista, os valores transformados foram substituídos pelos dados em suas unidades originais, mesmo para PAQ, em \%, sem transformação. Foram colocados em negrito aqueles que, transformados, apresentaram valores negativos, devendo ser descartados. Fica muito simples para o melhorista determinar, então, quem são os melhores genótipos, que devem ser recomendados como cultivares. Os valores do índice para a seleção de cultivares no caso 1 variou de 1,505 a 2,902 (Tabela 24) e de 1,645 a 2,857, no caso 2 (Tabela 25) 
O Índice 1 classificou em primeiro lugar o híbrido HD 9563, que apresentou PE pertencente ao $3^{\circ}$ grupo, $U$ do $1^{\circ}$ grupo, FLO, AP, AE, PROL e PAQ no $2^{\circ}$ grupo, $b$ com valor 1,00 e $R^{2}=0,91$, bem elevado. Isto mostro que este material, para o conjunto de seus atributos, é o mais próximo do ideótipo dentre os 49 tratamentos. Contudo, dificilmente os melhoristas o recomendariam como sendo o melhor material do conjunto, porque sua produtividade não é suficientemente elevada. Verifica-se que o segundo colocado é ligeiramente inferior para $U$, $\mathrm{PROL}, b$ e $\mathrm{R}^{2}$, mas mostra superioridade para $\mathrm{PE}$, que é o caráter mais importante, além de FLO, AE e PAQ, com agrupamento idêntico para AP. De forma geral, pode-se notar que o conjunto de genótipos superiores é aquele que tem melhores valores para o conjunto geral de caracteres, sendo que alguns deles, mesmo que bem posicionados, devem ser descartados, como é o caso do $4^{\circ}$ colocado, $Z$ 8452, que apresentou $R^{2}$ abaixo da média do experimento (valor em negrito). Outros exemplos: híbrido C $435 \mathrm{G}$, com AP estatisticamente acima da média do experimento; o híbrido $\mathrm{G} 167 \mathrm{~S}$, com $\mathrm{R}^{2}$ também abaixo da média do experimento.

Uma observação cuidadosa da classificação dos híbridos com os níveis de probabilidade adotados pelo Índice 1 permite verificar que ocorreram alguns problemas. Os híbridos C 505 B e C 505 C, com PE pertencente ao $1^{\circ}$ grupo, classificaram-se apenas em $28^{\circ}$ e $44^{\circ}$ lugares, respectivamente, o que não seria aceito pelos melhoristas. Pela importância deste caráter, mesmo que tais híbridos sejam descartados por valores inferiores nos outros caracteres, o melhorista deve ter ciência da causa de tal descarte, não podendo os mesmos apresentarem posições inferiores que sequer deêm ao melhorista a oportunidade de melhor observá-los. Isso ocorreu porque, propositalmente, não se fixaram adequadamente os níveis de probabilidade no momento do teste de agrupamento das médias. Caracteres mais importantes, como PE, devem formar mais grupos, e assim participar com maior peso na classificação final; o que acontece fixando-se os níveis de probabilidade em valores estatisticamente aceitáveis, mas não tão rigorosos, como ocorreu no Índice 1, com 0,01 para PE, exigindo que as diferenças entre os grupos sejam muito grandes para aceitá-las como significativas.

Ao se atribuir menor rigor para caracteres como U $(0,10)$, PROL $(0,07)$, FLO, AP, AE (todos com 0,05), criou-se uma situação parecida com aquela existente na seleção recorrente, com o agravante de se estar dando menor peso justamente ao caráter mais importante ( $P E$, no caso). Numa situação extrema, onde se permitisse que o nível de probabilidade exigido fosse tão pequeno que cada genótipo formasse um grupo individual, teríamos uma simples repetição do índice de distância ao ideótipo, já amplamente discutido como adequado apenas à seleção recorrente e não a de cultivares. 
Essa diferença nos níveis de significância influi no número de grupos formados e, pela observação da expressão usada no cálculo da distância eudidiana média, verifica-se que os caracteres com maior número de grupos são os que mais influem no cálculo do índice. Assim, 0 melhorista deve observar a amplitude dos dados antes de fixar os níveis de probabilidade. Isto pode ser facilmente conseguido no momento da análise de variância e obtenção das médias ajustadas. Para cada espécie e caracteres considerados, os níveis de significância devem ser escolhidos com cautela pelo melhorista. Como regra geral, os caracteres de maior importância devem aceitar menor precisão, de forma a permitir a formação de mais grupos. Já para os caracteres com menor amplitude de variação e menor importância econômica, deve-se elevar o nível de significância, de forma a permitir a formação de poucos grupos e exercer menor influência na classificação dos genótipos.

No exemplo, tem-se que o caráter PE apresentou uma amplitude de variação de $2.688 \mathrm{~kg} / \mathrm{ha}$ (Tabela 8), o que é um valor considerável. Deste modo, deseja-se que para tal caráter ocorra a formação de vários grupos, sem contudo ultrapassar níveis já normalmente fixados em testes estatísticos. Desse modo, optou-se pelo nível 0,05 para o Índice 2, ao invés de 0,01 , como para o Índice 1 . Com mais grupos, e em função da amplitude que a variável mostrou, atribuiu-se então maior peso a ela.

Para o caráter $U$, cuja amplitude de variação foi de apenas 3,2 \% (Tabela 8), verifica-se claramente que esta faixa de variação é muito pequena, devendo o caráter ter alguma importância na classificação dos híbridos apenas se as diferenças forem realmente muito grandes. Para tanto, fixou-se para o Índice 20 nível 0,001, muito rigoroso, mas satisfatório, já que a amplitude de variação tem pouca importância prática e se deseja que sejam formados grupos apenas quando as diferenças entre as médias forem realmente grandes. O mesmo pode ser dito a respeito do caráter FLOR, com amplitude de apenas 3,8 dias, que também não acarreta grandes diferenças na prática. Deste modo, também se exigiu elevado rigor na formação de grupos, com nível 0,001 para o Índice 2.

Os caracteres AP e AE mostraram amplitudes de 40 e 36 centímetros, respectivamente (Tabela 8 ), sendo estes níveis de variação intermediários, que já devem ser considerados na seleção. Uma variação no porte de grande magnitude pode ocasionar alterações no acamento, dificuldades na colheita, etc, sendo necessário então fixar níveis não tão rigorosos para que estes caracteres tenham razoável influência no índice, contudo menor que aquela para o caráter PE. Deste modo, fixaram-se os níveis de 0,01 para ambos caracteres, permitindo boa participação deles no Índice 2, mas menor que aquela de PE. 
Para o caráter PROL, a amplitude de variação foi de apenas 0,24 unidades, também de pequena magnitude (Tabela 8). Como na prática alterações desta ordem pouco significam, exigiu-se que os grupos se formassem apenas devido a grandes diferenças, o que foi conseguido adotando-se o nível de 0,001 para o Índice 2. Finalmente, para PAQ, a amplitude nos dados originais foi de $11,6 \%$, valor este que pode acarretar grandes consequêências na classificação dos genótipos. Assim, fixou-se o nível de 0,01 no Índice 2, dando grande importância ao caráter, porém, sem tomá-lo mais importante que PE.

Vale ressaltar neste ponto que a fixação dos níveis de significância usados para a formação dos grupos é de extrema importância para a correta dassificação dos genótipos para o conjunto de caracteres. O melhorista deve atentamente observar as amplitudes de variação que ocorreram entre as médias a serem selecionadas e permitir uma formação de um número pequeno de grupos para os caracteres cuja faixa de variação são pouco representativas; os caracteres de importância intermediária exigem níveis de probabilidade que identifiquem razoável número de grupos e, finalmente, deve-se fixar o nível do caráter mais importante de modo a permitir muitos grupos, sem contudo desrespeitar os níveis de probabilidade comumente usados nos testes estatísticos, como foi feito para PE $(0,05)$. Sempre que possível, os caracteres devem ter as médias testadas; embora isso não tenha sido feito para $b$ e $\mathrm{R}^{2}$, estes parâmetros foram induídos porque é muito importante que o melhorista conheça a estabilidade e adaptabilidade dos genótipos. É evidente que um bom conhecimento do melhorista da espécie e dos caracteres em questão pode facilitar na escolha das probabilidades adequadas.

Uma vez que os níveis para formação dos grupos foi corretamente fixado para o Índice 2, nota-se que, dentre os onze materiais melhores colocados, encontram-se aqueles com PE somente dos grupos 1, 2, 3 e 4 (Tabela 25). Essa situação reflete a importância que foi dada à $P E$, pois no grupo escolhido (11 genótipos) apenas um deles estava num grupo estatisticamente acima da média (4, no caso) e nenhum genótipo dos grupos 1 ou 2 está fora desta faixa selecionada. Tal fato garante ao melhorista que, ao escolher um grupo de genótipos, com certeza os materiais mais produtivos estarão nele contidos.

O híbrido classificado em primeiro lugar apresentou PE do grupo 4, que, por ser estatisticamente inferior a média do experimento, deve ser descartado (negrito na Tabela 25). Esta é uma garantia de que materiais com baixa produção não sejam escolhidos, mas com total 
conhecimento do pesquisador do que ocorreu. Este material, HD 9563, tem valores favoráveis para a maioria de seus atributos, exceto para PE, o que causou seu bom posicionamento.

Com respeito ao próximo híbrido, $Z$ 8452, nota-se que ele tem produção pertencente ao $2^{\circ}$ grupo, o que pode levar o melhorista a recomendá-lo. Observando porém os demais caracteres, verifica-se que 0 valor de $R^{2}$ está abaixo da média do experimento (Tabela 25). Porém, como este valor não foi testado, e ainda assim é aceitável, o melhorista pode optar ou não pela sua recomendação, julgando se aceita ou não tal valor.

Fica claro que este novo índice funciona interativamente: ele classifica os materiais, dando maior peso aos caracteres de interesse, e avisa ao melhorista quando algum atributo não está dentro dos níveis mínimos exigidos, cabendo a ele julgar se a recomendação de cultivo pode ou não ser feita, como no caso do híbrido $Z$ 8452, que muito provavelmente seria recomendado. Na terceira posição encontra-se o híbrido Z 84 E 98, do $3^{\circ}$ grupo para PE, e com bons valores para todos os caracteres, podendo ter cultivo recomendado. $O$ mesmo ocorre com o quarto colocado, XL 345. Já para o quinto colocado, o híbrido C 435 G, o caráter AP está estatisticamente acima do nível mínimo fixado para tal caráter. Caberá ao melhorista decidir se a altura de 209 cm inviabiliza ou não sua recomendação. Os demais atributos mostram bons valores.

O próximo híbrido classificado, C 625, tem bons valores para todos os caracteres, podendo ser recomendado. Porém, para o sétimo colocado, AGX 5542, o caráter PAQ está estatisticamente superior à média do experimento. Como tal valor é elevado e este caráter muito importante, provavelmente não seria liberado como cultivar. Na oitava colocação ficou o híbrido G 167 S, que mostrou bons valores para todos caracteres, exceto para $R^{2}$, que apresentou valor abaixo da média do experimento, podendo ou não ser selecionado pelo melhorista. Em nono lugar tem-se o híbrido C $505 \mathrm{~B}$, que, embora esteja no $2^{\circ}$ grupo para $\mathrm{PE}$, teve o descarte sugerido em função dos valores diferentes dos níveis mínimos para AP, AE e PAQ; o melhorista pode até selecioná-lo, mas sabendo que ele tem um comportamento diferente do desejado para tais características.

Em décimo lugar colocou-se o híbrido DINA 1000, que apesar de estar no $3^{\circ}$ grupo para produção, não infringiu nenhuma exigência comercial para cultivo. Finalmente, em seguida, temos o híbrido C 505 C, classificado isoladamente em $1^{\circ}$ lugar para PE. O que ocasionou esta posição sem grande destaque para ele foram as médias dos outros caracteres, nem sempre com bons valores. Além do mais, ele teve descarte recomendado para AP, AE e 
PAQ, e mostrou valor de $b$ muito acima do valor ideal, $b=1,39$, valor que caracteriza material muito exigente quanto as condições ambientais oncle deve ser cultivado. Novamente, com base neste grande conjunto de informações, o melhorista pode facilmente decidir se este material deve ser selecionado.

É possivel notar que, quando os níveis de probabilidade são adequadamente escolhidos, como é o caso do Índice 2, não haverá riscos dos materiais mais produtivos serem excluídos na classificação. Caberá ao melhorista julgar se eles devem ou não ser selecionados, mas com base em diversos subsídios oferecidos pelo índice. Deve-se ressaltar que os níveis mínimos de desempenho foram fixados com base na média do experimento, pela ausência de testemunhas comerciais; isto causa um excesso de rigor nas recomendações de descarte. É claro que a presença de pontos de referência mais objetivos facilitariam ainda mais a decisão de descartar ou não dados genótipos. De qualquer modo, a possibilidade de escolher à vontade tais níveis mínimos de desempenho é uma grande vantagem que este índice apresenta sobre os demais, que sequer consideram tal fato.

\subsubsection{Comparação com os índices não lineares}

O índice para a seleção de cultivares 1 , com os níveis inadequados de probabilidade no teste de agrupamento, mostrou uma baixa correlação com o índice de soma de classificação, $r=0,70$, indicando que eles levariam a diferentes dassificações dos genótipos. Os cinco primeiros híbridos classificados com o índice para a seleção de cultivares 1 foram HD 9563, Z 84 E 98, XL 345, Z 8452 e C 625; para o soma de dassificação, XL 345, C 625, Z 84 E 98, A 953 e AGX 5558, sendo apenas três deles em comum. Comparando-se o índice para a seleção de cultivares 1 com o índice multiplicativo, encontrou-se uma correlação $r=-0,81$ entre eles, sendo negativa por questões de escala. Os cinco primeiro dassificados com o índice multiplicativo foram XL 345, Z 84 E 98, Z 8452, C 625 e HD 9563, sendo os cinco coincidentes, mostrando que esta correlação tem, nesse caso, bom valor preditivo. A correlação entre o índice para a seleção de cultivares 1 e o índice de distância ao ideótipo foi $r=0,93$, ainda maior. Isso deve ter ocorrido em função do princípio básico envolvido no desenvolvimento desses dois índices ser basicamente o mesmo, que é a menor distância com relação a um genótipo ideal, contudo, considerando um agrupamento de médias no índice 1 . Os cinco primeiros classificados com o índice de distância ao ideótipo foram Z 84 E 98, HD 9563, Z 8452, XL 345 e AGX 5558, sendo quatro deles coincidentes, mostrando que a correlação tem alto valor preditivo, neste 
caso. Apesar de as correlações serem elevadas ( $r=0,70 ; r=-0,81$ e $r=0,93)$, os índices não lineares apresentam diversos problemas: a não realização de testes estatísticos entre as médias, a impossibilidade de identificar genótipos com desempenho diferente das exigências comerciais e a não ponderação dos caracteres. O exemplo utilizado pode não ter mostrado os defeitos dos índices não lineares, uma vez que se trata de um conjunto homogêneo de cultivares de milho do grupo precoce, já altamente selecionado pelas empresas mesmo antes da realização dos experimentos. É razoável supor que em experimentos com centenas de genótipos pré-comerciais sendo avaliados, a situação seria diferente, aumentando as diferenças entre os índices, mostrando com mais clareza as deficiências daqueles índices em relação ao proposto. 0 novo índice permite a inclusão de variáveis com seleção em níveis intermediários, como é o caso do parâmetro $b$, o que os índices multiplicativo e de soma de classificação impossibilitam. Permite ainda a realização de testes de comparação de médias, bem como identificar genótipos diferentes das exigências comerciais. Além disso, há possibilidade de facilmente atribuir maior peso aos caracteres mais importantes.

A correlação entre o índice para a seleção de cultivares 1 e 2 foi $r=0,92$, mostrando que este valor de correlação deve ser interpretado com muita cautela (Figura 11). Foi exaustivamente discutido que o índice 1 não foi adequado para a seleção de cultivares, principalmente por excluir do grupo de genótipos superiores materiais altamente produtivos, como o híbrido C 505 C ( $44^{\circ}$ colocado), que têm grande probabilidade de se tornarem cultivares. Tal fato não ocorreu com o índice 2, que classificou os genótipos adequadamente. Assim sendo, na situação de seleção de cultivares, a correlação entre os índices deve ser observada com muita cautela. Dentre os cinco primeiros colocados com o índice 1, HD 9563, Z 84 E 98, XL 345, Z 8452 e C 625, quatro deles também estavam entre os cinco primeiros colocados com o índice 2, mas nem por isso é possível concluir que os dois se prestem a seleção de cultivares. 
Comparaçoo entre os Índices para a seleçāo de cultivares 1 e 2 ( $r=0.92)$

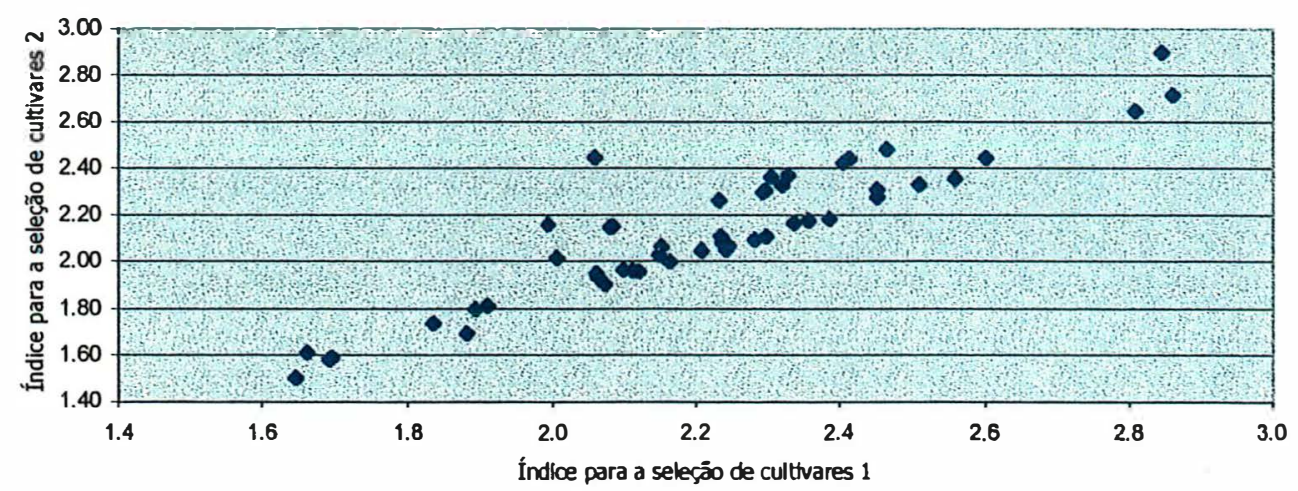

Figura 11. Correlação entre os índices para a seleção de cultivares 1 e 2.

Os cinco primeiros classificados com o índice para a seleção de cultivares 2 foram HD 9563, Z 8452, Z 84 E 98, XL 345 e C 435 G. A correlação deste índice com o de soma de classificação foi $r=0,75$, sendo que dentre esses cinco híbridos, apenas dois foram classificados entre os cinco primeiros com o soma de classificação, confirmando a baixa correlação. Comparando o índice 2 com o multiplicativo, encontrou-se uma correlação $r=-0,69$, negativa por questões de escala. Novamente, verificou-se baixa associação entre os índices, sendo que, entre os cinco primeiro colocados, quatro foram comuns. No entanto, o índice multiplicativo mostrou-se inadequado à seleção de cultivares, principalmente por não incluir apenas os materiais mais produtivos nas primeiras colocações; caso isso ocorresse com o novo índice, haveria sugestão de descartar os genótipos menos produtivos, o que é uma grande diferença entre eles. A correlação do índice 2 com o índice de distância ao ideótipo foi $r=0,89$ que, embora de grande magnitude, não possui alto valor preditivo, uma vez que o índice de distância ao ideótipo mostrou-se inadequado à seleção de cultivares; dentre os cinco primeiro colocados com os dois índices, quatro estavam nos dois grupos.

Cabe aqui uma consideração sobre o uso do coeficiente de correlação como forma de medir as semelhanças entre as classificações finais mostradas pelos índices. Muito embora, de forma geral, os valores encontrados sejam de grande magnitude, os índices soma de classificação, multiplicativo e de distância ao ideótipo não mostram nos resultados finais os genótipos que devam ser descartados por não atenderem as exigências mínimas. Já o índice 
para a seleção de cultivares, embora apresente os genótipos na classificação final, indicam qual(is) dele(s) deve(m) ser descartado(s), fornecendo uma importante contribuição para que o melhorista decida como proceder a seleção. Isso não é considerado no cálculo da correlação, que muitas vezes mostra valor alto, mas, ao se descontarem os genótipos abaixo das exigências mínimas, pode mostrar resultados completamente diferentes. Na seleção de cultivares, pouquíssimos genótipos são tomados, de forma que a correlação, mesmo que eventualmente alta, não serve para comparar adequadamente os índices.

\subsubsection{Considerações finais}

Uma vantagem que o índice para a seleção de cultivares apresenta é a possibilidade de o pesquisador poder incluir quaisquer caracteres ou parâmetros que desejar que sejam utilizados para dassificar os genótipos. Assim, se outros métodos de estabilidade fossem usados, como os modelos bi-segmentados, por exemplo, bastaria ao melhorista fixar qual valor será usado no ideótipo, e então proceder a classificação. O próprio uso de testemunhas pode auxiliar na montagem do ideótipo, mas deve-se tomar o cuidado de, sempre que possível, usar os melhores valores, e não médias de testemunhas. Isto decorre do fato que, usando médias de testemunhas corno ideótipo, ao menos teoricamente, materiais muito melhores que a testemunha podem até ser descartados, por apresentarem elevada distância em relação a essa média.

A escolha da distância euclidiana média como medida para classificar os genótipos tem a vantagem de permitir que a ausência eventual de alguma medida fenotípica não impeça que o índice seja calculado para o dado genótipo, bastando para isso ajustar o denominador da expressão da distância. Uma vantagem adicional é que sua interpretação é mais simples que a de outros tipos de distância, como a distância generalizada de Mahalanobis.

Um problema apresentado pela forma usada para identificar os níveis mínimos de desempenho exigidos é que não é possivel fixar faixas de variação, como seria desejável no caso para o caráter $b$ : estor entre 0,80 e 1,20, por exemplo; é possível identificar apenas os abaixo de 0,80, como foi feito, ou ainda, apenas os acima de 1,20. Isso ocorre devido a transformação proposta, onde um único valor mínimo é imposto a cada caráter. Contudo, uma simples observação dos dados permitiu verificar se algum dos genótipos selecionados excedeu a faixa escolhida, como foi o caso do híbrido C 505 C, com $b=1,39$, que, apesar de apresentar valor de $b$ superior a 1,20, não está em negrito (Tabela 25). 
O conjunto de procedimentos utilizado para cálculo do índice, embora numerosos e trabalhoso, pode ser facilmente conseguido com auxílio de algum programa computacional do tipo planilha eletrônica, que foi usada nesta tese. Espera-se que, por ter sido mostrada a validade do índice, no futuro, programas computacionais sejam desenvolvidos especificamente para tal finalidade.

Finalmente, deve-se ressaltar que o exemplo utilizado, com 49 genótipos, serviu apenas para ilustrar os cálculos e estudar como o índice classificou os genótipos Os materiais do Ensaio Nacional de Milho Precoce já são altamente selecionados, não representando um bom exemplo. Na prática, a quantidade de genótipos utilizada deve ser muito maior e os materiais devem apresentar maiores amplitudes de variação. 0 milho foi usado apenas como exemplo, mas o índice para a seleção de cultivares deve servir para qualquer espédie vegetal e qualquer tipo de genótipos, sejam eles clones, híbridos, linhagens endogâmicas, etc. Espera-se que tal índice possa auxiliar os melhoristas na escolha dentre dezenas ou até centenas de genótipos, de qualquer espécie vegetal, para efetuar a seleção de cultivares com o máximo de informaçães disponíveis e um mínimo de chance de erro. 


\section{CONCLUSÕES}

Nas condições do trabalho, as conclusões são as seguintes:

1) Nenhum índice de seleção disponível na literatura até o presente momento, seja ele linear ou não, pode ser utilizado para a seleção de cultivares.

2) O novo índice para a seleção de cultivares apresentado, se tiver níveis de probabilidade de significância para agrupamento das médias fenotípicas adequadamente fixados, pode ser extremamente útil para auxiliar o melhorista na seleção de cultivares, considerando vários caracteres simultaneamente. Tal índice permite facilmente o descarte de genótipos com desempenho inferior as exigências comerciais mínimas para a espécie em questão. 


\section{REFERÊNCIAS BIBLIOGRÁFICAS}

BAKER, R.J. Selection indices in plant breeding. Boca Raton: CRC Press, 1986. 218p.

BRIM, C.A.; JOHNSON, H.W.; COCKERHAM, C.C. Multiple selection criteria in soybeans. Agronomy Journal, v.51, p.42-46, 1959.

BUSSAB, W.O.; MIAZAKI, E.S.; ANDRADE, D.F. Introdução à análise de agrupamentos. In: SIMPÓSIO NACIONAL DE PROBABILIDADE E ESTATÍSTICA, 9., Anais. São Paulo: Associação Brasileira de Estatística, 1990. 105p.

CALDWELL, B.E.; WEBER, C.R. General, average and specific selection indices for yield in F4 and F5 soybean populations. Crop Science, v. 5, p.223-226, 1965.

COCHRAN, W.G.; COX, G.M. Experimental designs. New York: John Wiley, 1957. 617p.

CROSBIE, T.M.; MOCK, J.J.; SMITH, O.S. Comparison of gains predicted by several selection methods for cold tolerance traits of two maize populations. Crop Science, v.20, p.649$655,1980$.

CUNNINGHAM, E.P.; MOEN, R.A.; GJEDREM, T. Restriction of selection indexes. Biometrics, v.26, p.67-74, 1970.

DAVIS, J.H.C.; EVANS, A.M. Selection indices using plant type characteristics in navy beans (Phaseolus vulgaris L.). Journal of Agricultural Science, v.89, p.341-348, 1977.

DUNCAN, D.B. Multiple range and multiple F tests. Biometrics, v.11, p.1-42, 1955. 
DUNNETT, C.W. A multiple comparisons procedure for comparing several treatments with a control. Journal of American Statistician Association, v.50, p.1096-1121, 1955.

EAGLES, H.A.; FREY, K.J. Expected and actual gais in economic value of oat lines from five selection methods. Crop Science, v.14, p.861-864, 1974.

EBERHART, S.A.; RUSSELL, W.A. Stability parameters for comparing varieties. Crop Science, v.6, p.36-40, 1966.

EDWARDS, A.W.F.; CAVALLI-SFORZA, L.L. A method for cluster analysis. Biometrics, v.21, p.362-375, 1965.

ELGIN, J.H.; HILL JÚNIOR, R.R.; ZEIDERS, K.E. Comparison of four methods of multiple trait selection for five traits in alfafa. Crop Science, v.10, p.190-193, 1970.

ELSTON, R.C. A weight free index for the purpose of ranking of selection with respect to several traits at a time. Biometrics, v.19, p.85-97, 1963.

FINNEY, D.J. Genetic gains under three methods of selection. Genetical Research, v.3, p.417-423, 1962.

FISHER, R.A. On grouping for maximum homogeneity. Journal of American Statistician Association, v.53, p.789-798, 1958.

FISHER, R.A. The use of multiple measurements in taxonomic problems. Annals Eugenics, v.7, p.179-189, 1936.

GATES, C.E.; BILBRO, J.D. Ilustration of a cluster analysis method for mean separation. Agronomy Journal, v.70, p.462-465, 1978.

HANSON, W.D.; JOHNSON, H.W. Methods for correlation and evaluating a general selection index obtained by pooling information from two or more experiments. Genetics, v.42, p.421-432, 1957.

HAZEL, L.N. The genetic basis for constructing selection indices. Genetics, v.28, p.476-490, 1943.

HAZEL, L.N.; LUSH, J.L. The efficiency of three methods of selection. Journal of Heredity, v.33, p.393-399, 1942. 
HENDERSON, C.R. Selection index and expected genetic advances. In: HANSON, W.D.; ROBINSON, H.F. Statistical genetics and plant breeding. Washington: National Academy Science, 1963, p.141-163. (Natl. Res. Counc. Publ. 982).

JAMES, J.W. Index selection with restrictions. Biometrics, v.24, p.1015-1018, 1968.

KAUFFMAN, K.D.; DUDLEY, J.W. Selection indices for com grain yield, percent protein, and kemel weight. Crop Science, v.19, p.583-588, 1979.

KEMPTHORNE, O.; NORDSKOG, A.W. Restricted selection indices. Biometrics, v.15, p.10-19, 1959.

LAMKEY, K.R. Index Selection. Ames, 1989. 28 p. Monografia. Iowa State University.

MALLARD, J. La théorie et le calcul des index de seléction avec restrictions: synthèse critique. Biometrics, v.28, p.713-735, 1972.

MANLY, B.F.J. Multivariate statistical methods: a primer. 2.ed. London: Chapman \& Hall, 1994. 215p.

MOTTO, M.; PERENZIN, M. Index selection for grain yield and protein improvement in an opaque-2 synthetic maize population. Zeitschkift fur Pflanzenzuchtung, v.89, p.47-54, 1982.

MULAMBA, N.N.; MOCK, J.J. Improvement of yield potential of the Eto Blanco maize (Zea mays L.) population by breeding for plant traits. Egyptian Journal of Genetic and Cytology, v.7, p.40-51, 1978.

PESEK, J.; BAKER, R.J. Desired improvement in relation to selection indices. Canadian Journal of Plant Sciences, v.49, p.803-804, 1969.

RADWAN, S.R.; MOMTAZ, A. Evaluation of seven selection indices in flax (Linum usitatissimum L.). Egyptian Journal of Genetic and Cytology, v.4, p.153-160, 1975.

ROSIELLE, A.A.; FREY, K.J. Application of restricted selection indices for grain yield improvement in oats. Crop Science, v.15, p.544-547, 1975.

SAS INSTIUUE INC. Statistical Analysis System. Release 6.08, (software). Cary, 1992.

SCHEFFÉ, H. The analysis of variance. New York: John Wiley, 1959. 477p.

SCOTT, A.J.; KNOTT, M. A cluster analysis method for grouping means in the analysis of variance. Biometrics, v.30, p.507-512, 1974. 
SMITH, H.F. A discriminant function for plant selection. Annals Eugenics, v.7, p.240-250, 1936.

SMITH, O.S.; HALLAUER, A.R.; RUSSELL, W.A. Use of index selection in recurrent selection programs in maize. Euphytica, v.30, p.611-618, 1981.

St. MARTIN, S.K.; LOESCH JÚNIOR, P.J.; DEMOPULOS-RODRIGUEZ, J.T.; WISER, W.J. Selection indices for the improvement of opaque-2 maize. Crop Science, v.22, p.478$485,1982$.

STEEL, R.G.D.; TORRIE, J.H. Principles and procedures of statistics. New York: McGraw Hill Book Company, 1960. 481p.

SULLIVAN, J.G.; BLSS, F.A. Recurrent mass selection for increased seed yield and seed protein percentage in common bean (Phaseolus vulgaris L.) using a selection index. Journal of the American Society for Horticultural Science, v.108, p.42-46, 1983.

SUWANTARADON, K.; EBERHART, S.A.; MOCK, J.J.; OWENS, J.C.; GUTHRIE, W.D. Index selection for several agronomic traits in the BSSS2 maize population. Crop Science, v.15, p.827-833, 1975.

TAI, G.C.C. Index selection with desired gains. Crop Science, v.17, p.182-183, 1977.

TUKEY, J.W. Comparing individual means in the analysis of variance. Biometrics, v.5, p.99$114,1949$.

VENCOVSKY, R.; BARRIGA, P. Genética biométrica no fitomelhoramento. Ribeirão Preto: Sociedade Brasileira de Genética, 1992. 496p.

WILLIAMS, J.S. Some statistical properties of a genetic selection index. Biometrika, v.49, p.325-337, 1962b.

WILLIAMS, J.S. The evaluation of an selection index. Biometrics, v.18, p.375-393, 1962a.

WRICKE, G.; WEBER, W.E. Quantitative genetics and selection in plant breeding. New York: Walter de Gruyter, 1986. 406p.

YOUNG, S.S.Y. A further examination of the relative efficiency of three methods of selection for genetic gains under less restricted conditions. Genetic Research, v.2, p.106-121, 1961. 


\section{TABELAS}




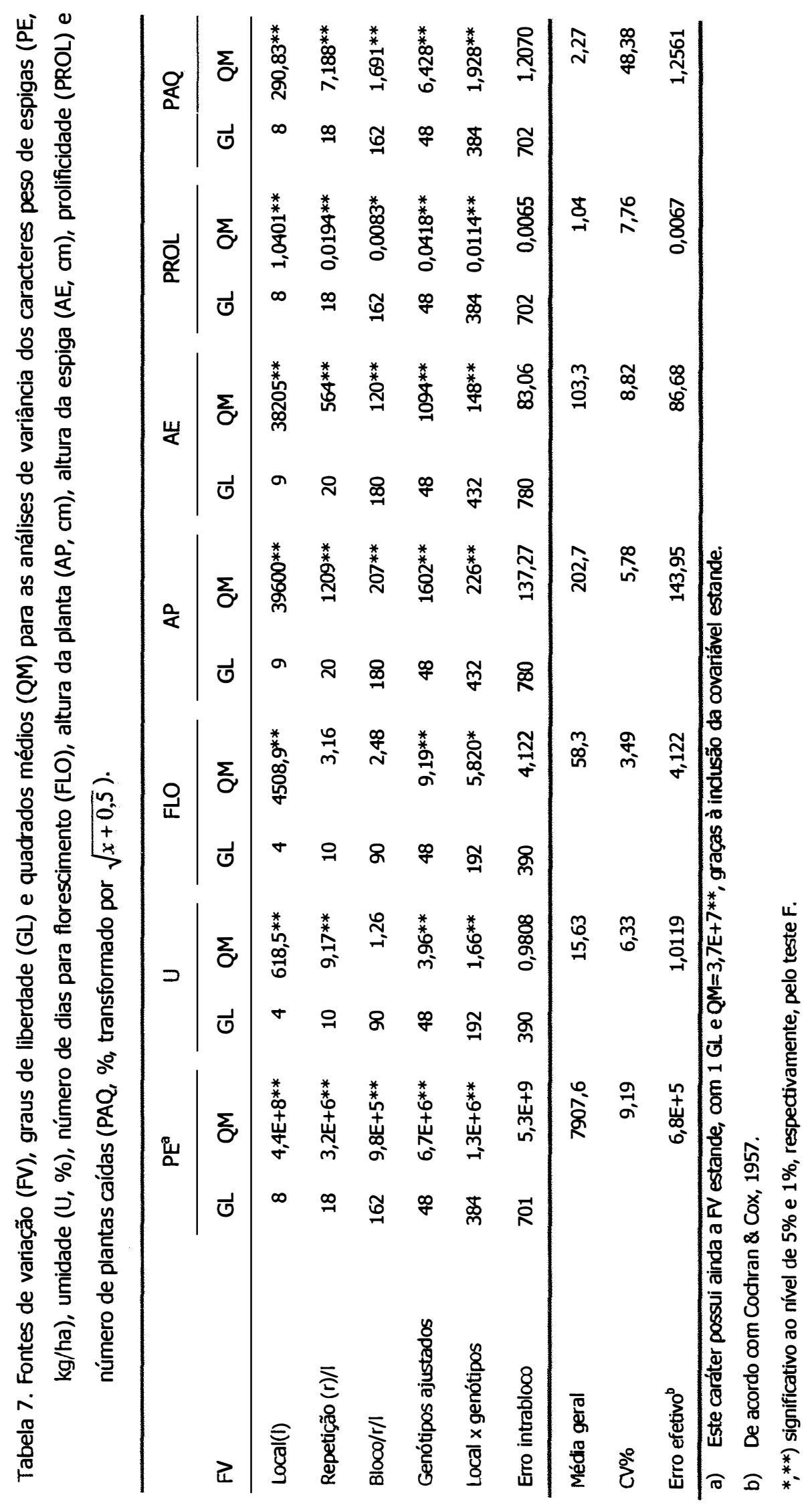


Tabela 8. Médias ajustadas para todos os caracteres avaliados dos 49 hibridos.

\begin{tabular}{|c|c|c|c|c|c|c|c|}
\hline HÍBRIDO & $\overline{P E}$ & $\mathbf{U}$ & FLO & AP & $\overline{A E}$ & PROL & PAQ \\
\hline 94 HT 31 QPM & 70585 & 1502 & 57,22 & 200,9 & 1017 & 105 & 2889 \\
\hline A 953 & $6.842,9$ & 14,51 & 56,87 & 198,0 & 100,4 & 1,06 & 1,458 \\
\hline AG 5014 & $7740 \%$ & 16,10 & 58,46 & 1969 & 1019 & 103 & 2799 \\
\hline AGROMEN 2003 & $8.321,3$ & 15,50 & 57,89 & 201,3 & 101,2 & 0,98 & 1,636 \\
\hline AGROMEN 2005 & 8.2527 & 15,89 & 58,63 & 2048 & 1061 & 1,02 & 2,289 \\
\hline AGROMEN 2007 & $8.240,1$ & 15,25 & 58,07 & 210,8 & 107,6 & 1,04 & 2,040 \\
\hline AGROMEN 2018 & 7649,2 & 1570 & 5703 & 197,4 & 102,7 & 1,03 & 2,372 \\
\hline AGX 2573 & $8.358,2$ & 15,68 & 58,40 & 205,7 & 101,5 & 1,03 & 2,344 \\
\hline AGX 5492 & 78201 & 1482 & 58,01 & 2049 & 1052 & 099 & 2290 \\
\hline AGX 5542 & $7.942,2$ & 15,67 & 58,71 & 196,5 & 100,5 & 1,06 & 2,624 \\
\hline AGX 5558 & $8,461,8$ & 1471 & 58,20 & 201,5 & 103,5 & 100 & 2867 \\
\hline AGX 5674 & $8.020,4$ & 15,71 & 58,24 & 194,9 & 97,9 & 1,02 & 2,949 \\
\hline A. $25 \times 11$ & 2430.5 & 1496 & 60,41 & 2187 & 117. & 1,04 & 3,463 . \\
\hline AS 3466 & $7.599,7$ & 16,01 & 58,04 & 189,6 & 96,5 & 1,03 & 1,944 \\
\hline C.435 & 79547 & 15,63 & 58,53 & 209,5 & 1095 & 105 & 2,253 \\
\hline C 435 G & $8.060,9$ & 15,64 & 58,07 & 209,3 & 105,6 & 1,06 & 1,574 \\
\hline c491W & 7518,5 & 1587 & 5804 & 2037 & 100,8 & 108 & 3,026 \\
\hline C $505 \mathrm{~B}$ & $9.056,6$ & 16,60 & 58,46 & 207,0 & 110,5 & 1,06 & 2,499 \\
\hline $\operatorname{cs} 05 \mathrm{c}$ & $9.531 \%$ & 17,36 & 5860 & 2120 & 110.5 & 107 & 2290 \\
\hline$C 625$ & $8.212,3$ & 15,86 & 57,63 & 196,6 & 95,4 & 1,02 & 1,593 \\
\hline $\cos 123$ & 836011 & 15,7 & 59,35 & 2047 & 1032 & 1,05 & 2071 \\
\hline $\mathrm{CO} 36$ & $7.325,7$ & 15,48 & 57,10 & 198,7 & 98,1 & 1,00 & 1,256 \\
\hline 002 & 7755,8 & 1577 & 57,76 & 2008 & 100, & 0,99 & 1921 \\
\hline $\mathrm{CO} 34$ & $7.380,9$ & 15,72 & 58,25 & 202,6 & 98,7 & 1,00 & 1,666 \\
\hline ETN 1000 & 81296 & 1658 & 58,88 & 188 & 1042 & 104 & 1789 \\
\hline DINA 270 & $8.164,2$ & 14,99 & 59,85 & 229,9 & 126,6 & 1,00 & 2,347 \\
\hline DINA 657 & $8,155,4$ & $16: 00$ & 58,8 & 199,6 & 1045 & 105 & 2,109 \\
\hline EXCELLER & $7.543,6$ & 15,85 & 58,74 & 209,9 & 105,1 & 1,05 & 2,243 \\
\hline T 10006 & 73828 & 15,04 & 58,37 & 1962 & 09,9 & 10 & 3,433 \\
\hline G $165 \$$ & $7.884,8$ & 14,71 & 58,76 & 197,4 & 102,9 & 1,04 & 2,064 \\
\hline G167S & $8.336,8$ & 1582 & 58,27 & 2033 & 103,2 & 107 & 1,594 \\
\hline G $176 \mathrm{~S}$ & $8.453,4$ & 16,05 & 57,63 & 192,6 & 95,9 & 1,00 & 2,778 \\
\hline HATA 3012 & 7506,5 & 16,13 & 5857 & 1955 & 951 & 1. 01 & 3,025 \\
\hline HD 9486 & $7.858,0$ & 15,55 & 59,08 & 210,9 & 106,8 & 1,04 & 2,459 \\
\hline HD. 95128 & 73899 & 14,63 & 58,51 & 198,2 & 99,5 & 1,11 & 2715 \\
\hline HD 9563 & $7.512,5$ & 15,04 & 58,62 & 202,3 & 100,9 & 1,13 & 2,032 \\
\hline 17951005 & 75709 & 14,88 & 60,46 & 198,5 & 1040 & 1,22 & 2,369 \\
\hline MASTER & $7.649,5$ & 16,26 & 57,81 & 206,8 & 112,7 & 1,08 & 2,054 \\
\hline P 3041 & 8555,6 & 1588 & 58.24 & 2077 & 1051 & $x, 05$ & 1,700 \\
\hline PL 320 & $7.334,6$ & 15,80 & 59,16 & 220,8 & 113,6 & 1,03 & 2,823 \\
\hline PL 322 & 7313,1 & 15,55 & 5735 & 2159 & 1136 & 102 & 2,166 \\
\hline$R \& G 01$ & $7.315,3$ & 15,96 & 59,12 & 197,1 & 101,6 & 1,03 & 2,601 \\
\hline$X L 345$ & 8.0963 & 15,61 & 56,67 & 1968 & 98,3 & 106 & 2,185 \\
\hline$X L 360$ & $8.140,9$ & 15,64 & 58,36 & 204,7 & 107,6 & 1,12 & 2,730 \\
\hline $264 \mathrm{E} 74$ & 8.0025 & 15,71 & 5675 & 1976 & $96 \%$ & 1,00 & 2,847 \\
\hline Z 84 E 90 & $7.429,5$ & 15,86 & 57,39 & 193,7 & 93,5 & 1,00 & 2,289 \\
\hline $284 E 98$ & 8.4571 & 16,17 & 5746 & 1990 & 98,4 & 1,06 & 1563 \\
\hline$Z 8440$ & $7.264,4$ & 15,26 & 56,91 & 192,5 & 91,2 & 1,00 & 2,522 \\
\hline$Z 8452$ & $8.998,0$ & 1569 & 58,88 & 2005 & 1028 & 1,07 & 11280 \\
\hline
\end{tabular}


Tabela 9. Médias ajustadas para PE (kg/ha) em cinco locais de avaliação.

\begin{tabular}{|c|c|c|c|c|c|}
\hline Híbrido & Atali & Brasil & Caleg & Capin & Goian \\
\hline 941 H 31 QPY & 70169 & $98690^{\circ}$ & 52833 & 50857 & 89077 \\
\hline A 953 & 6985,2 & 9801,7 & 4026,2 & 5789,3 & 7473,8 \\
\hline $\operatorname{Ag} 5014$ & $7751 / 4$ & 110583 & 53429 & 3976,2 & 91310 \\
\hline AGROMEN 2003 & 7905,5 & 10170,2 & 6481,0 & 6711,9 & 9500,0 \\
\hline GGROMEN2005 & 79890 & 1128,6 & 10690 & 6079,8 & 99018 \\
\hline AGROMEN 2007 & 8547,4 & 11614,8 & 6357,1 & 4763,1 & 9547,6 \\
\hline AGROMEN 2018 & 66486 & 10021,4 & 6052,4 & 5334 & 90690 \\
\hline AGX 2573 & 8133,3 & 10372,6 & 6164,3 & 5926,2 & 10257,1 \\
\hline AGX 5492 & 8263,3 & 10720,2 & 54476 & 4246,4 & 10650,0 \\
\hline AGX 5542 & 7825,0 & 11057,1 & 5323,8 & 3906,0 & 9485,7 \\
\hline AGX 558 & 88619 & 16845 & 54643 & 52095 & 110190 \\
\hline AGX 5674 & 7552,4 & 11248,8 & 6402,4 & 4202,4 & 9438,1 \\
\hline AL $25 \times 1$ & 71850 & 10148,8 & 52500 & $5917 \%$ & 87000 \\
\hline AS 3466 & 7790,5 & 10238,6 & 5819,0 & 5153,6 & 9700,0 \\
\hline C435. & 82250 & 100374 & 59167 & 51064 & 87524 \\
\hline $\mathrm{C} 435 \mathrm{G}$ & 7933,1 & 10420,7 & 5183,3 & 5032,1 & 9311,9 \\
\hline C $491 \mathrm{~W}$ & 77002 & $10764 \%$ & 4940,5 & 3848,8 & 95190 \\
\hline C $505 \mathrm{~B}$ & 8507,6 & 12103,8 & 6538,1 & 5235,7 & 11688,1 \\
\hline C505. & 91148 & 13088,3 & $6483 / 3$ & 55690 & 115190 \\
\hline C 625 & 8324,0 & 9986,9 & 6285,7 & 5685,7 & 10131,0 \\
\hline $\mathrm{CD} 1723$ & 78976 & 98286 & 58262 & $6960 \%$ & 98452 \\
\hline CO 36 & 6917,4 & 9216,7 & 5976,2 & 5567,9 & 7931,0 \\
\hline $\mathrm{CO}_{32}$ & 74057 & 98374 & 5481,6 & 57274 & 90952 \\
\hline $\mathrm{CO} 34$ & 7811,2 & 9907,6 & 5571,4 & 5791,7 & 8742,9 \\
\hline DINA 1000 & 35219 & 10923,8 & 62143 & 54190 & 98776 \\
\hline DINA 270 & 8013,6 & 11825,0 & 4995,2 & 6165,5 & 10395,2 \\
\hline DiNA 657 & 78000 & 10946,4 & 68071 & 5457, & 101452 \\
\hline EXCELLER & 7269,5 & 10187,1 & 5990,5 & 4958,3 & 8883,3 \\
\hline T 9006 & 76645 & 100643 & 55452 & 51369 & 7840,5 \\
\hline$G 165 \$$ & 7250,5 & 9490,7 & 5104,8 & 4920,2 & 10502,4 \\
\hline G $167 \mathrm{~S}$ & 17238,3 & 10414,9 & 50238 & 4708,3 & 9795,2 \\
\hline G $176 \mathrm{~S}$ & 8042,9 & 11144,0 & 5300,0 & 6247,6 & 10414,3 \\
\hline $197 A 3012$ & 7168,3 & 09202 & 8747,6 & 4608,3 & 8731,0 \\
\hline HD 9486 & 8160,2 & 9895,5 & 5095,2 & 4808,3 & 7928,6 \\
\hline 110951128 & $7352 \%$ & 9273,8 & 56857 & $6081 \%$ & 95119 \\
\hline HD 9563 & 8128,6 & 11154,0 & 4940,5 & 4951,2 & 8516,7 \\
\hline 117951005 & 8429,3 & 112040 & 55952 & 50524 & 98048 \\
\hline MASTER & 7895,7 & 10345,7 & 6021,4 & 4978,6 & 9254,8 \\
\hline P 3041 & 84057 & 116624 & 59048 & 605711 & 97262 \\
\hline PL 320 & 6528,6 & 10860,7 & 5047,6 & 2416,7 & 9726,2 \\
\hline $\mathrm{PL} 322$ & 75052 & 10402,4 & $4121 / 4$ & 3890,5 & 8678,6 \\
\hline$R \&$ G01 & 7098,3 & 9785,7 & 5302,4 & 4327,4 & 8790,5 \\
\hline $\mathrm{X}, 345$ & 81198 & 98179 & 6073,8 & 6278,6 & $9381 \%$ \\
\hline$X \mathrm{X} .360$ & 7841,7 & 10445,7 & 5519,0 & 6525,0 & 10747,6 \\
\hline $264 \mathrm{E} 74$ & 78126 & 110548 & 50095 & 6129,8 & 9614,3 \\
\hline$Z 84 E 90$ & 7404,3 & 10354,8 & 4264,3 & 5702,4 & 8997,6 \\
\hline $284 E 98$ & 69283 & 12143,1 & 56238 & 5240,5 & 103762 \\
\hline 28440 & 8178,3 & 10080,5 & 4926,2 & 5316,7 & 7542,9 \\
\hline 28452 & 85388 & 119548 & 62881 & 5574 & $10961 \%$ \\
\hline $\mathrm{CV} \%$ & 6,59 & 5,63 & 9,09 & 10,44 & 9,34 \\
\hline
\end{tabular}


Tabela 10. Médias ajustadas para PE (kg/ha) em quatro locais de avaliação.

\begin{tabular}{|c|c|c|c|c|}
\hline Híbrido & Rondo & Sgoes & Soore & Tang \\
\hline 94 1731 QRM & 42002 & 9788,1 & 64500 & 56667 \\
\hline A 953 & 5334,5 & 8544,0 & 6916,7 & 5685,0 \\
\hline$A G 5014$ & 95400 & 86476 & 6971,4 & 66274 \\
\hline AGROMEN 2003 & 9848,1 & 11742,9 & 7761,9 & 6150,7 \\
\hline AGROMEN 2005 & 77133 & 10303,6 & 7933,3 & 6493,3 \\
\hline AGROMEN 2007 & 5432,9 & 10804,8 & 7478,6 & 9289,8 \\
\hline$A G R O M E N 2018$ & 8030,5 & 89429 & 7657,1 & 8840,5 , \\
\hline AGX 2573 & 8322,9 & 10670,2 & 7616,7 & 8387,4 \\
\hline$A G X 5492$ & 5878,8 & 102095 & 78357 & 8183,8 \\
\hline AGX 5542 & 8762,1 & 9600,0 & 7164,3 & 8320,5 \\
\hline ACX 5558 & 9025,5 & 108643 & 17238 & 7668, \\
\hline AGX 5674 & 8804,3 & 8226,2 & 6811,9 & 9160,5 \\
\hline A. $25 \times 11$ & 58290 & 102643 & 66429 & $6352 \times 4$ \\
\hline AS 3466 & 8593,3 & 8277,4 & 6550,0 & 6514,5 \\
\hline$(435)$ & 84729 & 11333, & 68648 & 7342,4 \\
\hline $\mathrm{C} 435 \mathrm{G}$ & 9250,2 & 10889,3 & 7004,8 & 7806,2 \\
\hline C491W & 82372 & $8910 \%$ & 68976 & 64569 \\
\hline C 505 B & 10500,5 & 11294,0 & 8340,5 & 7657,6 \\
\hline C 505. & 8204,3 & 12884,5 & 88262 & 9891,0 \\
\hline$C 625$ & 8313,1 & 10711,9 & 8019,0 & 7773,8 \\
\hline CD 1723 & 55743 & 10958,3 & 7350,0 & 88112 \\
\hline $\mathrm{CO} 36$ & 6508,6 & 9863,1 & 6269,0 & 6698,6 \\
\hline$C 032$ & 71397 & 11833,3 & 63548 & 68529 \\
\hline $\mathrm{CO} 34$ & 6202,4 & 9139,3 & 6931,0 & 6396,2 \\
\hline DINA 1000 & 73816 & 9964,3 & 8338,1 & 1832,4 \\
\hline DINA 270 & 7600,0 & 10407,1 & 7302,4 & 6656,9 \\
\hline DINA 657 & 78876 & 90036 & $7900 \%$ & 7588,8 \\
\hline EXCELLER & 5955,8 & 9858,3 & 7738,1 & 6402,1 \\
\hline 179006 & 61786 & 9464,3 & 57381 & 78346 \\
\hline $\mathrm{G} 165 \$$ & 7812,4 & 9589,3 & 6931,0 & 9182,9 \\
\hline G 167 S & 8875,2 & 10515,5 & 90119 & 94581 \\
\hline G $176 \mathrm{~S}$ & 8837,4 & 10696,4 & 7783,3 & 8058,8 \\
\hline$M A T A 3012$ & 83350 & 11972,4 & 60810 & 6526,4 \\
\hline HD 9486 & 9119,5 & 11050,0 & 8092,9 & 6831,0 \\
\hline 40951128 & 7252,9 & 8589,3 & 69119 & 62948 \\
\hline HD 9563 & 7008,1 & 8725,0 & 6964,3 & 7248,6 \\
\hline $1 T 951005$ & 37976 & 9265.5 & 61976 & 80402 \\
\hline MASTER & 8826,7 & 8769,0 & 6807,1 & 6278,8 \\
\hline $\mathrm{P} 3041$ & 10178,6 & 102405 & 76000 & 84012 \\
\hline PL 320 & 6508,1 & 9764,3 & 7364,3 & 6522,4 \\
\hline PL 322 & 6415,2 & 96250 & 7040,5 & 64548 \\
\hline$R \&$ G01 & 7921,5 & 8848,8 & 6623,8 & 7362,4 \\
\hline $\mathrm{x}=345$ & 7611,5 & 10639,3 & $7207 / 1$ & 84007 \\
\hline$X L 360$ & 5732,9 & 11369,0 & 7369,0 & 7814,5 \\
\hline $264 \mathrm{Eq} 4$ & 7340,5 & 10428,6 & 8133,3 & 70507 \\
\hline 284 E 90 & 6699,7 & 9500,0 & 6990,5 & 6794,8 \\
\hline $284 \mathrm{Eg} 9$ & 8655,0 & $10076 / 2$ & 9019,0 & 83210 \\
\hline Z 8440 & 8221,0 & 8235,7 & 6604,8 & 6429,8 \\
\hline 28452 & 10112,4 & $10060 \%$ & 9545,2 & 8103,1 \\
\hline $\mathrm{CV} \%$ & 10,38 & 11,76 & 8,49 & 12,34 \\
\hline
\end{tabular}


Tabela 11. Hibridos e parâmetros de adaptabilidade $(b)$ e estabilidade $\left(R^{2}\right)$.

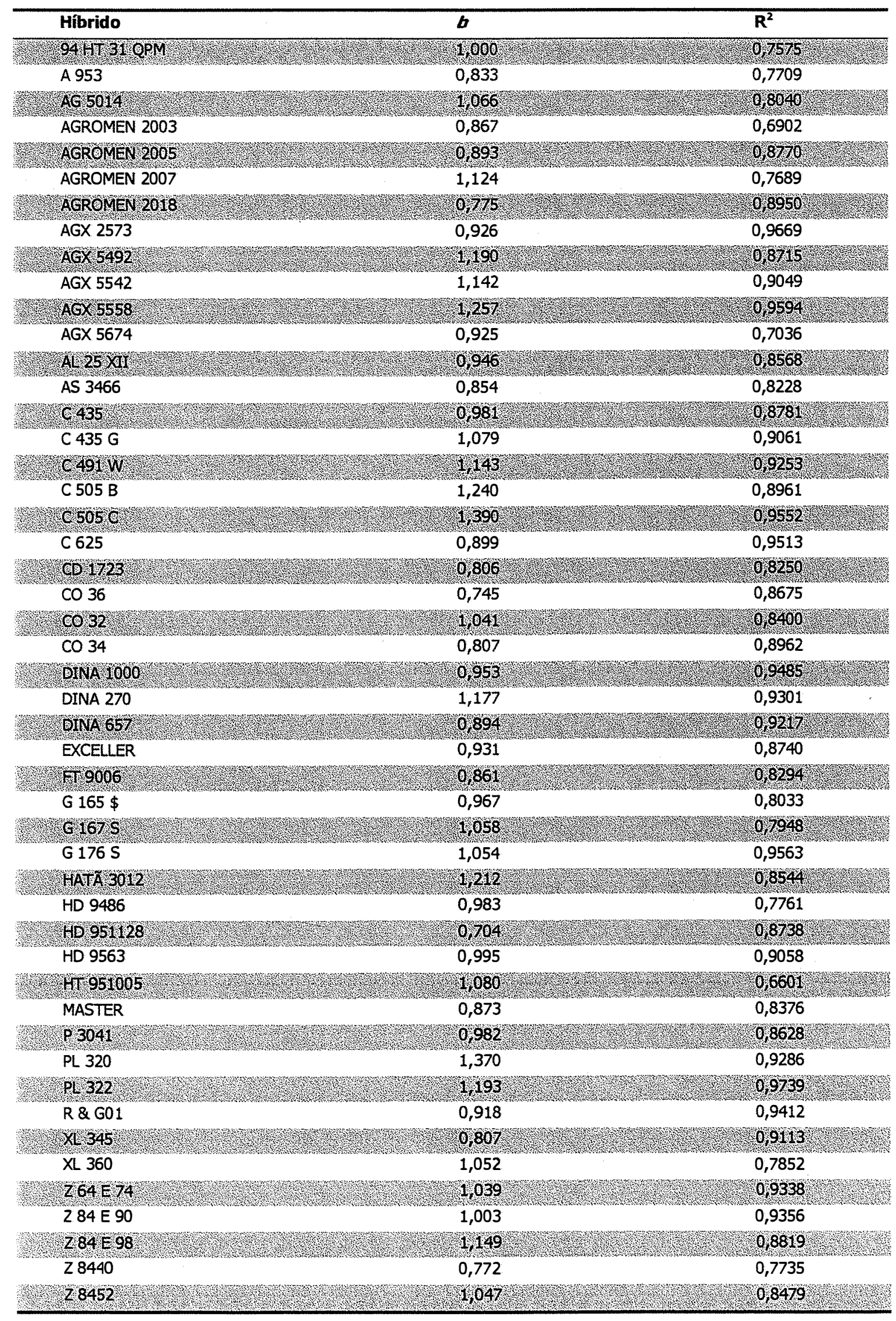


Tabela 12. Valores de $p_{i}^{\prime \prime}-k_{i}^{\prime \prime}$ e índice multiplicativo $\left(\mathrm{I}_{\mathrm{m}}\right)$.

\begin{tabular}{|c|c|c|c|c|c|c|c|c|c|c|}
\hline HÍBRIDO & PE & $\mathbf{U}$ & FLO & $\overline{\mathbf{A P}}$ & $\mathbf{A E}$ & $\overline{\text { PROL }}$ & PAQ & $\overline{R^{2}}$ & $I_{m}$ & \\
\hline$x<345$ & 14439 & 1506 & $1 / 25$ & 1,633 & 1616 & 4281 & 1,393 & 1638 & 2901 & \\
\hline $\mathrm{Z} 84 \mathrm{E} 98$ & 1,536 & 1,339 & 1,624 & 1,603 & 1,613 & 1,288 & 1,622 & 1,485 & 28,87 & 2 \\
\hline 28452 & 1649 & 1486 & 1,351 & 1,580 & 1,533 & 1,312 & $1 / 718$ & 1332 & 272 & 3 \\
\hline C 625 & 1,473 & 1,439 & 1,598 & 1,636 & 1,662 & 1,030 & 1,612 & 1,567 & 25,99 & 4 \\
\hline 10956 & S/ 197 & 1632 & 1143 & 1,55 & 1569 & 1546 & 1445 & 1594 & 2472 & 5 \\
\hline C $435 \mathrm{G}$ & 1,428 & 1,498 & 1,526 & 1,421 & 1,475 & 1,293 & 1,619 & 1,348 & 23,49 & 6 \\
\hline G 1675 & 1507 & 1,449 & 1,488 & 1,535 & 1525 & 1324 & 1612 & 468 & 1296 & 7 \\
\hline AGX 5558 & 1,537 & 1,693 & 1,502 & 1,564 & 1,519 & 1,076 & 1,314 & 1,709 & 22,44 & 8 \\
\hline 33041 & 1,567 & 428 & 1049 & 1455 & 4.486 & $1 / 245$ & 17575 & 462 & 22,22 & 9 \\
\hline$G 165 \$$ & 1,368 & 1,693 & 1,381 & 1,626 & 1,530 & 1,176 & 1,442 & 1,661 & 19,40 & 10 \\
\hline $61 N 65$ & $1+457$ & $1 / 394$ & 1.352 & 1,594 & 1499 & 1216 & 4 & 1439 & 1886 & 11 \\
\hline HD 951128 & 1,119 & 1,706 & 1,438 & 1,614 & 1,594 & 1,475 & 1,133 & 1,646 & 18,73 & 12 \\
\hline$A G X 5542$ & 1389 & 11489 & 1,393 & 1638 & 1456 & $1 \%$ & $1 / 185$ & 1,386 & 18,51 & 13 \\
\hline AGX 2573 & 1,512 & 1,487 & 1,461 & 1,493 & 1,559 & 1,060 & 1,325 & 1,357 & 18,42 & 14 \\
\hline AGROMEN & 1269 & 12483 & 1,682 & 1.625 & 1.535 & 1090 & 13312 & 437 & 18,30 & $t^{15}$ \\
\hline AS 3466 & 1,245 & 1,391 & 1,531 & 1,725 & 1,645 & 1,076 & 1,487 & 1,552 & 17,88 & 16 \\
\hline DINA 1000 & 1,450 & 161 & 1,349 & $1 \% 609$ & 1504 & 182 & 11562 & 1500 & 1720 & (17) \\
\hline$X L 360$ & 1,453 & 1,497 & 1,469 & 1,511 & 1,429 & 1,510 & 1,123 & 1,539 & 16,22 & 18 \\
\hline AGROMEN & 1,481 & 1589 & 1525 & 1,389 & 1430 & 1/ & 145 & 665 & 1615 & 19 \\
\hline CD 1723 & 1,512 & 1,474 & 1,202 & 1,511 & 1,515 & 1,202 & 1,439 & 1,623 & 15,82 & 20 \\
\hline C435 & 1,393 & 1,501 & 1,433 & 141 & 1382 & 1260 & 1364 & 1556 & 15,32 & 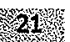 \\
\hline MASTER & 1,269 & 1,304 & 1,569 & 1,471 & 1,293 & 1,371 & 1,446 & 1,677 & 14,86 & 22 \\
\hline AGROMEN & 485 & 13428 & 1442 & 1508 & 1465 & 1005 & 10349 & 11623 & 1427 & 23 \\
\hline C 505 B & 1,654 & 1,151 & 1,450 & 1,469 & 1,355 & 1,263 & 1,251 & 1,583 & 14,10 & 24 \\
\hline G176s & 1,535 & 1379 & 1,598 & 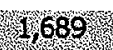 & 1654 & 0,60 & 19093 & 11576 & 13,39 & 25 \\
\hline CO 36 & 1,072 & 1,538 & 1,673 & 1,608 & 1,619 & 0,681 & 1,725 & 1,686 & 13,28 & 26 \\
\hline EXGEKER & 1,215 & 1,440 & 1,386 & 14408 & 4.48 & 1,201 & 11369 & 1518 & 13,24 & 27 \\
\hline Z 84 E 90 & 1,146 & 1,437 & 1,633 & 1,675 & 1,691 & 0,766 & 1,349 & 1,622 & 13,23 & 28 \\
\hline C41 W & 1,201 & 1,434 & 1530 & 1528 & 1570 & 1854 & 0,904 & 11.414 & 1288 & 29 \\
\hline Z $64 E 74$ & 1,410 & 1,479 & 1,716 & 1,623 & 1,653 & 0,733 & 1,047 & 1,725 & 12,35 & 30 \\
\hline co34. & 1113 & 1476 & 1491 & $1 / 547$ & 1608 & 0,765 & 1,587 & 1704 & 1201 & 311 \\
\hline HD 9486 & 1,358 & 1,520 & 1,294 & 1,388 & 1,448 & 1,162 & 1,271 & 1,636 & 10,76 & 32 \\
\hline $\mathrm{R} \& \mathrm{GO1}$ & 1063 & 1708 & 1,2812 & 1630 & 145 & 1092 & 198 & 0983 & 1073 & 38 \\
\hline AG 5014 & 1,311 & 1,361 & 1,450 & 1,633 & 1,550 & 1,044 & 1,079 & 0,035 & 10,61 & 34 \\
\hline 28440 & 1020 & 1587 & 1697 & 1,690 & 1725 & 0,752 & 1239 & 1670 & 10,07 & 35 \\
\hline PL 322 & 1,062 & 1,520 & 1,639 & 1,256 & 1,262 & 0,987 & 1,401 & 1,290 & 10,00 & 36 \\
\hline $94 \mathrm{HT} 3 \mathrm{LPM}$ & 0,75 & 1,635 & 1656 & 1,574 & 4555 & 1205 & 1016 & 1705 & 8,11 & 37 \\
\hline AGX 5674 & 1,415 & 1,481 & 1,494 & 1,660 & 1,622 & 0,982 & 0,970 & 1,679 & 7,89 & 38 \\
\hline MATA 3012 & 1,243 & 1351 & 1425 & 1652 & 1,667 & 0,811 & 0904 & 1601 & 750 & 39 \\
\hline PL 320 & 1,079 & 1,454 & 1,269 & 1,080 & 1,262 & 1,080 & 1,063 & 1,695 & 5,20 & 40 \\
\hline $\cos 32$ & 1,317 & 4.462 & 1,578 & 1956 & 1,578 & 0166 & 1496 & 1339 & 2,86 & 41 \\
\hline AGX 5492 & 1,343 & 1,672 & 1,535 & 1,507 & 1,483 & 0,143 & 1,349 & 1,699 & 2,35 & 42 \\
\hline 19006 & 1,114 & 1,631 & 1,469 & 1642 & 1587 & 0,879 & 0,184 & 1717 & 169 & 43 \\
\hline A 953 & 0,035 & 1,725 & 1,702 & 1,618 & 1,579 & 1,281 & 1,658 & 1,592 & 0,75 & 44 \\
\hline$c 505 \mathrm{C}$ & 1725 & 0,035 & 1,418 & 1,360 & 1,356 & 1,339 & 1,348 & 11587 & 0,49 & 45 \\
\hline AGROMEN 2003 & 1,503 & 1,532 & 1,556 & 1,567 & 1,563 & 0,035 & 1,597 & 0,849 & 0,42 & 46 \\
\hline$A-25 \times 11$ & 1,147 & 1,647 & 0,219 & 1161 & 103 & 1,185 & 0,035 & 11587 & 0,03 & 47 \\
\hline HT 951005 & 1,230 & 1,662 & 0,035 & 1,609 & 1,508 & 1,725 & 1,313 & 1,523 & 0,01 & 48 \\
\hline DINA270. & 1,460 & 1641 & 0,966 & 0,035 & 0,035 & 0,607 & 1,323 & 1,490 & 000 & 49 \\
\hline
\end{tabular}


Tabela 13. Índice multiplicativo $\left(I_{m}\right)$ para os 49 hibridos, com classificação.

\begin{tabular}{|c|c|c|c|c|c|c|c|c|c|}
\hline HİBRIDO & PE & $\mathbf{U}$ & FLO & AP & $A E$ & PROL & PAQ & $\mathbf{R}^{2}$ & $I_{m}$ \\
\hline X 345 & 8096119 & 156.19 & 567 & 197 & 98,10 & $106 \%$ & 6,921 & 0.91215 & 2901 . \\
\hline Z 84 E 98 & 8.4576 & 16,245 & 57,510 & 19921 & 9811 & 1,0611 & 4,24 & $0,88 \quad 22$ & 28,872 \\
\hline 2845 & $6.998,13$ & $15 / 24$ & 589,14 & 20123 & 103.26 & 1307 & $3 / 3$ & $0,855_{3}$ & $2 / z^{2}$ \\
\hline C 625 & 8.21214 & 15,934 & $57,6 \quad 11$ & $197^{9}$ & 954 & 1,0234 & 4,96 & $0,95 \quad 6$ & 25,994 \\
\hline 120563 & 2513 s. & 150010 & $58,6.35$ & 20238 & 101 & $1 / 32$ & 64 & 0,91 & 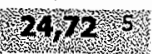 \\
\hline C $435 \mathrm{G}$ & $8.061^{20}$ & 15,620 & 58,119 & 20940 & 10637 & 1,0610 & 3,45 & $0,91 \quad 16$ & 23,496 \\
\hline$G 16 / S$ & 6.33710 & 158 & $58,3 \times 1$ & 20350 & $103 y^{2}$ & 1207,8 & 5,6 & 0,79 & 20967 \\
\hline AGX 5558 & 8.4625 & 14,73 & $58,2 \quad 21$ & 20227 & 10429 & 1,0330 & 7,330 & $0,96 \quad 3$ & 22,44 \\
\hline P $30 \% 1$ & $8596 \%$ & 15,9 & 58,23 & 208 \% & 105. & 105,16 & $5,2,6$ & $0,86{ }_{29}$ & $22,2,0$ \\
\hline G $165 \$$ & 7.88525 & $14,7^{4}$ & $58,8 \quad 39$ & $197^{13}$ & 10327 & 1,0424 & 8,217 & 0,8039 & 19,4010 \\
\hline GINA & 8.15516 & 6000 & $58,9,40$ & 200 & 105 & 105 & 7919 & 962,19 & 1886 Y \\
\hline HD 95 & 7.39040 & 14,62 & $58,5 \quad 31$ & 19817 & $100^{13}$ & 1,114 & 10,638 & $0,87 \quad 26$ & 18,7312 \\
\hline $\mathrm{AGX} 5542$ & $1942 / 4$ & $1577^{2}$ & $58 / 437$ & 1978 & 101 & 1296,12 & 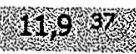 & 0,90 & (n) \\
\hline AGX 2573 & 8.3589 & 15,723 & $58,4 \quad 28$ & 20636 & 10221 & 1,0332 & $8,6 \quad 28$ & $0,97 \quad 2$ & 18,4214 \\
\hline AGROME & 764903 & 15725 & $57,0.5$ & $197=$ & 103. & 103.68 & $96 \%$ & 09023 & 18,3015 \\
\hline AS 3466 & 7.60032 & $16,0 \quad 41$ & $58,0 \quad 17$ & $190^{1}$ & 977 & 1,0331 & $5,8 \quad 13$ & $0,82^{37}$ & 17,8816 \\
\hline BNA 100 & 8113018 & 16,6477 & $58,9,6$ & 1998 & 1043 & $104 / 23$ & $56^{6}$ & 695 & 1720.17 \\
\hline XL 360 & $8.141^{17}$ & 15,621 & 58,426 & $205^{33}$ & 10841 & $1,12^{3}$ & 9,739 & 0,7941 & 16,2218 \\
\hline AGROMEN & 8240 & $15,3,12$ & $\left.58{ }^{2}\right) 20$ & $211+4$ & 108 \% & 104 25 & 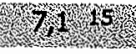 & 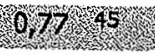 & 261519 \\
\hline CD 1723 & 8.3608 & $15,7 \quad 29$ & 59,446 & 20532 & 10430 & $1,05 \quad 19$ & 8,418 & $0,83 \quad 36$ & 15,8220 \\
\hline 0.435 & 1955.2 & 156 . & 58,53 & 210414 & 1 & 105, 1 & 6. 627 & (6) & $15 / 2,21$ \\
\hline MASTER & 7.65030 & 16,346 & $57,8 \quad 14$ & 20737 & 11345 & $1,08^{5}$ & 6,916 & $0,84^{34}$ & 14,8622 \\
\hline$A G R D$ & 825312 & 15968 & 58,626 & 205 & $106{ }^{6}$ & 100235 & 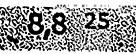 & 0,80 & (1) \\
\hline C 505 B & 9.0572 & 16,648 & 58,530 & $207^{3} 8$ & 11144 & $1,06 \quad 15$ & 9,734 & 0,9020 & 14,1024 \\
\hline G $176 s$ & 8453.7 & $16 / 1 x_{2}$ & 576 & 193. & $96 \%$ & 1400 & $11,3,40$ & 096 & $13,39 / 5$ \\
\hline CO 36 & 7.32644 & $15,5 \quad 14$ & 57,16 & 19920 & 989 & 1,0045 & 3,51 & 0,87 & 13,2826 \\
\hline EXELER & 954485 & 15983 & 587 & 210 , 2 & $105 \times 35$ & $405 \%$ & 8,42 & $018 / 2{ }^{2}$ & $1 s, 2 / 7$ \\
\hline Z 84 E 90 & 7.43039 & 15,935 & $57,4^{9}$ & 1944 & $94^{2}$ & 1,0040 & 8,424 & 0,949 & 13,2328 \\
\hline c491. W & $71 / 9,-36$ & 15,9636 & 58010 & 20453 & 101.18 & $1,08.6$ & 155 & 093 & $1688^{2}$ \\
\hline 264 E 74 & 8.00322 & 15,727 & 56,82 & 19815 & 966 & 1,0044 & 12,543 & 0,9310 & 12,3530 \\
\hline $63^{4}$ & $7,381.27$ & $15 \%$ & $58,3,4$ & $203 \%$ & 99 & $100.4 x$ & 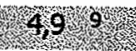 & 0,90 & $1201 \%$ \\
\hline HD 9486 & 7.85826 & $15,6 \quad 16$ & 59,143 & 21144 & 10739 & 1,0426 & 8,633 & $0,78 \quad 42$ & 10,7632 \\
\hline R8.601 & $7315{ }^{45}$ & $1610 \%$ & 59,14 & 19712 & 10222 & 1.1. $03 \%$ & 9,326 & 604 (8) & $10,25,33$ \\
\hline AG 5014 & 7.74129 & 16,143 & $58,5 \quad 29$ & $197^{11}$ & 10224 & $1,03^{33}$ & 14,541 & 0,8038 & 10,6134 \\
\hline 28440 & $7264 \times 17$ & $15,3,13$ & $56,9 \%$ & $193 \times 2$ & 911 & 10oj & X, 53 & 677.43 & $10 / 07>$ \\
\hline $\mathrm{PL} 322$ & 7.31346 & $15,6 \quad 17$ & 57,68 & 21646 & 11446 & 1,0236 & 7,220 & $0,97 \quad 1$ & 10,0036 \\
\hline $9414310 \mathrm{pM}$ & 7059.48 & 150,9 & 572 & 201225 & $10222^{3}$ & 105.18 & 13014 & 0,76 . & 8,1 , 87 \\
\hline AGX 5674 & 8.02021 & 15,726 & 58,222 & 1955 & 988 & 1,0237 & 14,845 & $0,70 \quad 47$ & 7,8938 \\
\hline HATA 3012 & $7.597,83$ & 16,144 & 586.33 & 196 & 95.3 & 10113 & 13,46 & $0 / 85 x_{1}$ & 750,39 \\
\hline L 320 & 7.33543 & $15,8 \quad 31$ & 59,245 & 22148 & $114^{47}$ & 1,0329 & 13,742 & 0,9312 & 5,2040 \\
\hline 8012 & $7756 \% 28$ & 158,30 & 578,18 & $2014^{24}$ & 100 lo & $0,99,9$ & $6,4,12$ & 08448 & $2,86,41$ \\
\hline AGX 5492 & 7.82027 & 14,85 & $58,0 \quad 16$ & 20535 & 10536 & 0,9948 & $8,5 \quad 26$ & 0,8727 & 2,3542 \\
\hline T9006 & 7383,41 & $15,0 \%$ & $58,4,77$ & 196 & $100 / 4$ & 10138 & $150 \%$ & 0,83 & 16964 \\
\hline A 953 & 6.84349 & $14,5 \quad 1$ & 56,93 & 19816 & $100^{15}$ & 1,0614 & $4,0 \quad 3$ & $0,77 \quad 44$ & 0,7544 \\
\hline 05056 & 9.531 & $177^{49}$ & $58,6,8$ & 21245 & 1) & 1,07 & $8,4 \%$ & $096 \%$ & $0 / 4 \%$ \\
\hline AGROMEN 2003 & 8.32111 & 15,515 & 57,915 & 20126 & 10120 & 0,9849 & 4,98 & $0,69 \quad 48$ & $0,42 \quad 46$ \\
\hline $425 \times 1$ & 7431 . 38 & 150 & $60,4,48$ & 219 & $1186 \%$ & $104{ }^{2} 2$ & 15,1499 & 0,86 & 0094 \\
\hline HT 951005 & $7.571^{34}$ & 14,96 & 60,549 & 19919 & $104^{31}$ & 1,221 & 10,331 & 0,6649 & 0,0148 \\
\hline OINA 270 & 816415 & $15,0.8$ & $59,9,47$ & & 12749 & $1 / 00 \% 46$ & 9.1.29 & 0,9311 & $0,00 \%$ \\
\hline
\end{tabular}


Tabela 14. Índice de soma de classificação $\left(I_{j}\right)$ para os 49 hibridos, com classificação.

\begin{tabular}{|c|c|c|c|c|c|c|c|c|c|}
\hline HIB & PE & $\mathbf{U}$ & FLO & AP & $\mathbf{A E}$ & ROL & & $\mathbf{R}^{2}$ & $\boldsymbol{I}_{\boldsymbol{j}}$ \\
\hline$x^{2} 345$ & opros & 15,6 & $56 / 1,19$ & 197800 & 98.10 & 780613 & 6 & & \\
\hline C 625 & $8.212^{14}$ & 15,934 & $57,6 \quad 11$ & 1979 & 954 & 1,0234 & 4,96 & 0,956 & 118 \\
\hline $8,4=$ & $8.457 \times$ & $162^{2} 65$ & $7_{1} 5^{10}$ & 19962 & 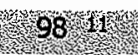 & 06 & 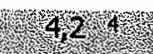 & 088 & 130 \\
\hline A 953 & 6.84349 & $14,5 \quad 1$ & 56,93 & $198 \quad 16$ & $100^{15}$ & 1,0614 & 4,03 & 0,7744 & 145 \\
\hline $16 \times 555$ & $8462 \mathrm{~s}$ & $14 \%$ & $58,2,13$ & 202 . & 10429 & 403,30 & $73^{3}$ & 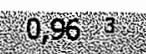 & 188 \\
\hline G $176 \mathrm{~S}$ & 8.4537 & 16,142 & $57,6 \quad 12$ & 1933 & 965 & 1,0042 & 11,340 & 0,964 & 155 \\
\hline 28452 & $8998 \mathrm{O}$ & $15 / 724$ & $58,9 \times 11$ & 201,23 & 103. & ( 07 & $3,3,2$ & $0,85 \times$ & 160 \\
\hline HD 9563 & $7.512 \quad 37$ & 15,010 & 58,635 & 20228 & 10119 & 1,132 & 6,314 & $0,91 \quad 17$ & 162 \\
\hline 84,9 & 3039 & $159 \times 5$ & 57, & 194 & 942 & Ho, 10 & $87^{4}+44$ & Oplas & ro ${ }^{2}$ \\
\hline C $435 \mathrm{G}$ & 8.06120 & 15,620 & $58,1 \quad 19$ & 20940 & 10637 & 1,0610 & 3,45 & 0,9116 & 16710 \\
\hline 036 & 3326 & 15,54 & $57 x^{1} 6$ & $199{ }_{20}$ & 98.28 & roos 45 & 35 & 0878 & $16 \%$ Th \\
\hline Z 64 E 74 & 8.00222 & 15,727 & 56,82 & $198 \quad 15$ & 966 & $1,00 \quad 44$ & $12,5 \quad 43$ & $0,93 \quad 10$ & 16912 \\
\hline 1DOS 12 & $1390 \times 100$ & $146 / 2$ & 58,531 & 198,17 & $100 \times 13$ & Kr. & 10668 & 087.6 & 175,19 \\
\hline AGX 5542 & 7.94224 & 15,722 & $58,7 \quad 37$ & $196^{8}$ & 10117 & $1,06 \quad 12$ & 11,937 & 0,9018 & $175^{1}$ \\
\hline AS 3466 & $7600 \% 32$ & 16,014 & 580,17 & 190 & 96 & Wos & 5,8 o & $082 \%$ & Hovis \\
\hline AGX 2573 & 8.3589 & 15,723 & 58,428 & 20636 & 10121 & 1,0332 & $8,6 \quad 28$ & 0,972 & $179 \quad 16$ \\
\hline G $167 S$ & 8337 & $1588_{2}$ & 58,35 & 203 & 103.28 & 1078 & 567 & $0,79 \times 10$ & 180 \\
\hline AGROMEI & 7.64931 & 15,725 & $57,0 \quad 5$ & $197 \quad 14$ & 10325 & $1,03 \quad 28$ & 9,632 & $0,90 \quad 21$ & 181 \\
\hline 2848 & 17) 264.4 & $15,3{ }_{1}$ & $56,9,4$ & 193 & 9114 & 100 & $9,5,5$ & 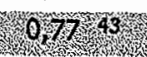 & 188,19 \\
\hline G $165 \$$ & $7.885 \quad 25$ & $14,7^{4}$ & 58,839 & 19713 & 10327 & 1,0424 & $8,2 \quad 17$ & $0,80 \quad 39$ & 18820 \\
\hline 83041 & 8.596 & 159 & $58 / 2 \times 3$ & 208. & 105.8 & W5ing & 52 & 086.29 & $102,1,1$ \\
\hline AGROME & 8.32111 & $15,5 \quad 15$ & $57,9 \quad 15$ & 20126 & 10120 & $0,98 \quad 49$ & $4,8 \quad 8$ & 0,6948 & 19222 \\
\hline DNA 100 & 8180 18 & $16,6 / 2$ & $5890 \%$ & 199418 & $1104 / 32$ & 104,23 & 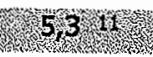 & 095 & $198 x^{2}$ \\
\hline [NA 657 & 8.15516 & 16,040 & 58,940 & $200 \quad 22$ & $105^{33}$ & $1,05 \quad 17$ & 7,919 & 0,9214 & 20124 \\
\hline $\mathrm{CO} 32$ & 7756.28 & 158,36 & 578.7 & $201 x^{24}$ & $100 \times 6$ & (99 & 6,6 & 0,846 & $20 s 2^{25}$ \\
\hline 34 & 7.38142 & 15,728 & $58,3 \quad 24$ & 20329 & 9912 & 1,0041 & 4,99 & 0,9019 & 20426 \\
\hline $6491 W$ & 751936 & $15 \% 8,86$ & $58,0,18$ & 20473 & 1011.18 & 1086 & S5. & 003 & 205 \\
\hline $505 \mathrm{C}$ & 9.5311 & 17,449 & $58,6 \quad 34$ & 21245 & 11043 & 1,077 & 8,427 & 0,965 & 21128 \\
\hline $46 \times 567$ & 8020 . & 15726 & 58222 & 195 & 198 & $1,02.37$ & 174896 & $070 \%$ & $2118 \%$ \\
\hline AGROMEN & 8.24013 & 15,212 & 58,120 & 21143 & $10840^{\circ}$ & 1,0425 & $7,1 \quad 15$ & 0,7745 & $213^{30}$ \\
\hline 1723 & 8360.8 & $15 g^{2}$ & $59,4 \% 6$ & 205,32 & 1045 & Mo5 19 & $8,8,18$ & 082,36 & $2 \pi g^{2} 1$ \\
\hline AGX 5492 & $7.820 \quad 27$ & 14,85 & 58,016 & 20535 & 10536 & 0,9948 & $8,5 \quad 26$ & 0,8727 & 22032 \\
\hline 322 & 313.6 & 15,6 , 17 & 574,8 & 216 & 1. & 1402,36 & 72220 & 0,971 & 220,83 \\
\hline HT 951005 & 7.57134 & 14,96 & 60,549 & 19919 & 10431 & 1,221 & 10,331 & 0,6649 & 22034 \\
\hline 14153 & 7059.78 & 15,0 & $5^{5} 2$ & 2012 & $102 / 2$ & 1) & 13004 & 076,46 & 220.35 \\
\hline XL 360 & $8.141^{17}$ & 15,621 & 58,426 & $205^{33}$ & 10841 & $1,12^{3}$ & 9,739 & 0,7941 & 22136 \\
\hline 19006 & $1383 \times 4$ & $15,0,11$ & $584 \% 2$ & 196 & 100 & 10188 & $15,0,48$ & 083 & 224 a 37 \\
\hline C 435 & $7.955 \quad 23$ & $15,6 \quad 19$ & 58,532 & 21041 & 11042 & 1,0521 & 9,623 & $0,88 \quad 23$ & 22438 \\
\hline $\begin{array}{l}\text { MASTER } \\
2505 \mathrm{~B}\end{array}$ & $\begin{array}{l}7.650 .0 \\
9.057^{2}\end{array}$ & $\begin{array}{l}16,3 \\
16,648\end{array}$ & $\begin{array}{l}5 / 814 \\
58,530\end{array}$ & $\begin{array}{l}207 / 37 \\
20738\end{array}$ & 13,45 & 108 & $69^{16}$ & 0,84 & 227.39 \\
\hline 8601 & 7315,45 & $16,0 \%$ & $591{ }^{4} 4$ & 197.12 & 10222 & $1,03,27$ & $\begin{array}{c}9,734 \\
9,316\end{array}$ & 0,9020 & $\begin{array}{l}23140 \\
233^{4}\end{array}$ \\
\hline -ATÃ 3012 & 7.59633 & $16,1^{44}$ & 58,633 & 1956 & $95^{3}$ & 1,0139 & 13,346 & 0,8531 & 23542 \\
\hline AROMEN & 8253.12 & $15,9 \times 8$ & $58,6 \%$ & $205{ }^{3} 4$ & 106.38 & 10235 & $8,8,25$ & 08824 & $242 / 43$ \\
\hline AG 5014 & $7.741^{29}$ & 16,143 & $58,5 \quad 29$ & 19711 & 10224 & 1,0333 & 14,541 & 0,8038 & 24844 \\
\hline XCEMER & 7.54435 & $15,9 \%$ & $58 \% 39$ & 210042 & 105.35 & 10520 & $84^{22}$ & 0.8725 & $250 \%$ \\
\hline DINA 270 & 8.16415 & 15,08 & 59,847 & 23049 & 12749 & $1,00 \quad 46$ & 9,129 & 0,9311 & 25446 \\
\hline 109486 & $7858 \%$ & 15,616 & 5911,43 & $211 / 44$ & 1078,9 & 10426 & $8,6.9$ & $0 / 78,42$ & 269047 \\
\hline L 25 XII & 7.43038 & 15,07 & $60,4^{48}$ & 21947 & 11848 & 1,0422 & 15,149 & 0,8630 & 28948 \\
\hline 320 & & $158 \% 31$ & 59245 & 221446 & $114,47 \%$ & $163{ }^{29}$ & 137642 & 0,9312 & $297 \times 49$ \\
\hline
\end{tabular}


Tabela 15. Índice de distância ao ideótipo $\left(d_{i I}\right)$ para os 49 hbridos, com classificação.

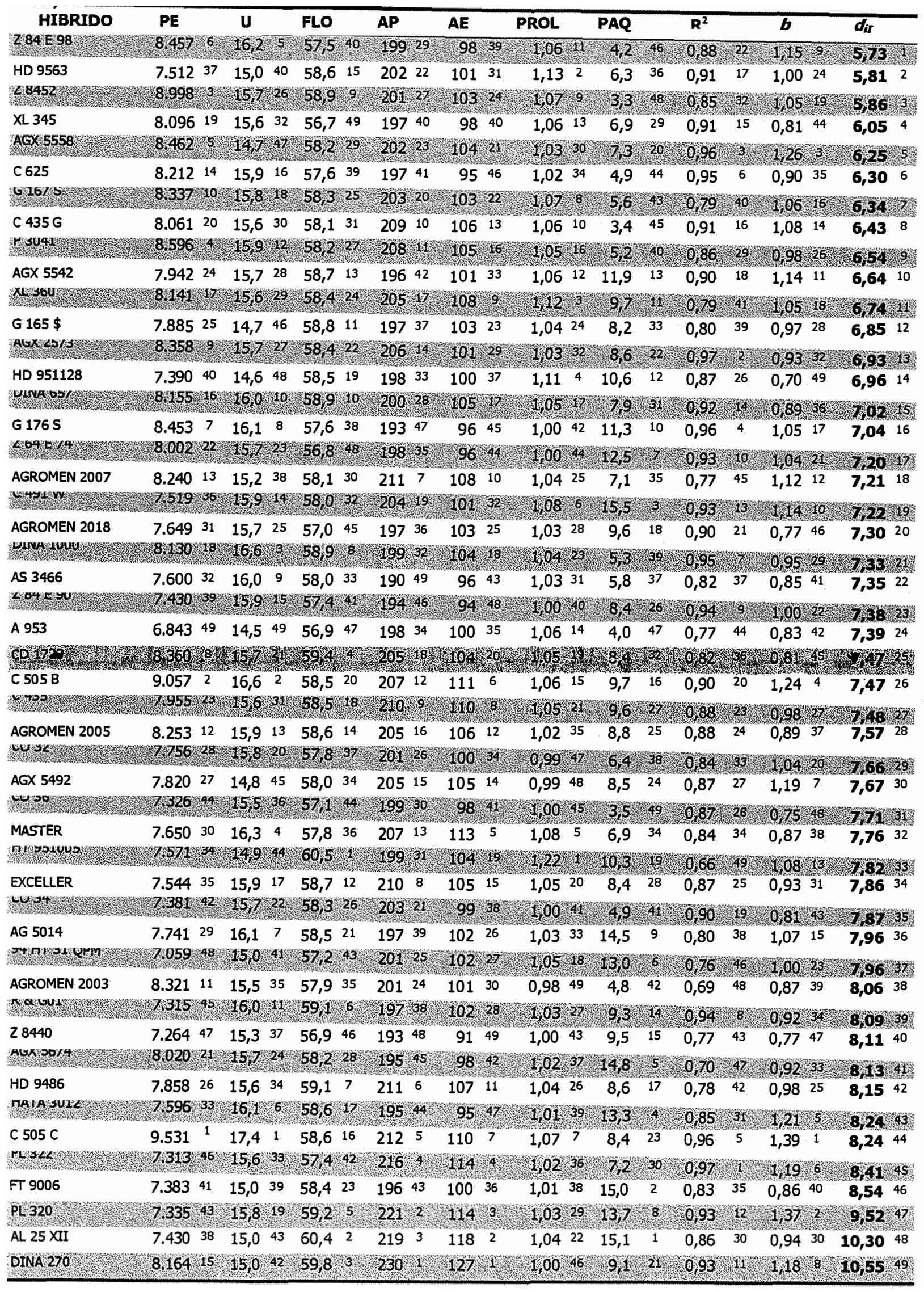


Tabela 16. Médias agrupadas de acordo com o critério de Scott \& Knott (1974) para obtenção do Índice 1. Médias seguidas do mesmo número não diferem entre si ao nível de significância indicado.

\begin{tabular}{|c|c|c|c|c|c|c|c|c|c|c|c|c|c|c|}
\hline HÍBRIDO & PE & 0,01 & $\bar{U}$ & 0,10 & FLO & 0,05 & $\mathbf{A P}$ & 0,05 & $\overline{\mathbf{A E}}$ & 0,05 & PROL & 0,07 & PAQ & $\overline{0,03}$ \\
\hline 94 HT3 & 7059 & 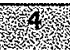 & 150 & $1+1$ & 572 & 倿 & 201 & 2 & 102 & 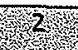 & 1605 & 14 & 289 & 4 \\
\hline A 953 & 6.843 & 4 & 14,5 & 1 & 56,9 & 1 & 198 & 1 & 100 & 2 & 1,06 & 3 & 1,46 & 1 \\
\hline AG5014 & 7741 & 3 & 161 & 2 & 585 & 2 & 197 & 11 & 102 & 2 & 103 & 25estest & 280 & 4 \\
\hline AGROMEN 20 & 8.321 & 2 & 15,5 & 2 & 57,9 & 1 & 201 & 2 & 101 & 2 & 0,98 & 5 & 1,64 & 1 \\
\hline ACROM & 8.253 & 2 & $15 \%$ & 2 & 58,6 & 2 & 205 & 3 & 106 & 2 & II 102 & 4 & 2,29 & 3 \\
\hline AGROMEN 20 & 8.240 & 2 & 15,2 & 1 & 58,1 & 2 & 211 & 3 & 108 & 3 & 1,04 & 4 & 2,04 & 2 \\
\hline AGROME & 7649 & 3. & 157 & 2 & 570 & 17: & 197 & 2rive & 103 & 2 & 103 & 4 & 2,37 & 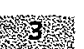 \\
\hline AGX 2573 & 8.358 & 2 & 15,7 & 2 & 58,4 & 2 & 206 & 3 & 101 & 2 & 1,03 & 4 & 2,34 & 3 \\
\hline AGX549 & 78820 & 称 & 118 & 1 & 580 & 2 & 205 & 3. & 105: & 2 & 099 & 5 & 229 & 3 \\
\hline AGX 5542 & 7.942 & 2 & 15,7 & 2 & 58,7 & 2 & 196 & 1 & 101 & 2 & 1,06 & 3 & 2,62 & 3 \\
\hline$A G \times 555$ & 8642 & 20 & 147 & 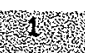 & 5882 & 2 & 202 & 2 & 104 & 2 & 103 & 34 & 237 & 3. \\
\hline AGX 5674 & 8.020 & 2 & 15,7 & 2 & 58,2 & 2 & 195 & 1 & 98 & 1 & 1,02 & 4 & 2,95 & 4 \\
\hline Al $25 \times 1$ & 7430 & 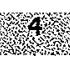 & 150 & 1 & 604 & 2 & 219 & 4 & 18 & 25 & 104 & 2 & 3. & Sy \\
\hline AS 3466 & 7.600 & 3 & 16,0 & 2 & 58,0 & 2 & 190 & 1 & 96 & 1 & 1,03 & 4 & 1,94 & 2 \\
\hline 6435 & 27955 & 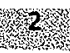 & 156 & 2 & $58 \% 5$ & 2 & 210 & 3 & 110 & 3 & 105 & (1) & 25 & 3. \\
\hline C 435 G & 8.061 & 2 & 15,6 & 2 & 58,1 & 2 & 209 & 3 & 106 & 2 & 1,06 & 3 & 1,57 & 1 \\
\hline c491u & 7.519: & 23. & 159 & 2 & 580 & 2 & 204 & 2 & 101 & 2 & 108 & & 303 & 4 \\
\hline C $505 \mathrm{~B}$ & 9.057 & 1 & 16,6 & 3 & 58,5 & 2 & 207 & 3 & 111 & 4 & 1,06 & 3 & 2,50 & 3 \\
\hline$C 505 C$ & 9531 & 1 & $1 / 4$ & ret & 586 & 2 & 242 & so & 110 & 4 & 107 & row & 20 & 3 \\
\hline C 625 & 8.212 & 2 & 15,9 & 2 & 57,6 & 1 & 197 & 1 & 95 & 1 & 1,02 & 4 & 1,59 & 1 \\
\hline $\operatorname{CD} 172$ & 8360 & 2 & 15 & re & 594 & 2 & 205 & S & 104 & 2 & 05 & 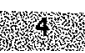 & 207 & 20 \\
\hline $\mathrm{CO} 36$ & 7.326 & 4 & 15,5 & 2 & 57,1 & 1 & 199 & 2 & 98 & 1 & 1,00 & 5 & 1,26 & 1 \\
\hline cos? & 7.756 & 3 & 158 & 2 & 578 & 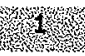 & 201 & 2 & roo & s & 029 & 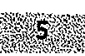 & Co2 & 2 \\
\hline $\mathrm{CO} 34$ & 7.381 & 4 & 15,7 & 2 & 58,3 & 2 & 203 & 2 & 99 & 1 & 1,00 & 5 & 1,67 & 1 \\
\hline DINA 1000 & 8,130 & 2 & 166 & ? & 58,9 & $2^{2}$ & 199 & 2 & 104 & 2 & 104 & 4. & 1. & (1) \\
\hline DINA 270 & 8.164 & 2 & 15,0 & 1 & 59,8 & 2 & 230 & 5 & 127 & 6 & 1,00 & 5 & 2,35 & $3^{3}$ \\
\hline DINA 65 & 8.155 & 8 & 16,0 & 2 & 589 & 2 & 200 & 2 & 105 & x & 1. 65 & 4 & 211 & \\
\hline EXCELLER & 7.544 & 3 & 15,9 & 2 & 58,7 & 2 & 210 & 3 & 105 & 2 & 1,05 & 4 & 2,24 & 3 \\
\hline FT 9006 & 7888 & 4 & 150 & 的 & $58 \times 4$ & 2 & 196 & & 100 & 2 & 1201 & ron & 3.3 & 4 \\
\hline $\mathrm{G} 165 \$$ & 7.885 & 3 & 14,7 & 1 & 58,8 & 2 & 197 & 1 & 103 & 2 & 1,04 & 4 & 2,06 & 2 \\
\hline G167S & 88337 & 2 & 158 & 2 & 583 & 2 & 203 & 2 & 103 & 2 & 107 & rat & 1. & (15y \\
\hline G $176 \mathrm{~S}$ & 8.453 & 2 & 16,1 & 2 & 57,6 & 1 & 193 & 1 & 96 & 1 & 1,00 & 5 & 2,78 & 4 \\
\hline HATA 3012 & 7.596 & 3 & 161 & 2 & 58,6 & 2 & 195 & 1 & 95 & 21 & 101 & 5 & 8.03 & 4 \\
\hline HD 9486 & 7.858 & 3 & 15,6 & 2 & 59,1 & 2 & 211 & 3 & 107 & 3 & 1,04 & 4 & 2,46 & 3 \\
\hline HO95112 & 7890 & 4 & 146 & 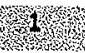 & $58 \% 5$ & 2 & 198 & 2 & 100 & 1 & (1) & 3 & 271 & 4 \\
\hline HD 9563 & 7.512 & 3 & 15,0 & 1 & 58,6 & 2 & 202 & 2 & 101 & 2 & 1,13 & 2 & 2,03 & 2 \\
\hline 179051005 & 7.571 & 3 & 149 & 1: & 60,5 & 2 & 99 & 2 & 104 & 2 & 122 & 1. & 237 & 3. \\
\hline MASTER & 7.650 & 3 & 16,3 & 2 & 57,8 & 1 & 207 & 3 & 113 & 4 & 1,08 & 3 & 2,05 & 2 \\
\hline P 3041 & 8.596 & 2 & 159 & 2 & 58,2 & 2 & 208 & 3 & 105 & 2 & 105 & 3ret & 110 & 1 \\
\hline PL 320 & 7.335 & 4 & 15,8 & 2 & 59,2 & 2 & 221 & 4 & 114 & 4 & 1,03 & 34 & 2,82 & 4 \\
\hline PL 322 & 7313 & 4 & 15,6 & 2 & 574 & 1 & 216 & 1. & 114 & 4 & 102 & 1. & 2,17 & 2 \\
\hline$R \& G 01$ & 7.315 & 4 & 16,0 & 2 & 59,1 & 2 & 197 & 1 & 102 & 2 & 1,03 & 34 & 2,60 & 3 \\
\hline $\mathrm{X}=345$ & 8096 & re & 156 & 2 & 567 & (1) & 197 & 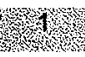 & 98 & 1 & x.306 & 3. & 219 & 2 \\
\hline$X L 360$ & 8.141 & 2 & 15,6 & 2 & 58,4 & 2 & 205 & 3 & 108 & 3 & 1,12 & 2 & 2,73 & 4 \\
\hline Z64 E Z4 & 8,002 & 2 & 152 & 2 & 56,8 & (1) & 198 & ry & 96 & (3) & 100 & ry & 285 & 4 \\
\hline Z 84 E 90 & 7.430 & 4 & 15,9 & 2 & 57,4 & 1 & 194 & 1 & 94 & 1 & 1,00 & 5 & 2,29 & 3 \\
\hline $284 E 98$ & 8.457 & 2 & 6,2 & 2 & 575 & 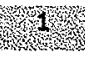 & 199 & $y^{2} 2$ & 98 & 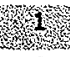 & 106 & 3ris & 156 & $x^{2} 1$ \\
\hline Z 8440 & 7.264 & 4 & 15,3 & 1 & 56,9 & 1 & 193 & 1 & 91 & 1 & 1,00 & 5 & 2,52 & 3 \\
\hline 28452 & 8.998 & .1 & 15 & 2 & 58,9 & $y_{2}^{2} 2$ & 200 & 2 & 103 & 25 & 1,07 & 3 & 1128 & 4 \\
\hline
\end{tabular}


Tabela 17. Médias agrupadas de acordo com o critério de Scott \& Knott (1974) para obtenção do Índice 2. Médias seguidas do mesmo número não diferem entre si ao nível de significância indicado.

\begin{tabular}{|c|c|c|c|c|c|c|c|c|c|c|c|c|c|c|}
\hline HIBRIDO & $\overline{\mathbf{P E}}$ & 0,05 & $\bar{U}$ & 0,001 & FLO & 0,001 & AP & 0,01 & $\mathbf{A E}$ & 0,01 & PROL & 0,001 & PAQ & 0,01 \\
\hline$9 4 1 \longdiv { 3 1 0 0 M }$ & 7059 & 5 & 150 & 1) & 57,2 & 1. & 201 & 12 & 102 & 12 & 190 & 4 & 289 & (4) \\
\hline A 953 & 6.843 & 5 & 14,5 & 1 & 56,9 & 1 & 198 & 1 & 100 & 2 & 1,06 & 3 & 1,46 & 1 \\
\hline AG 5014 & 7741 & 4 & 16.1 & 2 & 58,5 & 2 & 197 & 1 & 102 & 2 & 103 & 4 & 2,80 & 4 \\
\hline AGROMEN 2003 & 8.321 & 3 & 15,5 & 2 & 57,9 & 1 & 201 & 2 & 101 & 2 & 0,98 & 4 & 1,64 & 1 \\
\hline AGROMEN 2005 & 8253 & 3 & 15.9 & 2 & 58,6 & 2 & 205 & 3 & 106 & 2 & 102 & 4 & 2,29 & 3 \\
\hline AGROMEN 2007 & 8.240 & 3 & 15,2 & 1 & 58,1 & 2 & 211 & 3 & 108 & 3 & 1,04 & 4 & 2,04 & 2 \\
\hline AGROMEN 2018 & 7649 & 4 & 157 & $x^{2}$ & 570 & X & 197 & 11 & 108 & res & 103 & 4 & 2,37 & 3 \\
\hline AGX 2573 & 8.358 & 3 & 15,7 & 2 & 58,4 & 2 & 206 & 3 & 101 & 2 & 1,03 & 4 & 2,34 & 3 \\
\hline ASX5492. & 7820 & 4 & 148 & 1. & 58 & 2 & 205 & 3 & 105 & 2 & 099 & 4 & 229 & $x^{3}$ \\
\hline$A G \times 5542$ & 7.942 & 3 & 15,7 & 2 & 58,7 & 2 & 196 & 1 & 101 & 2 & 1,06 & 3 & 2,62 & 3 \\
\hline$A G X 5558$ & 8.462 & 3 & 147 & 1 & 582 & 2 & 202 & 2 & 104 & 2 & 103 & 4 & 237 & ? \\
\hline AGX 5674 & 8.020 & 3 & 15,7 & 2 & 58,2 & 2 & 195 & 1 & 98 & 1 & 1,02 & 4 & 2,95 & 4 \\
\hline$A / 25 \times 1$ & 7.430 & 6 & 150 & 1 & 60,4 & 2 & 219 & 4 & 118 & 4 & 104 & 4 & 346 & rex \\
\hline AS 3466 & 7.600 & 4 & 16,0 & 2 & 58,0 & 2 & 190 & 1 & 96 & 1 & 1,03 & 4 & 1,94 & 2 \\
\hline 6435 & 2955 & 3 & 156 & 2 & 58,5 & 2 & 210 & 3. & 110. & 3. & 1,05 & 4 & 225 & 3 \\
\hline $\mathrm{C} 435 \mathrm{G}$ & 8.061 & 3 & 15,6 & 2 & 58,1 & 2 & 209 & 3 & 106 & 2 & 1,06 & 3 & 1,57 & 1 \\
\hline C491w & 7519 & 4 & 159 & (2) & 580 & 2 & 204 & 2. & 101 & 2 & 1) & 3 & 3,03 & 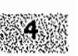 \\
\hline C $505 \mathrm{~B}$ & 9.057 & 2 & 16,6 & 2 & 58,5 & 2 & 207 & 3 & 111 & 3 & 1,06 & 3 & 2,50 & 3 \\
\hline $8505 \bigcirc$ & 9531 & 1 & 174 & 2 & 586 & 2 & 212 & 3 & 110 & 3 & 107 & (3) & 229 & 3 \\
\hline C 625 & 8.212 & 3 & 15,9 & 2 & 57,6 & 1 & 197 & 1 & 95 & 1 & 1,02 & 4 & 1,59 & 1 \\
\hline CD1723. & 8.360 & 3 & 157 & 2 & 594 & 22 & 205 & 3. & 104 & 2. & 105 & 4 & 207 & 2 \\
\hline CO 36 & 7.326 & 5 & 15,5 & 2 & 57,1 & 1 & 199 & 2 & 98 & 1 & 1,00 & 4 & 1,26 & 1 \\
\hline $\mathrm{CO}^{32}$ & 7756 & 4 & 158 & 2 & 578 & 11 & 201 & 2 & 100 & 2 & 0.99 & 4 & 192 & 2 \\
\hline CO 34 & 7.381 & 5 & 15,7 & 2 & 58,3 & 2 & 203 & 2 & 99 & 1 & 1,00 & 4 & 1,67 & 1 \\
\hline DINA 1000 & 8130 & 3 & 166 & 2 & 589 & 就被 & 199 & 2 & 104 & 2 & 104 & 4 & 178 & X1: \\
\hline DINA 270 & 8.164 & 3 & 15,0 & 1 & 59,8 & 2 & 230 & 5 & 127 & 5 & 1,00 & 4 & 2,35 & 3 \\
\hline DINA 659 & 8.155 & 3. & 160 & 2 & 589 & 2 & 200 & 2 & 105 & 2 & 105 & 84 & 211 & 2 \\
\hline EXCELLER & 7.544 & 4 & 15,9 & 2 & 58,7 & 2 & 210 & 3 & 105 & 2 & 1,05 & 4 & 2,24 & 3 \\
\hline F9006 & 7383 & 5 & $15 \%$ & 1 & 584 & 2 & 196 & 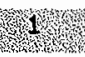 & 100 & 2 & 101 & 4. & 3,48 & (4) \\
\hline$G 165 \$$ & 7.885 & 4 & 14,7 & 1 & 58,8 & 2 & 197 & 1 & 103 & 2 & 1,04 & 4 & 2,06 & 2 \\
\hline G167S & 8337 & s. & 158 & 2 & $58 \%$ & 2 & 203 & $r^{2}$ & 103 & 2 & 107 & & 1,59 & 1. \\
\hline G 176 S & 8.453 & 3 & 16,1 & 2 & 57,6 & 1 & 193 & 1 & 96 & 1 & 1,00 & 4 & 2,78 & 4 \\
\hline HATA 3012 & 7596 & 4 & 161 & 2 & 58,6 & 2 & 195 & 2 & 95 & & 101 & 4 & 3,03 & 4 \\
\hline HD 9486 & 7.858 & 4 & 15,6 & 2 & 59,1 & 2 & 211 & 3 & 107 & 3 & 1,04 & 4 & 2,46 & 3 \\
\hline 10951128 & 7390 & 5 & 14,6 & 1 & 585 & 2 & 198 & 2 & 100 & 1 & 1/11 & 3. & 271 & 4 \\
\hline HD 9563 & 7.512 & 4 & 15,0 & 1 & 58,6 & 2 & 202 & 2 & 101 & 2 & 1,13 & 2 & 2,03 & 2 \\
\hline HT 951005 & 7571 & 4 & 14,9 & 1 & $60 \%$ & 2 & 199 & 2 & 104 & 2 & 122 & 1 & 2,3 & S3 \\
\hline MASTER & 7.650 & 4 & 16,3 & 2 & 57,8 & 1 & 207 & 3 & 113 & 3 & 1,08 & 3 & 2,05 & 2 \\
\hline$P 3041$ & 8596 & 3 & 159 & 2 & 582 & 2 & 208 & 3 & 105 & 2 & 105 & 4 & 170 & 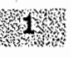 \\
\hline PL 320 & 7.335 & 5 & 15,8 & 2 & 59,2 & 2 & 221 & 4 & 114 & 3 & 1,03 & 4 & 2,82 & 4 \\
\hline PE 322 & 7313 & 5 & 15,6 & 2 & 57.4 & 1 & 216. & 4 & 1114 & 3 & 102 & 4 & 217 & 2 \\
\hline R \& G01 & 7.315 & 5 & 16,0 & 2 & 59,1 & 2 & 197 & 1 & 102 & 2 & 1,03 & 4 & 2,60 & 3 \\
\hline$X I 345$ & 8096 & 3 & 156 & 2 & 567 & 1 & 197 & 1 & 98 & 1. & 106 & 3. & 219. & 2 \\
\hline XL 360 & 8.141 & 3 & 15,6 & 2 & 58,4 & 2 & 205 & 3 & 108 & 3 & 1,12 & 2 & 2,73 & 4 \\
\hline$Z 64 E 74$ & 8.002 & 3 & 15,7 & 2 & 56,8 & 1 & 198 & 1 & 96 & 1 & 1,00 & 4 & 285 & 4 \\
\hline Z 84 E 90 & 7.430 & 5 & 15,9 & 2 & 57,4 & 1 & 194 & 1 & 94 & 1 & 1,00 & 4 & 2,29 & 3 \\
\hline $284 E 98$ & 8457 & 3 & 16,2 & 2. & 575 & 1 & 199 & 2 & 98 & 1 & 1,06 & 8 & 156 & 1. \\
\hline 28440 & 7.264 & 5 & 15,3 & 1 & 56,9 & 1 & 193 & 1 & 91 & 1 & 1,00 & 4 & 2,52 & $3^{3}$ \\
\hline 28452 & 8.998 & 23 & 157 & 2 & 58,9 & 2 & 201 & 2 & 103 & 26 & $\int^{2} .07$ & ris & 1,28 & 11. \\
\hline
\end{tabular}


Tabela 18. Médias agrupadas e recíprocos, para obtenção do Índice 1. Médias seguidas do mesmo número não diferem entre si ao nível de significância indicado.

\begin{tabular}{|c|c|c|c|c|c|c|c|c|c|c|c|c|c|c|}
\hline HÍBRIDO & PE & 0,01 & $1 / 0$ & 0,10 & 1/FLO & 0,05 & $1 / A P$ & 0,05 & 1/AE & 0,05 & PROL & 0,07 & 1/PAQ & 0,03 \\
\hline $24 / 4=3$ & 7059 & 4 & 0.0666 & 1 & 00125 & 1 & 0.0050 & 2] & 0,0098 & 2 & 105 & 4 & 0,346 & 84. \\
\hline A 953 & 6.843 & 4 & 0,0689 & 1 & 0,0176 & 1 & 0,0051 & 1 & 0,0100 & 2 & 1,06 & 3 & 0,686 & 1 \\
\hline AG 501 & 7741 & B. & 00621 & 2 & $0,1 \% 1$ & 2 & 010051 & yite & 0,0098 & 2 & 103 & t) & 0,357 & 4 \\
\hline AGROMEN & 8.321 & 2 & 0,0645 & 2 & 0,0173 & 1 & 0,0050 & 2 & 0,0099 & 2 & 0,98 & 5 & 0,611 & 1 \\
\hline AGROMEN & 8253 & 2 & 00629 & 2 & 0,0171 & 2 & 0,0049 & 3. & 0,0094 & 2 & 102 & 4 & 1487 & 3. \\
\hline AGROMEI & 8.240 & 2 & 0,0656 & 1 & 0,0172 & 2 & 0,0047 & 3 & 0,0093 & 3 & 1,04 & 4 & 490 & 2 \\
\hline AGROMEN 201 & 7649 & 3 & 00637 & 20 & 60175 & 管 & 0,0051 & 10 & 0,0097 & 2 & 103 & 4 & 0,422 & $3 x$ \\
\hline AGX 2573 & 8.358 & 2 & 0,0638 & 2 & 0,0171 & 2 & 0,0049 & 3 & 0,0099 & 2 & 1,03 & 4 & 0,427 & 3 \\
\hline$A G \times 5492$ & 1820 & 3. & 0,0675 & 1) & 00122 & 2 & 000049 & 3 & 0,0095 & 2 & 09 & 5 & 0,437 & 3 \\
\hline AGX 5542 & 7.942 & 2 & 0,0638 & 2 & 0,0170 & 2 & 0,0051 & 1 & 0,0099 & 2 & 1,06 & 3 & & 3 \\
\hline AGX 5558 & 8.462 & 2 & 00680 & 16 & $001 \% 2$ & 2. & 0,0050 & 2 & 0,0097 & 2 & 163 & 4. & 0423 & 3. \\
\hline$A G \times 5674$ & 8.020 & 2 & 0,0637 & 2 & 0,0172 & 2 & 0,0051 & 1 & 0,0102 & 1 & 1,02 & 4 & 0,339 & 4 \\
\hline AL 25 $\times 1$ & 7430 & 46 & 00668 & we & 0,0166 & 2. & 000046 & 4 & 0,0085 & 5. & 104 & 4 & 0289 & 4 \\
\hline AS 3466 & 7.600 & 3 & 0,0624 & 2 & 0,0172 & 2 & 53 & 1 & 0,0104 & 1 & 1,03 & 4 & 0,514 & 2 \\
\hline C.435 & 7955 & 2 & 00640 & 2 & 040174 & 2 & 00048 & 8 & 000091 & 3 & 105 & 4 & $0,4,4$ & 3 \\
\hline C 435 G & 8.061 & 2 & 0,0639 & 2 & 0,0172 & 2 & 0,0048 & 3 & 0,0095 & 2 & 1,06 & 3 & & 1 \\
\hline C491W & T 519 & 3. & 0,0630 & 斿知 & 06172 & 2 & 00049 & $z$ & 0,0099 & 2 & 1,08 & 3 & 0,330 & 4 \\
\hline C $505 \mathrm{~B}$ & 9.057 & 1 & 0,0602 & 3 & 0,0171 & 2 & 048 & 3 & 0,0090 & 4 & 1,06 & 3 & 0,400 & 3 \\
\hline (5058 & 29581 & 1 & 00576 & ax & ONon & 2 & 0.007 & 3 & 000911 & 4 & 1,07 & B & 0.037 & 3 \\
\hline C 625 & 8.212 & 2 & 0,0631 & 2 & 0,0174 & 1 & 151 & 1 & 0,0105 & 1 & 1,02 & 4 & 0,628 & 1 \\
\hline GDI 1723 & 8360 & 2 & 00636 & 2 & 00168 & X & 00049 & So & 00096 & 2 & 105 & 4 & 0,483 & 2 \\
\hline CO 36 & 7.326 & 4 & 0,0646 & 2 & 0,0175 & 1 & 0,0050 & 2 & 0,0102 & 1 & 1,00 & 5 & 796 & 1 \\
\hline co32 & 7256 & 3 & 00634 & 2 & $0,017 \%$ & 1 & 00050 & 2 & 0,0100 & 2 & 0,9 & 5 & 0,521 & 2 \\
\hline CO 34 & 7.381 & 4 & 0,0636 & 2 & 0,0172 & 2 & 0,0049 & 2 & 0,0101 & 1 & 1,00 & 5 & 600 & 1 \\
\hline DINA & 8130 & 2 & 00663 & 3 & 00170 & 2 & 0,0050 & 2. & 00096 & 2 & 104 & 4 & 0,55 & $i^{2}$ \\
\hline DINA 270 & 8.164 & 2 & 0,0667 & 1 & 67 & 2 & 0,0044 & 5 & 0,0079 & 6 & 1,00 & 5 & 0,426 & 3 \\
\hline DINA 657 & 8.55 & ? & 00625 & 2) & 0,0170 & 2 & 0,0050 & 2. & 0,0096 & 2 & 105 & 4 & 0,474 & 2 \\
\hline EXCELLER & 7.544 & 3 & 0,0631 & 2 & 0,0170 & 2 & 0,0048 & 3 & 0,0095 & 2 & 1,05 & 4 & 0,446 & 3 \\
\hline F9006 & $1 \times 383$ & 4 & 00665 & 1. & ogor 1 & 2 & 0,00513 & 11 & 00100 & 2 & 1,01 & 5 & 0.29 & 4 \\
\hline G $165 \$$ & 7.885 & 3 & 0,0680 & 1 & 0,0170 & 2 & 0,0051 & 1 & 0,0097 & 2 & 1,04 & 4 & 0,485 & 2 \\
\hline G167S & 8337 & 2 & 00632 & 2 & 0017 & 2 & 00099 & rot & 0,0097 & 2. & 107 & 3 & 0,628 & 1 \\
\hline G $176 \mathrm{~S}$ & 8.453 & 2 & 0,0623 & 2 & 0,0174 & 1 & 0,0052 & 1 & 0,0104 & 1 & 1,00 & 5 & 0,360 & 4 \\
\hline HATA 3012 & 7596 & 3 & 0,0620 & 2 & 00171 & 2 & 00051 & 19 & 00105 & 1 & 400 & 5 & 0331 & 4. \\
\hline HD 9486 & 7.858 & 3 & 0,0643 & 2 & 0,0169 & 2 & 0,0047 & 3 & 0,0094 & $3^{-1}$ & 1,04 & 4 & 0,407 & 3 \\
\hline HD 95112 & 7390 & 4 & 0,0683 & the & 0,0171 & 2 & 00050 & 2 & 0,0100 & 1 & 111 & 3 & 0.368 & 4 . \\
\hline & 7.512 & 3 & 0,0665 & 1 & 0,0171 & 2 & 0,0049 & 2 & 0,0099 & 2 & 1,13 & 2 & 0,492 & 2 \\
\hline HT951005 & 7571 & 3 & 0,0672 & 1 & 0,0165 & 2 & 0,0050 & 2 & 0,0096 & 2 & 1,22 & 1 & 0,422 & 3 \\
\hline MASTER & 7.650 & 3 & 0,0615 & 2 & 0,0173 & 1 & 0,0048 & 3 & 0,0089 & 4 & 1,08 & 3 & 0,487 & 2 \\
\hline P 3041 & 8596 & 2 & 00629 & ? & 0,0172 & 2 & 0,0048 & 3 & 0,0095 & 2 & 1,05 & 4 & 0,588 & 1 \\
\hline PL 320 & 7.335 & 4 & 0,0633 & 2 & 0,0169 & 2 & 0,0045 & 4 & 0,0088 & 4 & 1,03 & 4 & 0,354 & 4 \\
\hline PC 322 & 7313 & 4 & 0,0643 & 2 & 0,0174 & 1 & 0,0046 & 4 & 000088 & 4 & 402 & 4 & 0.462 & 2 \\
\hline$R \& G 01$ & 7.315 & 4 & 0,0627 & 2 & 0,0169 & 2 & 0,0051 & 1 & 0,0098 & 2 & 1,03 & 4 & 0,385 & 3 \\
\hline$x, 345$ & 8096 & 2 & 0,0641 & 2 & 0,0176 & 1 & 0.0051 & 1 & 0,0102 & 1 & 106 & 3 & 0,458 & $2^{2}$ \\
\hline XL 360 & 8.141 & 2 & 0,0639 & 2 & 0,0171 & 2 & 0,0049 & 3 & 0,0093 & 3 & 1,12 & 2 & 0,366 & 4 \\
\hline $264 \mathrm{EZ}^{2}$ & 8002 & 2 & 0,0636 & 2 & 0,0176 & 1 & 0,0051 & 1 & 0,0104 & 1 & 1,00 & 5 & 0,351 & 4 \\
\hline$Z 84$ E 90 & 7.430 & 4 & 0,0630 & 2 & 0,0174 & 1 & 0,0052 & 1 & 0,0107 & 1 & 1,00 & 5 & 0,437 & 3 \\
\hline $284 \mathrm{E} 98$ & 6.457 & 2 & 0,0619 & 2 & 0,0174 & 1 & 0,0050 & 2 & 0,0102 & 1 & 106 & 3 & 0,639 & 1 \\
\hline 28440 & 7.264 & 4 & 0,0655 & 1 & 0,0176 & 1 & 0,0052 & 1 & 0,0110 & 1 & 1,00 & 5 & 0,396 & 3 \\
\hline 28452 & 8.998 & 4 & 0,0638 & 2 & 0,0170 & $x^{2}$ & 0,0050 & $2^{2}$ & 0,0097 & 2 & 1,07 & 3 & 0782 & 11 \\
\hline
\end{tabular}


Tabela 19. Médias agrupadas e reciprocos, para obtenção do Índice 2. Médias seguidas do mesmo número não diferem entre si ao nível de significância indicado.

\begin{tabular}{|c|c|c|c|c|c|c|c|c|c|c|c|c|c|c|}
\hline HIBRIDO & PE & 0,05 & $1 / U$ & 0,001 & 1/FLO & 0,001 & 1/AP & 0,01 & $1 / A E$ & 0,01 & PROL & 0,001 & 1/PAQ & 0,01 \\
\hline 94 HT 31 QPM & 7.059 & 5 & 0,0666 & 1 & 0,0175 & 1 & 0,0050 & 2 & 0,0098 & 2 & 1,05 & 4 & 0,346 & 4 \\
\hline A 953 & 6.843 & 5 & 0,0689 & 1 & 0,0176 & 1 & 0,0051 & 1 & 0,0100 & 2 & 1,06 & 3 & 0,686 & 1 \\
\hline AG 5014 & 7.741 & 4 & 0,0621 & 2 & 0,0171 & 2 & 0,0051 & 1 & 0,0098 & 2 & 1,03 & 4 & 0,357 & 4 \\
\hline AGROMEN 2003 & 8.321 & 3 & 0,0645 & 2 & 0,0173 & 1 & 0,0050 & 2 & 0,0099 & 2 & 0,98 & 4 & 0,611 & 1 \\
\hline AGROMEN 2005 & 8.253 & 3 & 0,0629 & 2 & 0,0171 & 2 & 0,0049 & 3 & 0,0094 & 2 & 1,02 & 4 & 0,437 & 3. \\
\hline AGROMEN 2007 & 8.240 & 3 & 0,0656 & 1 & 0,0172 & 2 & 0,0047 & 3 & 0,0093 & 3 & 1,04 & 4 & 0,490 & 2 \\
\hline AGROMEN 2018 & 7.649 & 4 & 0,0637 & 2 & 0,0175 & 1 & 0,0051 & 1 . & 0,0097 & 2 & 1,03 & 4 & 0,422 & 3 \\
\hline AGX 2573 & 8.358 & 3 & 0,0638 & 2 & 0,0171 & 2 & 0,0049 & 3 & 0,0099 & 2 & 1,03 & 4 & 0,427 & 3 \\
\hline$A G \times 5492$ & 7.820 & 4 & 00675 & 1 & 0,0172 & 2 & 0,0049 & 3 & 0,0095 & 2 & 0,99 & 4 & 0,437 & 3 \\
\hline AGX 5542 & 7.942 & 3 & 0,0638 & 2 & 0,0170 & 2 & 0,0051 & 1 & 0,0099 & 2 & 1,06 & 3 & 0,381 & 3 \\
\hline AGX 5558 & 8.462 & 3 & 0,0680 & 1 & 0,0172 & 2 & 0,0050 & 2 & 0,0097 & 2 & 1,03 & 4 & 0,423 & 3 \\
\hline AGX 5674 & 8.020 & 3 & 0,0637 & 2 & 0,0172 & 2 & 0,0051 & 1 & 0,0102 & 1 & 1,02 & 4 & 0,339 & 4 \\
\hline AL $25 \times 1 I$ & 7.430 & 5 & 0,0668 & 1 & 0,0166 & 2 & 0,0046 & 4 & 0,0085 & 4 & 1,04 & 4 & 0,289 & 4 \\
\hline AS 3466 & 7.600 & 4 & 0,0624 & 2 & 0,0172 & 2 & 0,0053 & 1 & 0,0104 & 1 & 1,03 & 4 & 0,514 & 2 \\
\hline C 435 . & 7.955 & 3 & 0,0640 & 2 & 0,0171 & 2 & 0,0048 & 3 & 0,0091 & 3 & 1,05 & 4 & 0,444 & 3 \\
\hline C 435 G & 8.061 & 3 & 0,0639 & 2 & 0,0172 & 2 & 0,0048 & 3 & 0,0095 & 2 & 1,06 & 3 & 0,635 & 1 \\
\hline C $491 \mathrm{~W}$ & 7.519 & 4 & 0,0630 & 2 & 0,0172 & 2 & 0,0049 & 2 & 0,0099 & 2 & 1,08 & 3 & 0,330 & 4 \\
\hline C $505 \mathrm{~B}$ & 9.057 & 2 & 0,0602 & 2 & 0,0171 & 2 & 0,0048 & 3 & 0,0090 & 3 & 1,06 & 3 & 0,400 & 3 \\
\hline C $505 \mathrm{C}$ & 9.531 & 1 & 0,0576 & 2 & 0,0171 & 2 & 0,0047 & 3 & 0,0091 & 3. & 1,07 & 3 & 0,437 & 3 \\
\hline C 625 & 8.212 & 3 & 0,0631 & 2 & 0,0174 & 1 & 0,0051 & 1 & 0,0105 & 1 & 1,02 & 4 & 0,628 & 1 \\
\hline CD 1723 & 8.360 & 3 & 0,0636 & 2 & 0,0168 & 2 & $0,00,49$ & 3 & 0,0096 & 2 & 1,05 & 4 & 0,483 & 2 \\
\hline $\mathrm{CO} 36$ & 7.326 & 5 & 0,0646 & 2 & 0,0175 & 1 & 0,0050 & 2 & 0,0102 & 1 & 1,00 & 4 & 0,796 & 1 \\
\hline $\mathrm{CO} 32$ & 7.756 & 4 & 0,0634 & 2 & 0,0173 & 1 & 0,0050 & 2 & 0,0100 & 2 & 0,99 & 4 & $0 ; 521$ & 2 \\
\hline $\mathrm{CO} 34$ & 7.381 & 5 & 0,0636 & 2 & 0,0172 & 2 & 0,0049 & 2 & 0,0101 & 1 & 1,00 & 4 & 0,600 & 1 \\
\hline DINA 1000 & 8.130 & 3 & 0,0603 & 2 & 0,0170 & 2 & 0,0050 & 2 & 0,0096 & 2 & 1,04 & 4 & 0,575 & 1. \\
\hline DINA 270 & 8.164 & 3 & 0,0667 & 1 & 0,0167 & 2 & 0,0044 & 5 & 0,0079 & 5 & 1,00 & 4 & 0,426 & 3 \\
\hline DINA 657 & 8.155 & 3 & 0,0625 & 2 & 0,0170 & 2 & 0,0050 & 2 & 0,0096 & 2 & 1,05 & 4 & 0,474 & 2 \\
\hline EXCELLER & 7.544 & 4 & 0,0631 & 2 & 0,0170 & 2 & 0,0048 & 3 & 0,0095 & 2 & 1,05 & 4 & 0,446 & 3 \\
\hline FT 9006 & 7.383 & 5 & 0,0665 & 1 & 0,0171 & 2 & 0,0051 & 1 & 0,0100 & 2 & 1,01 & 4 & 0,291 & 4 \\
\hline G $165 \$$ & 7.885 & 4 & 0,0680 & 1 & 0,0170 & 2 & 0,0051 & 1 & 0,0097 & 2 & 1,04 & 4 & 0,485 & 2 \\
\hline G 167 S & 8.337 & 3 & 0,0632 & 2 & 0,0172 & 2 & 0,0049 & 2 & 0,0097 & 2 & 1,07 & 3 & 0,628 & 1 \\
\hline G $176 \mathrm{~S}$ & 8.453 & 3 & 0,0623 & 2 & 0,0174 & 1 & 0,0052 & 1 & 0,0104 & 1 & 1,00 & 4 & 0,360 & 4 \\
\hline HATA 3012 & 7.596 & 4 & 0,0620 & 2 & 0,0171 & 2 & 0,0051 & 1 & 0,0105 & 1 & 1,01 & 4 & 0,331 & 4 \\
\hline HD 9486 & 7.858 & 4 & 0,0643 & 2 & 0,0169 & 2 & 0,0047 & 3 & 0,0094 & 3 & 1,04 & 4 & 0,407 & 3 \\
\hline HD 951128 & 7.390 & 5 & 0,0683 & 1 & 0,0171 & 2 & 0,0050 & 2 & 0,0100 & 1 & 1,11 & 3 & 0,368 & 4 \\
\hline HD 9563 & 7.512 & 4 & 0,0665 & 1 & 0,0171 & 2 & 0,0049 & 2 & 0,0099 & 2 & 1,13 & 2 & 0,492 & 2 \\
\hline HT 951005 & 7.571 & 4 & 0,0672 & 1 & 0,0165 & 2 & 0,0050 & 2 & 0,0096 & 2 & 1,22 & 1 & 0,422 & 3 \\
\hline MASTER & 7.650 & 4 & 0,0615 & 2 & 0,0173 & 1 & 0,0048 & 3 & 0,0089 & 3 & 1,08 & 3 & 0,487 & 2 \\
\hline P 3041 & 8.596 & 3 & 0,0629 & 2 & 0,0172 & 2 & 0,0048 & 3 & 0,0095 & 2 & 1,05 & 4 & 0,588 & 1 \\
\hline PL 320 & 7.335 & 5 & 0,0633 & 2 & 0,0169 & 2 & 0,0045 & 4 & 0,0088 & 3 & 1,03 & 4 & 0,354 & 4 \\
\hline PL 322 & 7.313 & 5 & 0,0643 & 2 & 0,0174 & 1 & 0,0046 & 4 & 0,0088 & 3 & 1,02 & 4 & 0,462 & 2 \\
\hline$R \& G 01$ & 7.315 & 5 & 0,0627 & 2. & 0,0169 & 2 & 0,0051 & 1 & 0,0098 & 2 & 1,03 & 4 & 0,385 & 3 \\
\hline$X L 345$ & 8.096 & 3 & 0,0641 & 2 & 0,0176 & 1 & 0,0051 & 1 & 0,0102 & 1 & 1,06 & 3 & 0,458 & 2 \\
\hline XL 360 & 8.141 & 3 & 0,0639 & 2 & 0,0171 & 2 & 0,0049 & 3 & 0,0093 & 3 & 1,12 & 2 & 0,366 & 4 \\
\hline Z 64E 74 & 8.002 & 3 & 0,0636 & 2 & 0,0176 & 1 & 0,0051 & 1 & 0,0104 & 1 & 1,00 & 4 & 0,351 & 4 \\
\hline Z 84 E 90 & 7.430 & 5 & 0,0630 & 2 & 0,0174 & 1 & 0,0052 & 1 & 0,0107 & 1 & 1,00 & 4 & 0,437 & 3 \\
\hline$Z 84 E 98$ & 8.457 & 3 & 0,0619 & 2 & 0,0174 & 1 & 0,0050 & 2 & 0,0102 & 1 & 1,06 & 3 & 0,639 & 1 \\
\hline 28440 & 7.264 & 5 & 0,0655 & 1 & 0,0176 & 1 & 0,0052 & 1 & 0,0110 & 1 & 1,00 & 4 & 0,396 & 3 \\
\hline 28452 & 8.998 & 2 & 0,0638 & 2 & 0,0170 & 2 & 0,0050 & 2 & 0,0097 & 2 & 1,07 & 3 & $0 ; 782$ & 1 \\
\hline
\end{tabular}


Tabela 20. Médias transformadas para o Índice 1, usando $P_{i}^{\prime}=\left(P_{i}-N_{i}\right) / s_{i}$.

\begin{tabular}{|c|c|c|c|c|c|c|c|c|c|c|c|c|c|c|c|c|}
\hline HIBRIDO & PE & 0,01 & $1 / U$ & 0,10 & 1/FLO & 0,05 & 1/AP & 0,05 & $1 / A E$ & 0,05 & PROL & 0,07 & 1/PAQ & 0,03 & b & $R^{2}$ \\
\hline HT & 0,710 & 4 & 4,229 & 1 & 1,656 & 1 & 00 & 2 & 0,000 & 2 & 0,000 & 4 & 1,230 & 4 & 1,260 & $-1,411$ \\
\hline A 953 & $-0,710$ & 4 & 4,229 & 1 & 1,656 & 1 & 0,703 & 1 & 0,000 & 2 & 0,805 & 3 & 1,389 & 1 & 0,206 & $-1,233$ \\
\hline AG 5014 & 0,000 & 3 & 2,537 & 2 & 0,000 & 2 & 0,703 & & 0,000 & 2 & 0,000 & 4 & $-1,230$ & 4 & 1,681 & -0.794 \\
\hline AGROMEN 2003 & 1,036 & 2 & 2,537 & 2 & 1,656 & 1 & 0,000 & 2 & 0,000 & 2 & & 5 & 1,389 & 1. & 0,423 & \\
\hline AGROMEN 2005 & 1,036 & 2 & 2,537 & 2 & 0,000 & 2 & 0,932 & 3 & 0,000 & 2 & 0,000 & 4 & 0,557 & & 0,585 & 0,174 \\
\hline AGROMEN 2007 & 1,036 & 2 & & 1 & 0,000 & 2 & & 3 & $-0,803$ & 3 & 0,000 & 4 & 0,000 & 2 & 2,043 & \\
\hline AGROMEN 2018 & 0,000 & 3 & 2,537 & 2 & 1,656 & 1 & 0,703 & 1 & 0,000 & 2 & 0,000 & 4 & 0,557 & 3 & $-0,161$ & 0,412 \\
\hline AGX 2573 & 1,036 & 2 & 2,537 & 2 & 0,000 & 2 & & 3 & 0,000 & 2 & & 4 & & 3 & & 1,365 \\
\hline$A G \times 5492$ & 0,000 & 3 & 4,229 & 1 & 0,0010 & 2 & $-0,932$ & 3 & 0,000 & 2 & & 5 & & 3 & 2,464 & 0,101 \\
\hline AGX 5542 & 1,036 & 2 & 2,537 & 2 & 0,000 & 2 & 0,703 & 1 & 0,000 & 2 & & 3 & & 3 & 2,155 & 0,543 \\
\hline AGX 5558 & 1,036 & 2 & 4,229 & 1 & 0,000 & 2 & 0,000 & 2 & 0,000 & 2 & 0,000 & 4 & 0,557 & 3 & 2,885 & 1,266 \\
\hline AGX & 1,036 & 2 & 2,537 & 2 & 0,000 & 2 & 03 & 1 & 1,103 & 1 &, 000 & 4 & $-1,230$ & 4 & 0,786 & $-2,125$ \\
\hline AL $25 \mathrm{XII}$ & $-0,710$ & 4 & 4,229 & 1 & 0,000 & 2 & $-2,217$ & 4 & $-2,143$ & 5 & 0,000 & 4 & $-1,230$ & 4 & 0,906 & $-0,094$ \\
\hline AS 3466 & 0,000 & 3 & 2,537 & 2 & 000 & 2 & & 1 & & 1 & & 4 & 0,000 & 2 & 0,344 & $-0,544$ \\
\hline c 435 & 1,036 & 2 & 2,537 & 2 & 0,000 & 2 & 0,932 & 3 & $-0,803$ & 3 & 100 & 4 & $-0,557$ & 3 & 1,145 & 0,188 \\
\hline C $435 \mathrm{G}$ & 1,036 & 2 & 2,537 & 2 & 0,000 & 2 & $-0,932$ & 3 & 0,000 & 2 & & 3 & 389 & 1 & 1,763 & 0,560 \\
\hline C $491 \mathrm{~W}$ & 0,000 & 3 & 2,537 & 2 & 0,000 & 2 & 0,000 & 2 & 0,000 & 2 & 0,805 & 3 & $-1,230$ & 4 & 2,162 & 0,814 \\
\hline C 505 B & 2,848 & 1 & 1,196 & 3 & 000 & 2 & $-0,5$ & 3 & -1 & 4 & & 3 & $-0,557$ & 3 & 2,779 & 0,426 \\
\hline$C 505 \mathrm{C}$ & 2,848 & 1 & 0,000 & 4 & 0,000 & 2 & 0,932 & 3 & 1,415 & 4 & 0,805 & 3 & $-0,557$ & 3 & 3,726 & 1,209 \\
\hline C 625 & 1,036 & 2 & 2,537 & 2 & 1,656 & 1 & 0,703 & 1 & & 1 & 0,000 & 4 & 1,389 & 1 & 0,622 & 1,158 \\
\hline $\operatorname{CD} 1723$ & 1,036 & 2 & 2,537 & 2 & 0,000 & 2 & 0,932 & 3 & 0,000 & 2 & 0,000 & 4 & 0,000 & 2 & 0,037 & $-0,516$ \\
\hline CO 36 & $-0,710$ & 4 & 2,537 & 2 & 1,656 & 1 & 000 & 2 & 1,103 & 1 & & 5 & 1,389 & 1 & 345 & 0,048 \\
\hline $\mathrm{CO} 32$ & 0,000 & 3 & 2,537 & 2 & 1,656 & 1 & 0,000 & 2 & 0,000 & 2 & 888 & 5 & 0,000 & 2 & 1,522 & $-0,317$ \\
\hline CO 34 & $-0,710$ & 4 & 2,537 & 2 & 0,000 & 2 & 00 & 2 & 1,103 & 1 & 388 & 5 & 1,389 & 1 & 043 & 0,428 \\
\hline DINA 1000 & 1,036 & 2 & 1,196 & 3 & 0,000 & 2 & 0,000 & 2 & 0,000 & 2 & 0,000 & 4 & 1,389 & 1 & 0,964 & 1,121 \\
\hline DINA 270 & 1,036 & 2 & 4,229 & 1 & 0,000 & 2 & $-3,457$ & 5 & $-3,182$ & 6 & $-0,888$ & 5 & $-0,557$ & 3 & 2,382 & 0,877 \\
\hline DINA 657 & 1,036 & 2 & 2,537 & 2 & 0,000 & 2 & 0,000 & 2 & 0,000 & 2 & 0,000 & 4 & 0,000 & 2 & 0,593 & 0,766 \\
\hline EXCELLER & 0,000 & 3 & 2,537 & 2 & 0,000 & 2 & $-0,932$ & 3 & 0,000 & 2 & 0,000 & 4 & $-0,557$ & 3 & 0,825 & 0,134 \\
\hline FT 9006 & $-0,710$ & 4 & 4,229 & 1 & 0,000 & 2 & 0,703 & 1 & 0,000 & 2 & 0,888 & 5 & $-1,230$ & 4 & 0,387 & $-0,458$ \\
\hline$G 165 \$$ & 0,000 & 3 & 4,229 & 1 & 0,000 & 2 & 0,7 & 1 & 0,000 & 2 & 0,000 & 4 & 0,000 & 2 & 1,053 & $-0,803$ \\
\hline G $167 \mathrm{~S}$ & 1,036 & 2 & 2,537 & 2 & 0,000 & 2 & 0,000 & 2 & 0,000 & 2 & 0,805 & 3 & 1,389 & 1 & 1,627 & $-0,917$ \\
\hline G $176 \mathrm{~S}$ & 1,036 & 2 & 2,537 & 2 & 1,656 & 1 & 0,7 & 1 & 1,103 & 1 & $-0,8$ & 5 & $-1,230$ & 4 & 1,606 & 1,224 \\
\hline HATÁ 3012 & 0,000 & 3 & 2,537 & $2^{2}$ & 0,000 & 2 & 0,703 & 1 & 1,103 & 1 & 0,888 & 5 & $-1,230$ & 4 & 2,602 & $-0,126$ \\
\hline HD 9486 & 000 & 3 & 2,537 & 2 & 00 & 2 & $-0,932$ & 3 & $-0,803$ & 3 & 0,000 & 4 & $-0,557$ & 3 & 1,153 & $-1,164$ \\
\hline HO 951128 & $-0,710$ & 4 & 4,229 & 1 & 0,000 & 2 & 0,000 & 2 & 1,103 & 1 & 0,805 & 3 & $-1,230$ & 4 & 0,604 & 0,131 \\
\hline HD 9563 & 0,000 & 3 & 4,229 & 1 & 0,000 & 2 & 0,000 & 2 & 0,000 & 2 & 2,166 & 2 &, 000 & 2 & 1,231 & 0,556 \\
\hline HT 951005 & 0,000 & 3 & 4,229 & 1 & 0,000 & 2 & 0,000 & 2 & 0,000 & 2 & 4,410 & 1 & $-0,557$ & 3 & 1,764 & $-2,701$ \\
\hline MASTER & 0,000 & 3 & 2,537 & 2 & 1,656 & 1 & $-0,932$ & 3 & $-1,415$ & 4 & 0,805 & 3 & 0,000 & 2 & 0,461 & $-0,348$ \\
\hline P 3041 & 1,036 & 2 & 2,537 & 2 & 0,000 & 2 & $-0,932$ & 3 & 0,000 & 2 & 0,000 & 4 & 1,389 & 1 & 1,147 & $-0,014$ \\
\hline PL 320 & $-0,710$ & 4 & 2,537 & 2 & 0,000 & 2 & $-2,217$ & 4. & $-1,415$ & 4 & 0,000 & 4 & $-1,230$ & 4 & 3,594 & 0,858 \\
\hline$P L 322$ & $-0,710$ & 4 & 2,537 & 2 & 1,656 & 1 & $-2,217$ & 4 & $-1,415$ & 4 & 0,000 & 4 & 0,000 & 2 & 2,480 & 1,458 \\
\hline$R \& G 01$ & $-0,710$ & 4 & 2,537 & 2 & 0,000 & 2 & 0,703 & 1 & 0,000 & 2 & 0,000 & 4 & $-0,557$ & 3 & 0,744 & 1,024 \\
\hline$X<345$ & 1,036 & 2 & 2,537 & 2 & 1,656 & t & 0,703 & 1 & 1,103 & 1 & 0,805 & 3 & 0,000 & 2 & 0,042 & 0,627 \\
\hline XL 360 & 1,036 & 2 & 2,537 & 2 & 0,000 & 2 & $-0,932$ & 3 & $-0,803$ & 3 & 2,166 & 2 & $-1,230$ & 4 & 1,592 & $-1,043$ \\
\hline $264 \mathrm{E} 74$ & 1,036 & 2 & 2,537 & 2 & 1,656 & 1 & 0,703 & 1 & 1,103 & 1 & $-0,888$ & 5 & $-1,230$ & 4 & 1,507 & 0,927 \\
\hline Z $84 E 90$ & $-0,710$ & 4 & 2,537 & 2 & 1,656 & 1 & 0,703 & 1 & 1,103 & 1 & $-0,888$ & 5 & $-0,557$ & 3 & 1,281 & 0,950 \\
\hline Z84E98 & 1,036 & 2 & 2,537 & 2 & 1,656 & 1 & 0,000 & 2 & 1,103 & 1 & 0,805 & 3 & 1,389 & 1 & 2,202 & 0,239 \\
\hline Z 8440 & $-0,710$ & 4 & 4,229 & 1 & 1,656 & 1 & 0,703 & 1 & 1,103 & 1 & $-0,888$ & 5 & $-0,557$ & 3 & $-0,177$ & $-1,200$ \\
\hline 28452 & 2,848 & 1 & 2,537 & 2 & 0,000 & 2 & 0,000 & & 0,000 & 2 & 0,805 & 3 & 1,389 & 1 & 1,557 & $-0,213$ \\
\hline
\end{tabular}


Tabela 21. Médias transformadas para o Índice 2, usando $P_{i}^{\prime}=\left(P_{i}-N_{i}\right) / s_{i}$.

\begin{tabular}{|c|c|c|c|c|c|c|c|c|c|c|c|c|c|c|c|c|}
\hline HÍB & PE & 0,05 & $1 / U$ & & 1/FLO & 0,001 & 1/AP & 0,01 & 1/AE & 0,01 & PROL &, 001 & 1/PAQ & 0,01 & $\bar{b}$ & $\mathbf{R}^{2}$ \\
\hline $4 H T 31$ & $-1,746$ & 5 & 1,837 & 1 & 1,656 & 1 & 0,000 & 2 & 0,000 & 2 & & 4 & 230 & 4 & 1,260 & $-1,411$ \\
\hline 953 & $-1,746$ & 5 & 1,837 & 1 & 1,656 & 1 & 0,703 & 1 & 0,000 & 2 & & 3 & 1,389 & 1 & 0,206 & $-1,233$ \\
\hline G 5014 & $-1,036$ & 4 & 0,000 & 2 & 0,000 & 2 &, 703 & 1 & 0,000 & 2 & 000 & 4 & 1,230 & 4 & 1,681 & 0,794 \\
\hline GROMEN 2003 & 0,000 & 3 & 0,000 & 2 & 1,656 & 1 & 0,000 & 2 & 0,000 & 2 & & 4 & & 1 & 0,423 & $-2,302$ \\
\hline GROMEN 2005 & 0,000 & 3. & 0,000 & 2 & 0,000 & 2 & 0,932 & 3 & 0,000 & 2 & 000 & 4 & & 3 & 0,585 & 0,174 \\
\hline GROMEN 2007 & 0,000 & 3 & 837 & 1 & & 2 & & 3 & & 3 & 000 & 4 & 000 & 2 & 2,043 & $-1,260$ \\
\hline AGROMEN 2018 & 1,036 & 4 & 0,000 & 2 & 1,656 & 1 & 0,703 & 1 & 0,000 & 2 & 000 & 4 & $-0,557$ & 3 & & 0,412 \\
\hline$G \times 2573$ & 0,000 & 3 & 0,000 & 2 & 0,000 & 2 & $-0,932$ & 3 & 0,000 & 2 & 00 & 4 & & 3 & 0,798 & 1,365 \\
\hline $16 \times 5492$ & $-1,036$ & 4 & 1,837 & 1 & 0,000 & 2 & $-0,932$ & 3 & 0,000 & 2 & 000 & 4 & $-0,557$ & 3 & 2,464 & 0,101 \\
\hline GX 5 & 0,000 & 3 & 0,000 & 2 & 000 & 2 & & 1 & 000 & 2 & & 3 & & 3 & & 0,543 \\
\hline GX5 & 0,000 & 3 & 1,837 & 1 & 0,000 & 2 & 0,000 & 2 & 0,000 & 2 & 000 & 4 & 557 & 3 & 2,885 & 266 \\
\hline GQX 5 & 0,000 & 3 & 000 & 2 & & 2 & & 1 & & 1 & & 4 & & 4 & & $-2,125$ \\
\hline $125 \mathrm{XII}$ & 1,746 & 5 & 1,837 & 1 & 0,000 & 2 & $-2,217$ & 4 & $-2,143$ & 4 & 0,000 & 4 & & 4 & 0,906 & 0,094 \\
\hline AS 3466 & $-1,036$ & 4 & 000 & 2 & 000 & 2 & & 1 & & 1 & & 4 & & 2 & 0,344 & $-0,544$ \\
\hline 8435 & 0,000 & 3 & 0,000 & 2 & 0,000 & 2 & $-0,932$ & 3 & $-1,143$ & 3 & 0,000 & 4 & & 3 & & 188 \\
\hline $435 \mathrm{G}$ & 0,000 & 3 & 000 & 2 & & 2 & & 3 & & 2 & & 3 & & 1 & & ,560 \\
\hline $491 \mathrm{~W}$ & $-1,036$ & 4 & 0,000 & 2 & 0,000 & 2 & 0,000 & 2 & 0,000 & 2 & 119 & 3 & & 4 & 2,162 & 0,814 \\
\hline 505 B & 1,498 & 2 & 000 & 2 & & 2 & & 3 & & 3 & & 3 & & 3 & & 0,426 \\
\hline 5050 & 2,438 & 1 & 0,000 & 2 & 0,000 & 2 & -0 , & 3 & $-1,143$ & 3 & & 3 & 0,557 & 3 & 3,726 & 1,209 \\
\hline 625 & 0,000 & 3 & 000 & 2 & & 1 & & 1 & & 1 & & 4 & 389 & 1 & 0,622 & 1,45 \\
\hline CD 1723 & 0,000 & 3 & 0,000 & 2 & 0,000 & 2 & $-0,932$ & 3 & 0,000 & 2 & 000 & 4 & 0,000 & 2 & 0,037 & -0 \\
\hline CO 36 & $-1,746$ & 5 & 000 & 2 & & 1 & & 2 & & 1 & & 4 & 389 & 1 & & 048 \\
\hline $\mathrm{CO} 32$ & $-1,036$ & 4 & 0,000 & 2. & 1,656 & 1 & 0,000 & 2 & 0,000 & 2 & 0,000 & 4 & 0,000 & 2 & 1,522 & $-0,317$ \\
\hline $\mathrm{CO} 34$ & $-1,746$ & 5 & 0,000 & 2 & 0,000 & 2 & & 2 & & 1 & & 4 & 389 & 1 & 43 &, 428 \\
\hline DINA 100 & 0,000 & 3 & 0,000 & 2 & 0,000 & 2 & 0,000 & 2 & 0,000 & 2 & 0,000 & 4 & 1,389 & 1 & 0,964 & 1,121 \\
\hline DINA 270 & 0,000 & 3 & 837 & 1 & & 2 & -3 , & 5 & & 5 & & 4 & & 3 & 2,382 & 0,877 \\
\hline DINA 657 & 0,000 & 3 & 0,000 & 2 & 0,000 & 2 & 0,000 & 2 & 0,000 & 2 & 0,000 & 4 & 0,000 & 2 & 0,593 & 0,766 \\
\hline EXCELLER & $-1,036$ & 4 & 0,000 & 2 & 000 & 2 & & 3 & & 2 & & 4 & 557 & 3 & 0,825 & 0,134 \\
\hline$F 9006$ & $-1,746$ & 5 & 1,837 & 1 & 0,000 & 2 & 0,703 & 1 & 0,000 & 2 & 0,000 & 4 & $-1,230$ & 4 & 0,387 & $-0,458$ \\
\hline G $165 \$$ & $-1,036$ & 4 & 837 & 1 & & 2 & & 1 & & 2 & 000 & 4 & 000 & 2 & 1,053 & $-0,803$ \\
\hline$G 167 \mathrm{~S}$ & 0,000 & 3 & 0,000 & 2 & 0,000 & 2 & 0,000 & 2 & 0,000 & 2 & 1,119 & 3 & 1,389 & 1 & 1,627 & $-0,917$ \\
\hline G 17 & 0,000 & 3 & 000 & 2 & & 1 & & 1 & & 1 & & 4 & & 4 & 606 & 1,224 \\
\hline HATÃ 30 & $-1,036$ & 4 & 0,000 & 2 & 0,000 & 2 & & 1 & & 1 & & 4 & & 4 & 2,602 & 0,126 \\
\hline HD 9486 & $-1,036$ & 4 & 0,000 & 2 & & 2 & & 3 & & 3 & & 4 & & 3 & & $-1,164$ \\
\hline HD 951128 & $-1,746$ & 5 & 1,837 & 1. & 0,000 & 2 & & 2 & & 1 & & 3 & & 4 & $-0,604$ & 0,131 \\
\hline HD 9563 & $-1,036$ & 4 & 1,837 & 1 & & 2 & & 2 & & 2 & & 2 & & 2 & & 556 \\
\hline HT 951005 & $-1,036$ & 4 & 1,837 & 1 &, 000 & 2 & 0,000 & 2 & & 2 & 723 & 1 & 557 & 3 & 1,764 & $-2,701$ \\
\hline MASTER & $-1,036$ & 4 & 0,000 & 2 & 656 & 1 & & 3 & & 3 & & 3 & & 2 & 161 & $-0,348$ \\
\hline P 3041 & 0,000 & 3 & 0,000 & 2 & 0,000 & 2 & $-0,932$ & 3 & 0,0 & 2 &, 000 & 4 & 1,389 & 1 & 1,147 & 0,014 \\
\hline PL 320 & $-1,746$ & 5 & 0,000 & 2 & 000 & 2 & & 4 & & 3 & & 4 & & 4 & 3,594 & 0,858 \\
\hline PL 322 & $-1,746$ & 5 & 0,000 & 2 & 1,656 & 1 & $-2,217$ & 4 & $-1,143$ & 3 & .000 & 4 & 0,000 & 2 & 2,480 & 1,458 \\
\hline R \& G01 & $-1,746$ & 5 & 000 & 2 & 000 & 2 & 703 & 1 & 0,000 & 2 &, 000 & 4 & $-0,557$ & 3 & 0,744 & 1,024 \\
\hline$x<345$ & 0,000 & 3 & 0,000 & 2 & 1,656 & 1 & 0,703 & 1 & 1,103 & 1 & 119 & 3 & 000 & 2 & 0,042 & 0,627 \\
\hline$X L 360$ & 0,000 & 3 & 0,000 & 2 & 0,000 & 2 & & 3 & -1 & 3 & & 2 & 1,230 & 4 & 1,592 & $-1,04$ \\
\hline $264 E 74$ & 0,000 & 3 & 0,000 & 2 & 1,656 & 1 & 0,703 & 1 & 1,103 & 1 & 0,000 & 4 & 230 & 4 & 1,507 & 0,927 \\
\hline Z 84 E 90 & $-1,746$ & 5 & 0,000 & 2 & 656 & 1 & 703 & 1 & 1,103 & 1 & 0,000 & 4 & $-0,557$ & 3 & 1,281 & 0,950 \\
\hline $284 E 98$ & 0,000 & 3 & 0,000 & 2 & 1,656 & 1 & 0,000 & 2 & 1,103 & 1 & 1,119 & 3 & 1,389 & 1 & 2,202 & 0,239 \\
\hline 28440 & $-1,746$ & 5 & 1,837 & 1 & 1,656 & 1 & 0,703 & 1 & 1,103 & 1 & 0,000 & 4 & $-0,557$ & 3 & $-0,177$ & $-1,200$ \\
\hline 28452 & 1,498 & 2 & 0,000 & 2 & 0,000 & 2 & 0,000 & 2 & 0,000 & 2 & 1,119 & 3 & 1,389 & 1 & 1,557 & 0,213 \\
\hline
\end{tabular}


Tabela 22. Distância euclidiana média ( $d m_{i I}$ ) entre os genótipos $i$ e ideótipo $I$ para o Índice 1 .

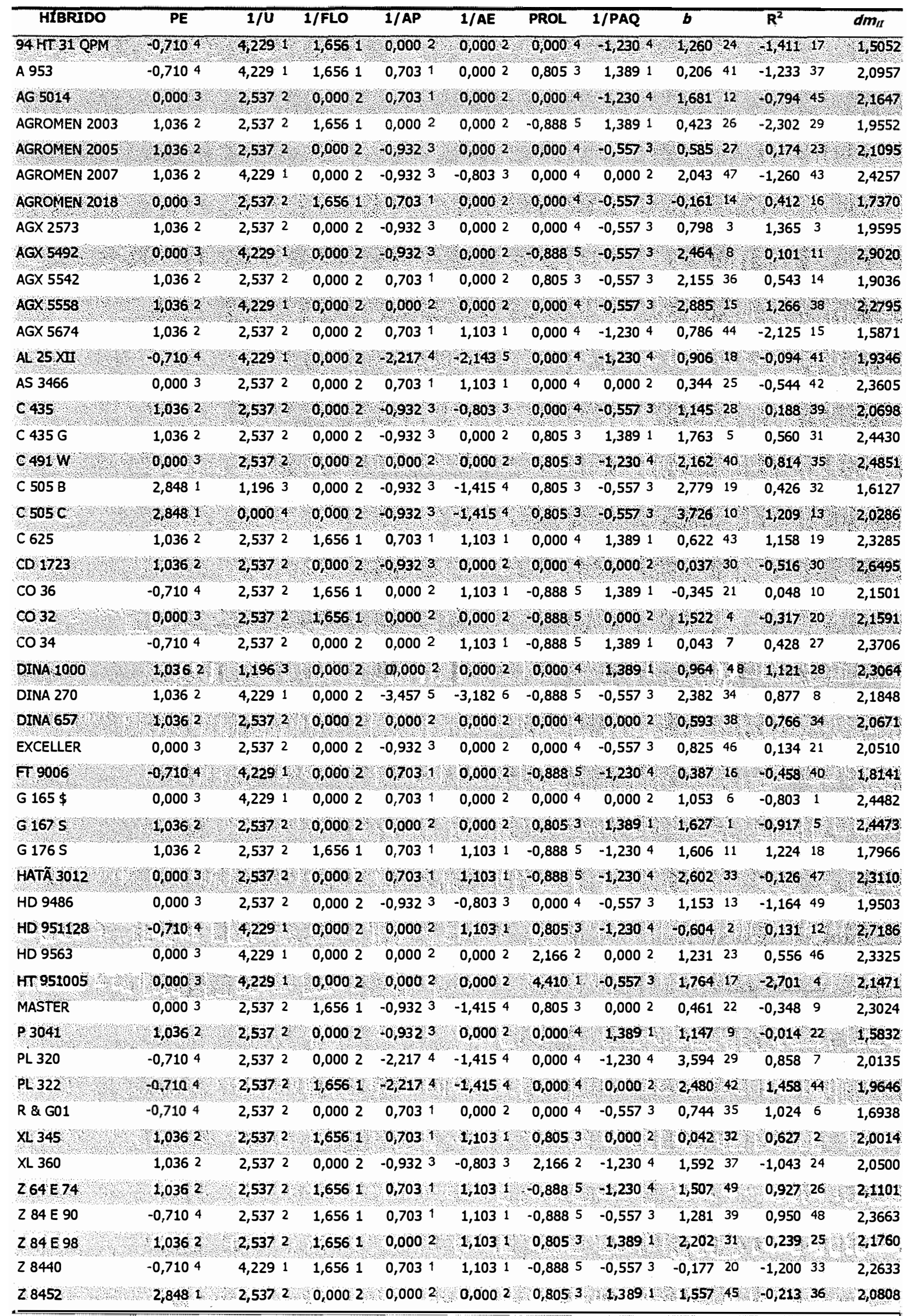


Tabela 23. Distância euclidiana média $\left(d m_{i l}\right)$ entre os genótipos $i$ e ideótipo $I$ para o Índice 2.

\begin{tabular}{|c|c|c|c|c|c|c|c|c|c|c|c|}
\hline HIBRIDO & PE & $1 / 0$ & 1/FLO & 1/AP & 1/AE & PROL & 1/PAQ & $\boldsymbol{b}$ & $\mathbf{R}^{2}$ & & $d m_{i t}$ \\
\hline $94 \mathrm{HT}$ & $-1,7465$ & 1,8371 & 1,6561 & 0,0002 & 0,0002 & 0,0004 & $-1,2304$ & 1,260 & $-1,411$ & 46 & 2,5095 \\
\hline A 953 & $-1,7465$ & 1,8371 & 1,6561 & 0,7031 & 0,0002 & 1,1193 & 1,3891 & 0,206 & $-1,233$ & 44 & 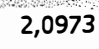 \\
\hline AG 5014 & $-1,0364$ & 0,0002 & 0,0002 & 0,7031 & 0,0002 & 0,0004 & $-1,2304$ & 1,681 & 0,794 & 38 & 2,4518 \\
\hline AGROMEN 2 & 0,0003 & 0,0002 & 1,6561 & 0,0002 & 0,0002 & 0,0005 & 1,3891 & 0,423 & $-2,302$ & 48 & 2,3047 \\
\hline AGROMEN 2005 & 0,0003 & 0,0002 & 0,0002 & $-0,9323$ & 0,0002 & 0,0004 & 0,5573 & 0,585 & 0,174 & 24 & 2,2076 \\
\hline AGROMEN 2007 & 0,0003 & 1,8371 & 0,0002 & $-0,9323$ & $-1,1433$ & $0,000^{4}$ & 0,0002 & 2,043 & $-1,260$ & 45 & 2,3360 \\
\hline AGROMEN 2 & $-1,0364$ & 0,0002 & 1,6561 & 0,7031 & 0,0002 & 0,0004 & $-0,5573$ & $-0,161$ & 0,412 & 21 & 2,2410 \\
\hline AGX 2573 & 0,0003 & 0,0002 & 0,0002 & $-0,9323$ & 0,0002 & 0,0004 & $-0,5573$ & 0,798 & 1,365 & 2 & 2,1625 \\
\hline$A G \times 5492$ & 1,0364 & 1,8371 & $0,000.2$ & 0,9323 & 0,0002 & $0,000 \mathrm{~s}$ & 0,5573 & 2,464 & 0,101 & 27 & 2,3281 \\
\hline AGX 5542 & 0,0003 & 0,0002 & 0,0002 & 0,7031 & 0,0002 & 1,1193 & $-0,5573$ & 2,155 & 0,543 & 18 & 1,8922 \\
\hline AGX 5558 & 0,0003 & 1,8371 & 0,0002 & $0,000^{2}$ & 0,0002 & 0,0004 & $-0,5573$ & 2,885 & 1,266 & 3 & 2,1103 \\
\hline AGX 5674 & 0,0003 & 0,0002 & 0,0002 & 0,7031 & 1,1031 & 0,0004 & $-1,2304$ & 0,786 & $-2,125$ & 47 & 2,4519 \\
\hline AL $25 \times$ II & $-1,7465$ & 1,8371 & 0,0002 & $-2,2174$ & $-2,1434$ & 0,0004 & $-1,2304$ & 0,906 & 0,094 & 30 & 2,8066 \\
\hline 5346 & $-1,0364$ & 0,0002 & 0002 & 0,7031 & 1,1031 & 0,0004 & 0,0002 & 0,344 & $-0,544$ & 37 & 2,2819 \\
\hline C 435 & 0,0003 & 0,0002 & 0,0002 & $-0,9323$ & $-1,1433$ & 0,0004 & 00,5573 & 1,145 & 0,188 & 23 & 2,2974 \\
\hline C 435 & 0,0003 & 0,0002 & 0,0002 & $-0,9323$ & 0,0002 & 1,1193 & 1,3891 & 1,763 & 0,560 & 16 & 1,8357 \\
\hline $\mathrm{C} 491 \mathrm{~W}$ & $-1,0364$ & 0,0002 & 0,0002 & 0,0002 & 0,0002 & 1,1193 & $-1,230.4$ & 2,162 & 0,814 & 13 & 2,1476 \\
\hline C 505 B & 1,4982 & 0,0002 & 0,0002 & $-0,9323$ & $-1,1433$ & 1,1193 & $-0,5573$ & 2,779 & 0,426 & 20 & 1,9923 \\
\hline$C 505$ & 2,4381 & 0,0002 & 0,0002 & 0,9323 & $-1,143,3$ & 1,1193 & 0,5573 & 3,726 & 1,209 & 5 & 2,0575 \\
\hline 625 & 0,0003 & 0,0002 & 5561 & 0,7031 & 1,1031 & $0,000^{4}$ & 1,3891 & 0,622 & 1,158 & 6 & 1,8814 \\
\hline CD 172 & 0,0003 & 0,0002 & 0,0002 & $00,932,3$ & 0,0002 & 0,0004 & 0,0002 & 0,037 & 0,516 & 36 & 2,2362 \\
\hline C & $-1,7465$ & 0,0002 & & 0,0002 & 1,1031 & 0,0005 & 1,3891 & $-0,345$ & 0,048 & 28 & 2,2968 \\
\hline $\mathrm{CO} 32$ & $-1,0364$ & 0,0002 & 1,6561 & 0,0002 & 0,0002 & 0,0005 & 0,0002 & 1,522 & $-0,317$ & 33 & 2,2315 \\
\hline $\mathrm{CO} 34$ & $-1,7465$ & 0,0002 & 0002 & 0,0002 & 1,1031 & 0,0005 & 1,3891 & 0,043 & 0,428 & 19 & 2,3190 \\
\hline$D$ & 0,0003 & 0,0002 & $0 ; 0002$ & 0,0002 & 0,0002 & 0,0004 & 1,3891 & 0,964 & 1,121 & 7 & 2,0053 \\
\hline 年 & 0,0003 & 1,8371 & 0002 & $-3,4575$ & $-3,1825$ & 0,0005 & $-0,5573$ & 2,382 & 0,877 & 11 & 2,8421 \\
\hline D & 0,0003 & 0,0002 & 0,0002 & 0,0002 & 0,0002 & 0,0004 & $0,000^{2}$ & 0,593 & 0,766 & 14 & 2,0723 \\
\hline E & $-1,0364$ & 0,0002 & 0002 & $-0,9323$ & 0,0002 & 0,0004 & $-0,5573$ & 0,825 & 0,134 & 25 & 2,3559 \\
\hline & $-1,746.5$ & 1,8371 & 0,0002 & $0,703 \%$ & 0,0002 & 0,0005 & $-1,2304$ & 0,387 & 0,458 & 35 & 2,4647 \\
\hline & $-1,0364$ & 1,8371 & 0,0002 & 0,7031 & 0,0002 & 0,0004 & 0,0002 & 1,053 & $-0,803$ & 39 & 2,2456 \\
\hline 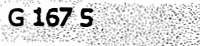 & 0,0003 & 0,0002 & 0,0002 & 0,0002 & 0,0002 & 1,1193 & 1,3891 & 1,627 & 0,917 & 40 & 1,9088 \\
\hline & 0003 & 0002 & 6561 & 0,7031 & 1,1031 & 0,0005 & $-1,2304$ & 1,606 & 1,224 & 4 & 2,0791 \\
\hline & $-1,0364$ & 0,0002 & 0,0002 & 0,7031 & 1,103 & $0,000 \mathrm{~s}$ & $-1,2304$ & 2,602 & $-0,126$ & 31 & 2,4135 \\
\hline & $-1,0364$ & 0,0002 & 0,0002 & $-0,9323$ & $-1,1433$ & 0,0004 & $-0,5573$ & 1,153 & $-1,164$ & 42 & 2,5581 \\
\hline & $-1,7465$ & 1,8371 & 0,0002 & 0,0002 & 1,1031 & 1,1193 & $-1,2304$ & 0,604 & 0,131 & 26 & 2,2342 \\
\hline & $-1,0364$ & 1,8371 & 0,0002 & 0,0002 & 0,0002 & 2,4802 & 0,0002 & 1,231 & 0,556 & 17 & 1,6449 \\
\hline & $-1,0364$ & 1,8371 & 0,0002 & 0,0002 & 0,0002 & 4,7231 & $-0,5573$ & 1,764 & $-2,701$ & 49 & 2,0601 \\
\hline 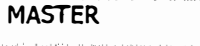 & $-1,0364$ & 0,0002 & 1,6561 & $-0,9323$ & $-1,1433$ & 1,1193 & 0,0002 & 0,461 & $-0,348$ & 34 & 2,1508 \\
\hline $07+$ & 0,0003 & 0,0002 & 0,0002 & $-0,9323$ & 0,0002 & 0,0004 & 1,3891 & 1,147 & $-0,014$ & 29 & 2,1199 \\
\hline & $-1,7465$ & 0,0002 & 0,0002 & $-2,2174$ & $-1,1433$ & 0,0004 & $-1,2304$ & 3,594 & 0,858 & 12 & 2,8567 \\
\hline 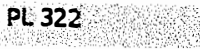 & $-1,7465$ & 0,0002 & 1,6561 & $-2,2174$ & $-1,1433$ & 0,0004 & $0,000 \%$ & 2,480 & 1,458 & 1 & 2,6008 \\
\hline & $-1,7465$ & 0,0002 & 0,0002 & 0,7031 & 0,0002 & $0,000^{4}$ & $-0,5573$ & 0,744 & 1,024 & 8 & 2,3848 \\
\hline & $0,000^{3}$ & 0,0002 & 1,6561 & 0,7031 & 1,1031 & 1,1193 & 0,0002 & 0,042 & 0,627 & 15 & 1,6946 \\
\hline 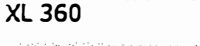 & 0,0003 & 0,0002 & 0,0002 & $-0,9323$ & $-1,1433$ & 2,4802 & $-1,2304$ & 1,592 & $-1,043$ & 41 & 2,0621 \\
\hline $264=74$ & $0 ; 0003$ & 0,0002 & 1,6561 & 0,7031 & 1,1031 & 0,0005 & $-1,2304$ & 1,507 & 0,927 & 10 & 2,0822 \\
\hline$\angle 84 E 90$ & $-1,746.5$ & 0,0002 & 1,6561 & 0,7031 & 1,1031 & 0,0005 & $-0,5573$ & 1,281 & 0,950 & 9 & 2,2927 \\
\hline$\angle 84598$ & 0,0003 & 0,0002 & 1,6561 & 0,0002 & 1,1031 & 1,1193 & 1,389 & 2,202 & 0,239 & 22 & 1,6910 \\
\hline 28440 & $-1,7465$ & 1,8371 & 1,6561 & 0,7031 & 1,1031 & 0,0005 & $-0,5573$ & $-0,177$ & $-1,200$ & 43 & 2,4048 \\
\hline$Z 8452$ & 1,4982 & 0,0002 & 0,0002 & 0,0002 & 0,0002 & 1,1193 & 1,3891 & 1,557 & $-0,213$ & 32 & 1,6601 \\
\hline
\end{tabular}


Tabela 24. Índice para a seleção de cultivares $1\left(I_{s c}\right)$, com classificação dos hỉbridos.

\begin{tabular}{|c|c|c|c|c|c|c|c|c|c|c|c|}
\hline & HÍBRIDO & PE & $\mathbf{u}$ & FLO & AP & $\mathbf{A E}$ & PROL & PAQ & $\bar{b}$ & $\overline{\mathbf{R}^{2}}$ & $\overline{I_{s c} \mathbf{I}}$ \\
\hline 12 & HD 9563 & 75123 & 15,0 & 58,62 & $202^{2}$ & $101^{2}$ & 1,132 & 6,292 & $1,00 \%$ & 0,9117 & 1,505 \\
\hline 2 & Z 84 E 98 & $8.457^{2}$ & 16,22 & $57,5^{1}$ & 1992 & $98^{1}$ & $1,06^{3}$ & 4,231 & 1,15 & $0,88 \quad 22$ & 1,583 \\
\hline 3 & $x<345$ & 8.0962 & 15,62 & 56,7 & $197 \%$ & 981 & $1,06^{3}$ & 6,942 & 0,81 & 0,9115 & 1,587 \\
\hline 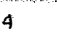 & $Z 8452$ & $8.998^{1}$ & 15,72 & 58,92 & 2012 & $103^{2}$ & 1,073 & 3,331 & 1,05 & 0,8532 & 1,613 \\
\hline & C625. & $8.212^{2}$ & 15,92 & 57,61 & 1971 & 951 & 1,024 & 4,891 & 0,90 & 0,956 & 1,694 \\
\hline 5 & C $435 \mathrm{G}$ & $8.061^{2}$ & 15,62 & 58,12 & $209^{3}$ & 1062 & $1,06^{3}$ & 3,351 & 1,08 & 0,9116 & 1,737 \\
\hline & AGX 5542 & 79422 & 15,72 & 58,72 & 1961 & $101^{2}$ & 1,063 & 11,85 & 1,14 & 0,9018 & 1,797 \\
\hline 3 & G $167 \mathrm{~S}$ & $8.337^{2}$ & $15,8^{2}$ & $58,3^{2}$ & $203^{2}$ & $103^{2}$ & 1,073 & 5,581 & 1,06 & 0,7940 & 1,814 \\
\hline 3 & DINA 657 & $8.155 \%$ & $16,0^{2}$ & 58,92 & 2002 & $105^{2}$ & 1,054 & 7,902 & 0,893 & $0,92 \quad 14$ & 1,904 \\
\hline 10 & $\mathrm{XL} 360$ & $8.141^{2}$ & $15,6^{2}$ & 58,42 & $205^{3}$ & $108^{3}$ & $1,12^{2}$ & 9,694 & 1,05 & 0,7941 & 1,935 \\
\hline 11 & HT 951005 & $7.571^{3}$ & 14,91 & $60,5^{2}$ & 1992 & 1042 & 1,221 & $10,27^{3}$ & 1,08 & $0,66^{49}$ & 1,950 \\
\hline 12 & P 3041 & $8.596^{2}$ & 15,92 & 58,22 & $208^{3}$ & $105^{2}$ & $1,05^{4}$ & 5,151 & 0,982 & 0,8629 & 1,955 \\
\hline 13 & AGX 5558 & 8.4622 & 14,7 & 58,22 & 2022 & 1042 & 1,034 & 7,343 & 1,26 & 0,963 & 1,959 \\
\hline 14 & A 953 & 6.8434 & 14,51 & 56,91 & 1981 & $100^{2}$ & $1,06^{3}$ & $4,00^{1}$ & 0,834 & 0,7744 & 1,965 \\
\hline 15. & AGX 2573 & 8.3582 & 15,72 & $58,4^{2}$ & 2063 & 1012 & 1,034 & 8,583 & 0,93 & 0,972 & 2,001 \\
\hline 16 & DINA 1000 & $8.130^{2}$ & $16,6^{3}$ & 58,92 & 1992 & 1042 & $1,04^{4}$ & 5,261 & 0,95 & 0,957 & 2,013 \\
\hline 17 & C $491 \mathrm{~W}$ & $7519^{3}$ & 15,92 & 58,02 & 2042 & $101^{2}$ & $1,08^{3}$ & 15,544 & 1,14 & $0,93^{13}$ & 2,029 \\
\hline 18 & AGROMEN 2005 & $8.253^{2}$ & 15,92 & 58,62 & $205^{3}$ & 1062 & 1,024 & 8,813 & 0,893 & $0,88 \quad 24$ & 2,050 \\
\hline 19 & AGROMEN 201 & 7.6493 & 15,72 & $570 \%$ & 1971 & 1032 & $1,03 \%$ & 9,563 & 0,77 & 0,9021 & 2,051 \\
\hline 20 & MASTER & $7.650^{3}$ & $16,3^{2}$ & $57,8^{1}$ & 2073 & $113^{4}$ & $1,08^{3}$ & 6,922 & 0,873 & 0,8434 & 2,067 \\
\hline 21. & G $165 \$$ & $7.885^{3}$ & 14,7 & 58,82 & 1971 & $103^{2}$ & $1,04^{4}$ & 8,162 & 0,97 ? & 0,8039 & 2,070 \\
\hline 22 & CD 1723 & $8.360^{2}$ & 15,72 & 59,42 & $205^{3}$ & 1042 & $1,05^{4}$ & 8,392 & 0,81 & 0,8236 & 2,081 \\
\hline 23 & AS 3466 & 7.6003 & $16,0^{2}$ & 58,02 & 1901 & 961 & $1,03^{4}$ & 5,762 & $0,85^{4}$ & 0,8237 & 2,096 \\
\hline 24 & C 435 & $7.955^{2}$ & 15,62 & 58,52 & $210^{3}$ & $110^{3}$ & $1,05^{4}$ & $9,58^{3}$ & 0,982 & 0,8823 & 2,110 \\
\hline 25 & HD 951128 & 7.3904 & $14,6 \%$ & $58,5^{2}$ & 1982 & 1001 & 1,113 & 10,554 & 0,70 & 0,8726 & 2,110 \\
\hline 26 & G $176 \mathrm{~S}$ & $8.453^{2}$ & 16,12 & $57,6^{1}$ & $193^{1}$ & 961 & $1,00^{5}$ & 11,264 & 1,05 & 0,964 & 2,147 \\
\hline 27. & $264 E 74$ & $8.002^{2}$ & 15,72 & 56,81 & 1981 & 961 & 1,005 & 12,524 & 1,042 & 0,9310 & 2,150 \\
\hline 28 & $\mathrm{C} 505 \mathrm{~B}$ & $9.057^{1}$ & $16,6^{3}$ & 58,52 & $207^{3}$ & 1114 & $1,06^{3}$ & $9,71^{3}$ & 1,24 & $0,90 \quad 20$ & 2,159 \\
\hline 29 & AGROMEN 2 & 8.2402 & 15,21 & $58,1^{2}$ & 2113 & 1083 & $1,04^{4}$ & 7,142 & 1,12 & 0,7745 & 2,165 \\
\hline 30 & EXCELLER & $7.544^{3}$ & 15,92 & 58,72 & $210^{3}$ & $105^{2}$ & $1,05^{4}$ & $8,422^{3}$ & 0,93 & $0,87 \quad 25$ & 2,176 \\
\hline 31 & R \& G01 & $7.315^{4}$ & $16,0^{2}$ & 59,12 & 1971 & 1022 & $1,03^{4}$ & 9,293 & 0,92 & 0,948 & 2,185 \\
\hline 32 & $\mathrm{CO} 32$ & $7.756^{3}$ & 15,82 & 57,81 & 2012 & 1002 & 0,995 & 6,402 & 1,04 & 0,8433 & 2,263 \\
\hline 33. & AG 5014 & $7741^{3}$ & 16,12 & $58 ; 52$ & 1971 & 1022 & 1,034 & 14,524 & 1,07 & 0,8038 & 2,279 \\
\hline 34 & $Z 84$ E 90 & $7.430^{4}$ & 15,92 & 57,41 & 1941 & 941 & $1,00^{5}$ & 8,393 & 1,00 & 0,949 & 2,302 \\
\hline 35 & $\mathrm{CO} 36$ & 7.3264 & $15,5^{2}$ & 57,11 & 1992 & 981 & $1,00^{5}$ & 3,481 & 0,75 & 0,8728 & $2 ; 306$ \\
\hline 36 & AGX 5674 & $8.020^{2}$ & 15,72 & 58,22 & 1951 & 981 & 1,024 & 14,794 & 0,92 & 0,7047 & 2,311 \\
\hline 37 & $\cos 34$ & 7.3814 & 15,72 & $58,3^{2}$ & 2032 & 991 & 1,005 & 4,901 & 0,81 & $0,90 \quad 19$ & 2,329 \\
\hline 38 & $94 \mathrm{HT} 31 \mathrm{Q}$ & $7.059^{4}$ & 15,01 & $57,2^{1}$ & 2012 & 1022 & $1,05^{4}$ & 12,984 & 1,00 & 0,7646 & 2,332 \\
\hline 39 & HD 9486 & $7.858^{3}$ & 15,62 & 59,12 & 2113 & $107^{3}$ & $1,044^{4}$ & 8,583 & 0,98 ? & 0,7842 & 2,360 \\
\hline 40 & AGROMEN 2003 & 8.3212 & $15,5^{2}$ & 57,91 & 2012 & 1012 & $0,98^{5}$ & 4,851 & 0,87 & 0,6948 & 2,366 \\
\hline 41. & AGX 5492 & 7.8203 & 14,81 & 58,02 & $205^{3}$ & $105^{2}$ & 0,995 & 8,523 & 1,19 & 0,8727 & 2,371 \\
\hline 42 & $Z 8440$ & $7.264^{4}$ & 15,31 & 56,91 & 1931 & 911 & $1,00^{5}$ & $9,54^{3}$ & 0,77 & 0,7743 & 2,426 \\
\hline 43 & HATÁ 3012 & $7.596^{3}$ & 16,12 & 58,62 & 1951 & 951 & 1,015 & 13,344 & 1,21 & 0,8531 & 2,443 \\
\hline 44 & $C 505 C$ & 9.5311 & $17,4^{4}$ & $58,6^{2}$ & $212^{3}$ & $110^{4}$ & $1,07^{3}$ & 8,413 & 1,39 & $0,96^{5}$ & 2,447 \\
\hline 45 & PL 322 & $7.313^{4}$ & 15,62 & 57,4 & 2164 & 1144 & 1,024 & 7,152 & 1,19 & 0,971 & 2,448 \\
\hline 46 & FT 9006 & $7.383^{4}$ & 15,01 & $58,4^{2}$ & 1961 & 1002 & $1,01^{5}$ & 14,974 & 0,86 & 0,8335 & 2,485 \\
\hline 47 & $\mathrm{AL} 25 \mathrm{XII}$ & $7.430^{4}$ & 15,01 & 60,42 & $219^{4}$ & $118^{5}$ & 1,044 & $15,07^{4}$ & 0,94 & 0,8630 & 2,649 \\
\hline 48 & PL 320 & $7.335^{4}$ & $15,8^{2}$ & 59,22 & $221^{4}$ & $114^{4}$ & 1,034 & 13,714 & 1,37 & $0,93 \quad 12$ & 2,719 \\
\hline 49 & DINA 270 & 8.1642 & 15,0 & 59,82 & 2305 & 1276 & 1,005 & 9,063 & 1,18 & 0,9311 & $2 ; 902$ \\
\hline
\end{tabular}


Tabela 25. Índice para a seleção de cultivares $2\left(I_{s c}\right)$, com classificação dos hibridos.

\begin{tabular}{|c|c|c|c|c|c|c|c|c|c|c|c|}
\hline & HIBI & PE & $\mathbf{U}$ & FLO & AP & AE & PROL & PAQ & 6 & $\mathbf{R}^{2}$ & $I_{s e} 2$ \\
\hline 1 & HD 9563 & 7.5124 & 5,01 & 58,62 & 2022 & 1012 & $1,13^{2}$ & 6,292 & 1,00 & $0,91,17$ & 1,645 \\
\hline 2 & 28452 & $8.998^{2}$ & 15,72 & 58,92 & 2012 & $103^{2}$ & 1,073 & 3,331 & 1,05 & 0,8532 & 1,660 \\
\hline 3 & $Z 84 E 98$ & 8.4573 & 16,22 & 57,51 & 1992 & 981 & 1,063 & 4,231 & 1,15 & 0,8822 & 1,691 \\
\hline 4 & XL 345 & 8.0963 & 15,62 & 56,71 & 1971 & 981 & 1,063 & 6,942 & 0,81 & $0,91 \quad 15$ & 1,695 \\
\hline 5 & $\mathrm{C} 435 \mathrm{G}$ & 8.0613 & 15,62 & 58,12 & 2093 & 1062 & 1,063 & 3,351 & 1,08 & 099116 & 1,836 \\
\hline 6 & C 625 & $8.212^{3}$ & 15,92 & 7,61 & 1971 & 951 & 1,024 & 4,891 & 0,90 & 0,956 & 1,881 \\
\hline 7 & $A G X 5542$ & 7.9423 & 15,72 & 58,2 & 1961 & 1012 & 1,063 & $11,85^{3}$ & 1,14 & 0,9018 & 1,892 \\
\hline 8 & G $167 \mathrm{~S}$ & $8.337^{3}$ & $15,8^{2}$ & 58,32 & $203^{2}$ & $103^{2}$ & 1,073 & 5,581 & 1,06 & 0,7940 & 1,909 \\
\hline 9 & C505 B & $9.057^{2}$ & $16,6^{2}$ & 58,52 & 2073 & 1113 & 1,063 & 9,713 & 1,24 & 0,9020 & 1,992 \\
\hline 10 & DINA 1000 & $8.130^{3}$ & 16,62 & 8,92 & 1992 & 1042 & 1,044 & 5,261 & 0,95 & 0,957 & 2,005 \\
\hline 11 & $\mathrm{C} 505 \mathrm{C}$ & 9.5311 & $174^{2}$ & 58,62 & $212 \%$ & 1103 & 1,073 & 8,413 & 1,39 & 0,965 & 2,057 \\
\hline 12 & 51005 & $7.571^{4}$ & 14,91 & 0,52 & 1992 & 1042 & 1,221 & 10,273 & 1,08 & 0,6645 & 2,060 \\
\hline 13 & $X L 360$ & 8.1413 & 15,62 & 58,42 & 2053 & 1083 & 1,122 & 9,694 & 1,05 & 0,794 & 2,062 \\
\hline 14 & DINA 657 & $8.155^{3}$ & 16,02 & 8,92 & 2002 & $105^{2}$ & $1,05^{4}$ & 7,902 & 0,89 & $0,92 \quad 14$ & 2,072 \\
\hline 15 & G $176 \mathrm{~S}$ & 8.4533 & 16,12 & $57.6 \%$ & 1931 & 961 & 1,005 & 11,264 & 1,05 & 0,964 & 2,079 \\
\hline 16 & 74 & $2^{3}$ & 15,72 & 6,81 & 1981 & 961 & 1,005 & 12,524 & 1,04 & $0,93 \quad 10$ & 2,082 \\
\hline 17 & A953 & 6.8435 & 14,51 & 56,91 & 1981 & 1002 & 1,063 & 4,001 & 0,83 & 0,7744 & 2,097 \\
\hline 18 & & & 4,71 & 22 & 2022 & 1042 & 1,034 & 7,343 & 1,26 & 0,963 & 2,110 \\
\hline 19 & P 3041 & 8.5963 & 15,92 & 58,22 & 2083 & $105^{2}$ & 1,054 & 5,151 & 0,98 & 0,862 & 2,120 \\
\hline 20 & & .5194 & 15,92 & 3,02 & 2042 & 1012 & $1,08^{3}$ & 15,544 & 1,14 & 0,93 & 2,148 \\
\hline 21 & ER & 7.6504 & 16,32 & 57.81 & 2073 & 1133 & 1,083 & 6,922 & 0,87 & 0,8434 & 2,151 \\
\hline 22 & $A G \times 2573$ & & 15,72 & 58,42 & 2063 & 1012 & 1,034 & $8,588^{3}$ & 0,93 & $0,97 \quad 2$ & 2,163 \\
\hline 23 & AGROMEN 2005 & 33 & 15,92 & 58,62 & 2053 & $106^{2}$ & 1,024 & $8,81^{3}$ & 0,89 & 0,882 & 2,208 \\
\hline 24 & CO 32 & 54 & 15,82 & 7,81 & 2012 & 1002 & 0,995 & 6,402 & 1,04 & 0,8433 & 2,232 \\
\hline 25 & HD 951128 & $7.390 \mathrm{~s}$ & $14,6$. & $585^{2}$ & 1982 & 1001 & 1,113 & $10,55^{4}$ & $0,70 \%$ & 0,8726 & 2,234 \\
\hline 26 & CD 1723 & $360^{3}$ & 15,72 & 59,42 & $205^{3}$ & 1042 & $1,05^{4}$ & 8,392 & 0,81 & 0,8236 & 2,236 \\
\hline 27 & AGROMEN 2018 & 7.6494 & 15,72 & 57,01 & 1971 & 1032 & 1,034 & 9,563 & 0,77 & 0,902 & 2,241 \\
\hline 28 & G $165 \$$ & & 14,71 & 58,82 & 1971 & 1032 & 1,044 & 8,162 & 0,97 & 0,80 & 2,246 \\
\hline 29 & AS 3 & $7.600^{4}$ & 16,02 & 58,02 & $190 \%$ & 961 & 1,034 & 5,762 & 0,85 & 0,8237 & 2,282 \\
\hline 30 & 90 & 7.4305 & 15,92 & $57,4^{1}$ & 1941 & 941 & 1,005 & 8,393 & 1,00 & 0,949 & 2,293 \\
\hline 31 & $\mathrm{CO} 36$ & 7.3265 & 15,52 & 57,11 & 1992 & 981 & 1,005 & 3,481 & 0,75 & 0,872 & 2,297 \\
\hline 32 & C 435 & & 5,62 & $3,5^{2}$ & $210^{3}$ & $110^{3}$ & $1,05^{4}$ & 9,583 & 0,98 & $0,88 \quad 23$ & 2,297 \\
\hline 33 & natrons & 8.32 & 15,52 & 5791 & 2012 & 1012 & 0,985 & $4,85^{1}$ & 0,87 & 0,6948 & 2,305 \\
\hline 34 & $\mathrm{CO} 34$ & 15 & 15,72 & 58,32 & 032 & 991 & 1,005 & 4,901 & 0,81 & $0,90 \quad 19$ & 2,319 \\
\hline 35 & AGX 5492 & $7.820^{4}$ & 4,81 & 8,02 & 2053 & $105^{2}$ & 0,995 & 8,523 & 1,19 & 0,8727 & 2,328 \\
\hline 36 & AGRC & & 21 & 3,12 & $11^{3}$ & $108^{3}$ & 044 & $7,14^{2}$ & 1,12 & 0,7745 & 2,336 \\
\hline 37 & EXCELLER & 7.5444 & 15,92 & $58,7^{2}$ & 2103 & 1052 & $1,05^{4}$ & 8,423 & 0,93 & $0,87^{2}$ & 2,356 \\
\hline 38 & $R \&$ & & $5,0^{2}$ & 12 & 1971 & 1022 & 034 & 9,293 & 0,92 & 0,948 & 2,385 \\
\hline 39 & 28440 & 7.2645 & 15,31 & 56,91 & 1931 & $91^{1}$ & $1,00 \mathrm{~s}$ & 9,543 & 0,77 & 0,7743 & 2,405 \\
\hline 40 & 3012 & 64 & 12 & 62 & 1951 & $95^{1}$ & 1,015 & 13,344 & 1,21 & 0,85 & 2,414 \\
\hline 41 & AG 5014 & 7.7414 & $16,1^{2}$ & $58,5^{2}$ & 1971 & 1022 & 1,034 & $14,52^{4}$ & 1,07 & 0,80 , & 2,452 \\
\hline 42 & AGX 5674 & 8.0203 &, 72 & 58,22 & 1951 & 981 & 1,024 & 14,794 & 0,92 & 0,7047 & 2,452 \\
\hline 43 & FT 9006 & 7.3835 & 15,01 & 58,42 & 1961 & $100^{2}$ & 1,015 & $14,97^{4}$ & 0,86 & 0,833 & 2,465 \\
\hline 44 & 94 HT 31 QPM & 0595 & 01 & 57,21 & 2012 & 1022 & $1,05^{4}$ & $12,98^{4}$ & 1,00 & 0,7646 & 2,509 \\
\hline 45 & HD 9486 & 7.8584 & 15,62 & 59,12 & 2113 & 1073 & 1,044 & 8,583 & 0,98 & 0,78 & 2,558 \\
\hline 46 & PL 322 & $7.313^{5}$ & 15,62 & $57,4^{1}$ & $216^{4}$ & $114^{3}$ & $1,02^{4}$ & 7,152 & 1,19 & 0,971 & 2,601 \\
\hline 47 & $A L 25 \times I I$ & 7.4305 & 15,01 & $60,4^{2}$ & 2194 & $118^{4}$ & 1,044 & 15,074 & 0,94 & 0,86 & 2,807 \\
\hline 48 & DINA 270 & 8.164 .3 & $15,0^{1}$ & $59,8^{2}$ & 2305 & 1275 & 1,005 & 9,063 & 1,18 & 0,93 & 2,842 \\
\hline 49 & PL 320 & 7.3355 & $15,8^{2}$ & $59,2^{2}$ & 2214 & 1143 & 1,034 & 13,714 & 1,37 & 0,9312 & 2,857 \\
\hline
\end{tabular}


